\title{
Recent Advances of Cobalt-Based Electrocatalysts for Oxygen Electrode Reactions and Hydrogen Evolution Reaction
}

\author{
Haihong Zhong ${ }^{1}$, Carlos A. Campos-Roldán ${ }^{2}$, Yuan Zhao ${ }^{2,3}$, Shuwei Zhang ${ }^{1}$, \\ Yongjun Feng ${ }^{1, * \mathbb{D}}$ and Nicolas Alonso-Vante ${ }^{2, * \mathbb{D}}$ \\ 1 State Key Laboratory of Chemical Resource Engineering, Beijing University of Chemical Technology, \\ No. 15 Beisanhuan East Road, Beijing 100029, China; 2014200922@grad.buct.edu.cn (H.Z.); \\ zhangshuwei024@gmail.com (S.Z.) \\ 2 IC2MP, UMR-CNRS 7285, University of Poitiers, F-86022 Poitiers cedex, France; \\ carlos.campos.roldan@univ-poitiers.fr (C.A.C.-R.); yuan.zhao@univ-poitiers.fr (Y.Z.) \\ 3 College of Material Science and Science Technology, Nanjing University of Aeronautics and Astronautics, \\ Nanjing 211106, China \\ * Correspondence: yjfeng@mail.buct.edu.cn (Y.F.); nicolas.alonso.vante@univ-poitiers.fr (N.A.-V.); \\ Tel.: +86-106-443-6992 (Y.F.); +33-549-453-625 (N.A.-V.)
}

Received: 1 September 2018; Accepted: 14 November 2018; Published: 19 November 2018

\begin{abstract}
This review summarizes recent progress in the development of cobalt-based catalytic centers as the most potentially useful alternatives to noble metal-based electrocatalysts (Pt-, Ir-, and Ru-based) towards the oxygen reduction reaction (ORR), oxygen evolution reaction (OER), and hydrogen evolution reaction (HER) in acid and alkaline media. A series of cobalt-based high-performance electrocatalysts have been designed and synthesized including cobalt oxides/chalcogenides, $\mathrm{Co}-\mathrm{N}_{x} / \mathrm{C}$, Co-layered double hydroxides (LDH), and Co-metal-organic frameworks (MOFs). The strategies of controllable synthesis, the structural properties, ligand effect, defects, oxygen vacancies, and support materials are thoroughly discussed as a function of the electrocatalytic performance of cobalt-based electrocatalysts. Finally, prospects for the design of novel, efficient cobalt-based materials, for large-scale application and opportunities, are encouraged.
\end{abstract}

Keywords: electrocatalysis; cobalt-based electrocatalysts; oxygen reduction reaction; oxygen evolution reaction; hydrogen evolution reaction; non-precious metal

\section{Introduction}

Considering the continuous decrease of fossil fuels and deteriorated environments, it is of great importance and urgency to explore abundant, eco-friendly and renewable energy sources. Many energy conversion and storage technologies, e.g., proton exchange membrane fuel cells (PEMFCs, in which the free energy of a chemical reaction is directly converted into electrical energy), water electrolyzers (WEs, where oxygen and hydrogen from water are produced), unitized regenerative cells (URCs, a system comprising an electrolyzer and a fuel cell), due to their high efficiency and friendly environments, have been extensively developed [1,2]. To some extent, electrochemical processes play an essential role in these systems, for example, the oxygen reduction reaction (ORR) and hydrogen oxidation reaction (HOR) occurring on the cathode and anode of a $\mathrm{H}_{2}-\mathrm{O}_{2}$ fuel cell, whereas the oxygen evolution reaction (OER) and hydrogen evolution reaction (HER) are, respectively, the anodic and cathodic reactions in an electrolyzer [3-5]. Platinum-based materials perform efficiently the HOR with much less $\mathrm{Pt}$ mass loading $\left(0.05 \mathrm{mg} \mathrm{cm}^{-2}\right)$ at the anode [6]. The complex oxygen electrode reactions (oxygen reduction reaction and oxygen evolution reaction), which involve various elementary steps, 
are kinetically intrinsic sluggish reactions, and primarily catalyzed by precious metal centers, e.g., Pt, $\mathrm{Ir}, \mathrm{Ru}$. The limited resources and high cost of these precious metals are an unavoidably obstacle for widespread commercial applications [7]. Therefore, it is of increasing interest to reduce the usage of precious metals, or completely replace precious metals with abundant, cheap and highly active ones. In the past few years, various kinds of novel non-precious metal nanomaterials have been explored as alternatives to precious metal-based electrocatalysts, including strongly coupled transition metals (oxides, phosphides, chalcogenides, hydroxides, double perovskites, and so on) [8-14], nanocarbon hybrids [15], and free-metal carbon-based materials [7,16].

Cobalt (Co), the 32nd most abundant element in the Earth's crust, has emerged as an attractive non-precious metal for electrochemical reactions due to its catalytic performance. The price of cobalt per mass fluctuates over the years; currently its average-price is estimated at $72.82-48.07 € / \mathrm{kg}$ (January-October 2018). From 2005 to 2018, the price has been subjected to small or important changes, meaning that the market is rather sensitive to the use purposes and to the localized reserve in the world. Regarding selenium and sulfur, for the period January to October 2018, the average-price ranges are $23.208-36.109 € / \mathrm{kg}$, and $0.063-0.067 € / \mathrm{kg}$, respectively. A series of cobalt-based catalytic center materials such as chalcogenides [17-22], oxides [23-25], metal-organic frameworks (MOFs) [26-30] and layered double hydroxides (LDHs) [31-33], have been recognized as potential candidates because of their parallel or even better activities, and superior electrochemical stability, compared with precious metals ( $\mathrm{Pt}$, Ir and $\mathrm{Ru}$ ) [34]. Additionally, recent research results have established that cobalt-containing compounds supported onto conducting carbonaceous materials, e.g., Vulcan-XC-72 [35], nitrogen-doped carbon nanotubes (CNTs) [36], carbon nanowebs (CNWs) [37], graphene [38], reduced graphene oxide (RGO) [39,40] and so on, represent a valid way to endow the catalysts with rich exposed catalytic sites, high surface area, high electrical conductivity and fast mass transport, thus enhancing the catalytic activities.

In this review, we stress this novel cobalt-based material (CoCat) associated with some electrochemical processes, e.g., ORR, OER and HER in acid and alkaline electrolytes from the surface electrochemistry perspective. All these carbons supported cobalt-centered catalysts are organized into several categories, namely, cobalt oxides, cobalt chalcogenides (selenides, sulfides), Co-LDH, $\mathrm{Co}-\mathrm{MOFs}$, and $\mathrm{Co}-\mathrm{N}_{x} / \mathrm{C}$, see Figure 1. In what follows, we firstly illustrate the basic reaction mechanism of ORR, OER and HER, then summarize recent progress in the development of cobalt-based electrocatalysts towards ORR, OER, HER. For the Co-centered electrocatalysts, particular attention is paid to the design, synthesis strategies, and electrocatalytic performance. Finally, we further discuss the challenges ahead in designing novel, highly efficient cobalt-based electrocatalysts for large-scale applications and opportunities.

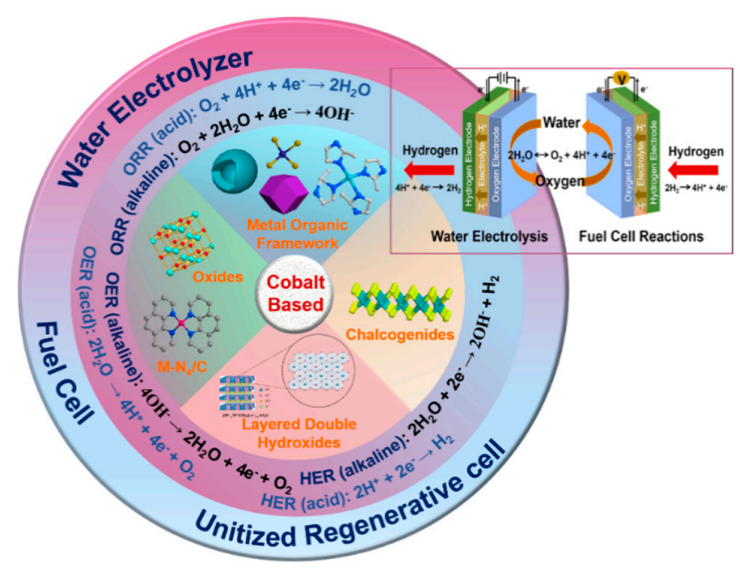

Figure 1. Schematic organization of the cobalt-based catalysts (CoCat) including layered double hydroxides, chalcogenides, oxides, $\mathrm{M}-\mathrm{N}_{x} / \mathrm{C}$ and metal organic framework with some major applications. 


\section{Electrocatalysts for Oxygen Reduction Reaction (ORR)}

\subsection{Mechanism of ORR}

The oxygen reduction reaction is the cathodic electrode reaction. The ORR electrochemical properties can be evaluated from rotating disc electrode (RDE) measurements (namely, the onset potential $\left(E_{\text {onset }}\right)$, half-wave potential $\left(E_{1 / 2}\right)$, overpotential $(\eta)$, and diffusion-limiting current density $\left.\left(j_{L}\right)\right)$. The ORR electrochemical reactions, in acid and alkaline medium, are shown below. The adsorbed molecular oxygen is reduced by a "direct" four-electron charge transfer process or reduced to water (acid medium) or $\mathrm{OH}^{-}$(alkaline medium) via the formation of $\mathrm{HO}_{2}{ }^{-}$and $\mathrm{H}_{2} \mathrm{O}_{2}$ intermediates with the consumption of two electrons [41]. In acid condition, oxygen can be reduced to water with a standard thermodynamic potential at $1.229 \mathrm{~V}$ vs. SHE (Standard Hydrogen Electrode) for the four-electron pathway (Equation (1)); while in the alkaline medium, hydroxide is produced with a standard thermodynamic potential at $0.401 \mathrm{~V}$ vs. SHE in the four-electron reaction (Equation (4)). The charge-transfer reaction depends on the electrolyte nature and the surface properties of the catalytic centers. Even for Pt, considered as the best ORR catalyst, a substantial cathodic overpotential of 300 $\mathrm{mV}$ [41] is observed in acid electrolyte. Clearly, a selectivity for the four-e ${ }^{-}$reduction pathway is highly desirable to improve the electrocatalytic ORR efficiency.

Acid medium:

$$
\mathrm{O}_{2}+4 \mathrm{H}^{+}+4 \mathrm{e}^{-} \rightarrow 2 \mathrm{H}_{2} \mathrm{O}
$$

or

$$
\begin{gathered}
\mathrm{O}_{2}+2 \mathrm{H}^{+}+2 \mathrm{e}^{-} \rightarrow \mathrm{H}_{2} \mathrm{O}_{2}, \\
\mathrm{H}_{2} \mathrm{O}_{2}+2 \mathrm{H}^{+}+2 \mathrm{e}^{-} \rightarrow 2 \mathrm{H}_{2} \mathrm{O},
\end{gathered}
$$

Alkaline medium:

$$
\mathrm{O}_{2}+2 \mathrm{H}_{2} \mathrm{O}+4 \mathrm{e}^{-} \rightarrow 4 \mathrm{OH}^{-},
$$

or

$$
\begin{gathered}
\mathrm{O}_{2}+\mathrm{H}_{2} \mathrm{O}+2 \mathrm{e}^{-} \rightarrow\left(\mathrm{HO}_{2}\right)^{-}+\mathrm{OH}^{-}, \\
\left(\mathrm{HO}_{2}\right)^{-}+\mathrm{H}_{2} \mathrm{O}+2 \mathrm{e}^{-} \rightarrow 3 \mathrm{OH}^{-},
\end{gathered}
$$

\subsection{Oxygen Reduction on Cobalt Chalcogenides Catalysts}

\subsubsection{Bond Ionicity or Covalency of S, Se, $\mathrm{Te}$}

In transition metals (TM) chalcogenides, the increase of covalency is obtained when d-state of $\mathrm{TM}$ interact with p-state of chalcogenides take place in $\mathrm{MX}_{2}$ compounds (e.g., $\mathrm{M}: \mathrm{Co}$; $\mathrm{X}: \mathrm{S}, \mathrm{Se}$ ). The hybridization degree of chalcogenides $p$-state with d-state of TM favors the metal-metal interaction. Moreover, metal cluster chalcogenides catalysts, $\mathrm{Ru}_{2} \mathrm{Mo}_{4} \mathrm{X}_{8}$ (Chevrel phase), where $\mathrm{X}$ : Se- and S-based, have motivated a strong interest since Alonso-Vante and Tributsch [42] in 1986 reported the comparable ORR activity of $\mathrm{Ru}_{2} \mathrm{Mo}_{4} \mathrm{Se}_{8}$ to that of $\mathrm{Pt}_{\text {in }} \mathrm{H}_{2} \mathrm{SO}_{4}$ [43-46]. In binary metal clusters (e.g., $\mathrm{Ru}$ ) coordinated with $\mathrm{X}$, they proposed that the activity of $\mathrm{Ru}_{x} \mathrm{X}_{y}$ catalysts depends on the chalcogen, and increases according to: $\mathrm{Ru}_{x} \mathrm{~S}_{y}<\mathrm{Ru}_{x} \mathrm{Te}_{y}<\mathrm{Ru}_{x} \mathrm{Se}_{y} \sim \mathrm{Mo}_{x} \mathrm{Ru}_{y} \mathrm{Se}_{z}$ in acid solution [47]. The structure analysis from the EXAFS (Extended X-ray Absorption Fine Structure) data suggested that that the variation of the chalcogen nature led to a change in its amount in the first co-ordination sphere of ruthenium. The latter apparently affected the strength of ruthenium interaction with oxygen, which is evidenced by significant differences observed in the $\mathrm{Ru} / \mathrm{O}$ distances. For $\mathrm{Ru}_{x} \mathrm{~S}_{y}$ clusters, the high co-ordination number of Ru to sulfur resulted in blocking the ruthenium active sites towards adsorption of molecular oxygen, which showed lowest ORR catalytic activity. In this respect, the coordinating strength of S, Se, Te on Ru chalcogenides was demonstrated (ligand effect). This is in contrast to cobalt dichalcogenides compound $\left(\mathrm{CoX}_{2}\right)$ demonstrated by Behret et al. [48] that reported a trend of ORR activity basically followed the sequence: $\mathrm{M}_{x} \mathrm{~S}_{y}>\mathrm{M}_{x} \mathrm{Se}_{y}>\mathrm{M}_{x} \mathrm{Te}_{y}$. In addition, the activity was also related to the catalytic 
centers with $\mathrm{Co}$. Both theoretical and experimental results confirmed that $\mathrm{Co}$-selenides are less active than its sulfides by $\sim 0.2 \mathrm{~V}$ [49]. The considerable decrease in activity was observed when $\mathrm{S}$ was partly or totally substituted by $\mathrm{O}, \mathrm{Se}$, and $\mathrm{Te}$, probably attributed to the geometric and electrostatic conditions in spinel structures. It was claimed that the selenium and tellurium with higher atomic radii give a weaker electrostatic repulsion to the reduction product $\left(\mathrm{O}^{2-}\right)$ and also to the intermediate reduction products. Therefore, the reaction products on the surface of seleno- and tellurospinels were not as easily desorbed as those on thiospinels [48].

Furthermore, a series of transition metal chalcogenides were reported by Behret et al. [48] consisting of the anionic substitution ( $\mathrm{S}, \mathrm{Se}$ and $\mathrm{Te}$ ), and the cationic substitution $(\mathrm{Fe}, \mathrm{Co}, \mathrm{Ni})$. These primary results disclosed a trend for ORR electrochemical performance with the metal cations as follows: $\mathrm{Co}>\mathrm{Ni}>\mathrm{Fe}$, and for the chalcogenide anions: $\mathrm{S}>\mathrm{Se}>\mathrm{Te}$. They found that $\mathrm{Co}-\mathrm{S}$ and $\mathrm{Co}-\mathrm{NiS}$ systems possessed very high catalytic activity in acidic medium. They declaimed that better catalytic activity may be caused by the minimal energy difference between the oxygen $2 p$ orbital and the highest occupied d orbital of sulfides [50]. CoS was, apparently, the most promising ORR non-precious metal catalyst in alkaline media. Besides, $\mathrm{Co}_{9} \mathrm{~S}_{8}$ was predicted to have similar ORR activity with that of $\mathrm{Pt}$ via a four-electron ORR pathway in acidic solution [51]. Zhu et al. [52] developed a simple and scalable route to synthesize 3D hybrid nanocatalyst-the $\mathrm{Co}_{9} \mathrm{~S}_{8}$ incorporated in N-, S-doped porous carbon exhibited an excellent catalytic activity, superior long-term stability, and good tolerance against methanol. Recently, Dai et al. [19], for the first time, designed and prepared the etched and doped $\mathrm{Co}_{9} \mathrm{~S}_{8} /$ graphene hybrid as an advanced bifunctional oxygen electrode reactions catalyst.

\subsubsection{Crystal Structure and Particle Size Effect}

The different crystal structures with the same chemical composition led to the different ORR catalytic activity. For instance, $\mathrm{CoSe}_{2}$ has two common crystal structures: cubic (pyrite-type), and orthorhombic marcasite-type. Alonso-Vante and Feng [53,54] discovered that the orthorhombic $\mathrm{CoSe}_{2}$ was obtained after a heat treatment of $250-300{ }^{\circ} \mathrm{C}$. The cubic $\mathrm{CoSe}_{2}$ phase was obtained at high temperature $\left(400-430^{\circ} \mathrm{C}\right)$. The latter showed a higher ORR activity by $30 \mathrm{mV}$ in $0.5 \mathrm{M} \mathrm{H}_{2} \mathrm{SO}_{4}$. Wu et al. [55] prepared cubic $\mathrm{Co}_{9} \mathrm{~S}_{8}$ particles surrounded by nitrogen-doped graphene sheets for the ORR in alkaline medium with an improved ORR activity and stability comparable to Pt/C. Similarly, cobalt sulfides with different chemical compositions and crystal structures, namely, $\mathrm{Co}_{1-x} \mathrm{~S}, \mathrm{CoS}$ (hexagonal phase) [56], $\mathrm{CoS}_{2}, \mathrm{Co}_{9} \mathrm{~S}_{8}$ and $\mathrm{Co}_{3} \mathrm{~S}_{4}$ (cubic phase) [56], are the most promising type of chalcogenides for the ORR. As an illustration, Dai et al. [18] obtained the $\mathrm{Co}_{2} \mathrm{~S} / \mathrm{RGO}$ with an average particle size of ca. $50 \mathrm{~nm}$ and $\mathrm{Co}_{1-x} \mathrm{~S} / \mathrm{RGO}$ with an average particle size of 10-20 nm. The latter displayed a better ORR activity in terms of the onset potential of ca. $0.8 \mathrm{~V}$ vs. RHE (Reversible Hydrogen Electrode) in $0.5 \mathrm{M} \mathrm{H}_{2} \mathrm{SO}_{4}$. The authors noticed that the ORR performance depends on the particle size and on the crystal structure.

Generally, the mass activity (MA, activity mass ${ }^{-1}$ ) of a catalyst is defined as the current normalized by the noble metal loading or catalyst loading as measured at a specific electrode potential. In order to increase MA, some strategies can be adopted, i.e., increasing the specific surface area of the catalysts by decreasing the particle size [57]. The particle size effect on the specific activity of catalysts has been attributed to different factors, such as, the structural sensitivity, i.e., the dependence of surface geometry, the electronic state, and the metal-support interaction [58]. Moreover, the particle size of the catalysts on the oxygen reduction reaction can be influenced by the adsorption of oxygen during the reaction, which is mainly associated with the fraction of active sites on the surface of the catalysts. Wang et al. [59] demonstrated that the $\mathrm{Pd}_{3} \mathrm{Co}$ alloy had a slightly smaller lattice spacing than that of $\mathrm{Pd}$, and thus a further shifting to larger size was expected due to the stronger lattice-induced compression. The 3-fold enhancement in the specific activity of $\mathrm{Pd}_{3} \mathrm{Co}$ could be attributed to the nanosized-, and lattice mismatch-induced contraction in (111) facets, based on the DFT (density Functional Theory) calculation using a nanoparticle model. Feng et al. [46] developed cubic $\mathrm{CoS}_{2}$ nanocatalysts with different particle size from $30 \mathrm{~nm}$ to $80 \mathrm{~nm}$ by adjusting the initial $\mathrm{Co}^{2+}$ concentration in the presence of 
hexa-decylcetyl-trimethylammonium (CTAB), and further demonstrated that the ORR activity depends on the average particle size, see Figure 2. The ORR activity remained similar to the particle size from $30 \mathrm{~nm}$ to $50 \mathrm{~nm}$, and then significantly decreased with size from $50 \mathrm{~nm}$ to $80 \mathrm{~nm}$. The $\mathrm{CoS}_{2}$ catalyst with an average particle size of $30.7 \mathrm{~nm}$ demonstrated an excellent electrocatalytic performance with an onset potential ( $\left.E_{\text {onset }}\right)$ of $0.94 \mathrm{~V}$ vs. RHE, a half-wave potential of $0.71 \mathrm{~V}$ vs. RHE, and high tolerance in methanol-containing $0.1 \mathrm{M} \mathrm{KOH}$. Such a trend was also found for $20 \mathrm{wt} \% \mathrm{Co}_{3} \mathrm{~S}_{4} / \mathrm{C}$ nanoparticles and $20 \mathrm{wt} \% \mathrm{CoSe}_{2} / \mathrm{C}$ [60]. The particle size can be approximately adjusted within a certain range by controlling the initial feeding concentrations, which has strong effect on the crystal nucleation and crystal growth.
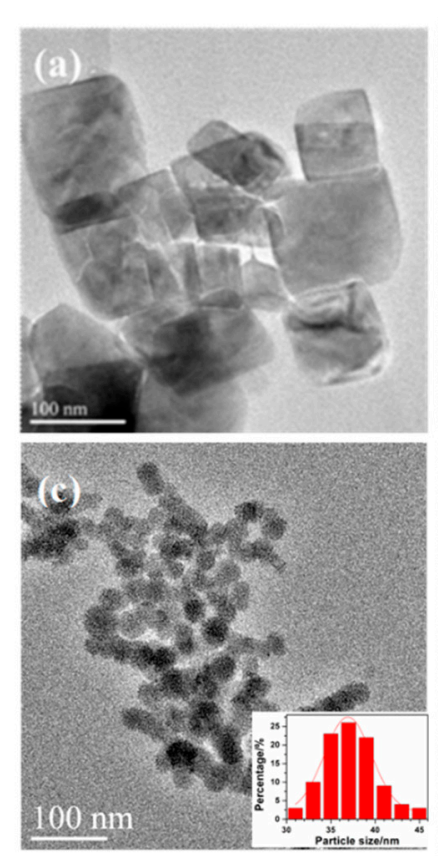
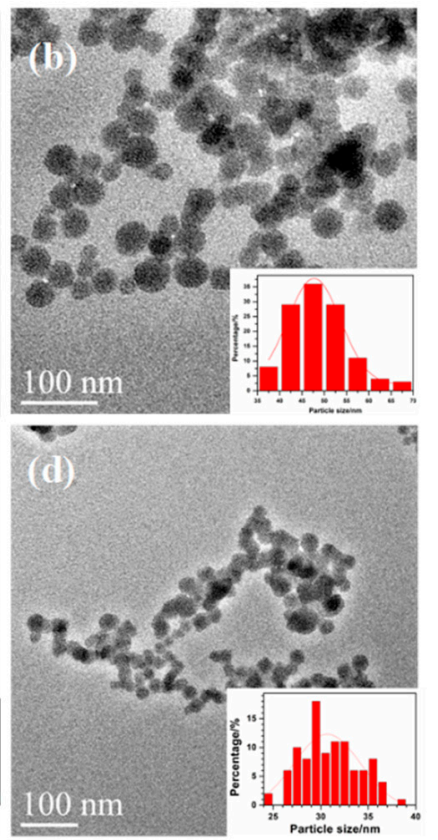
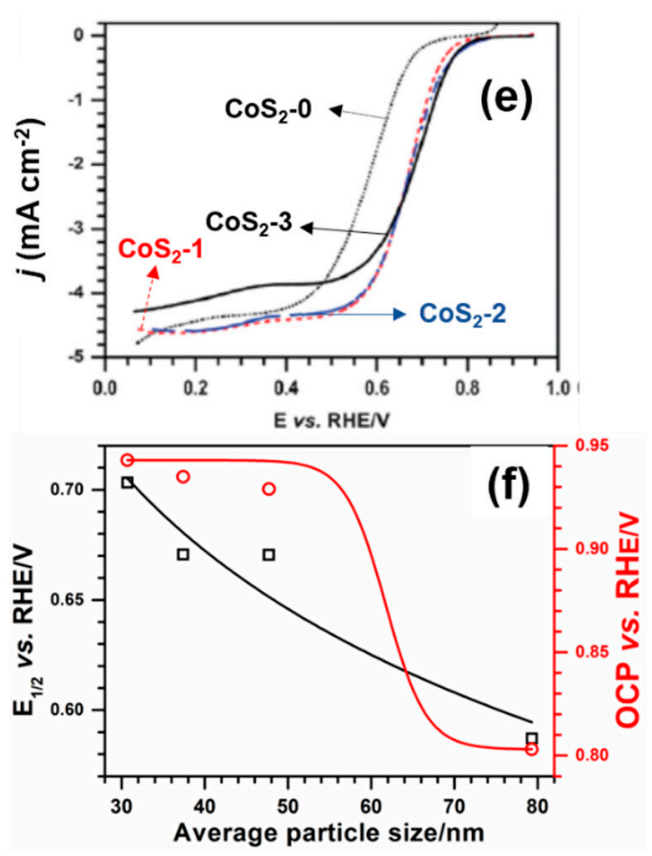

Figure 2. (a-d) High-resolution transmission electron microscope (HRTEM) images of $\mathrm{CoS}_{2}-0$ (without addition of hexa-decylcetyl-trimethylammonium (CTAB)), $\mathrm{CoS}_{2}-1,-2$, and -3 nanoparticles with the initial $\mathrm{Co}^{2+}$ concentrations from $0.025 \mathrm{M}$ to $0.075 \mathrm{M}$ in the presence of $0.5 \mathrm{mM} \mathrm{CTAB}$; (e) rotating disc electrode (RDE) curves of the four $\mathrm{CoS}_{2}$ samples in $\mathrm{O}_{2}$-saturated $0.1 \mathrm{KOH}$ at $1600 \mathrm{rpm}$ at a scan rate of $5 \mathrm{mV} \mathrm{s}^{-1}$ (cathodic sweep) at room temperature. The catalyst loading was $0.1 \mathrm{mg} \mathrm{cm}^{-2}$; (f) half-wave potential $\left(E_{1 / 2}\right)$ and OCP (Open Circuit Potential) extracted from Tafel plots as a function of the average $\mathrm{CoS}_{2}$ particle size. Reproduced from [46], Copyright (C) Royal Society of Chemistry, 2013.

\subsubsection{Synthesis and Support Effect}

Cobalt selenides have received extensive attention for their ORR activity [61,62]. This electrocatalyst deposited on highly conductive supporting material is very important to enhance the electrocatalytic performance. The ideal supporting materials for catalytic centers have high surface area, high electrical conductivity, and high chemical stability [63]. Taking advantage of the high surface area of amorphous carbon, Feng et al. [62] synthetized via a surfactant-free way the $\mathrm{CoSe}_{2}$ orthorhombic-phase nanoparticle supported onto XC-72 Vulcan with a promising ORR performance in acid media. Zhou et al. [64] developed supported $\mathrm{CoSe}_{2}$ nanostructures by a hydrothermal approach using the increased disordered domains of carbon nanotubes (CNTs) derived from a MOF with excellent ORR performance in $0.1 \mathrm{M} \mathrm{KOH}$ with a Tafel slope of $45 \mathrm{mV} \mathrm{dec}^{-1}$, onset potential of ca. $0.8 \mathrm{~V}$ vs. RHE, and a long-term stability. Although a relative success was obtained, the major drawback of the hybrid catalysts is the weak interaction between the catalytic centers and the support leading to low activity and stability. The formation of interfacial bonds between the catalytic center and the support favors the adsorption properties, therefore, enhancing the kinetics toward the electrocatalytic reaction [65]. 
The catalytic-support interaction may weaken the adsorption events, and then decrease the energy barriers for the reaction. This phenomenon, known as strong metal-support interaction (SMSI) is an important ingredient to tailor, and tune highly active and stable catalyst centers. Unni et al. [66] fabricated high-surface area N-doped carbon nanohorns (NCNH) supported cubic-phase $\mathrm{CoSe}_{2}$ via a simple $\mathrm{NaBH}_{4}$-chemical reduction process of $\mathrm{CoCl}_{2}$ and $\mathrm{SeO}_{2}$, Figure 3a,b. The $\mathrm{CoSe}_{2} / \mathrm{NCNH}$ demonstrated considerable ORR activity in alkaline medium, cf. Figure $3 c, d$, as a result of the electronic structure modification of chalcogenide $\left(\mathrm{CoSe}_{2}\right)$ centers throughout its interaction with $\mathrm{NCNH}$ via the nitrogen moieties, Figure 3e.
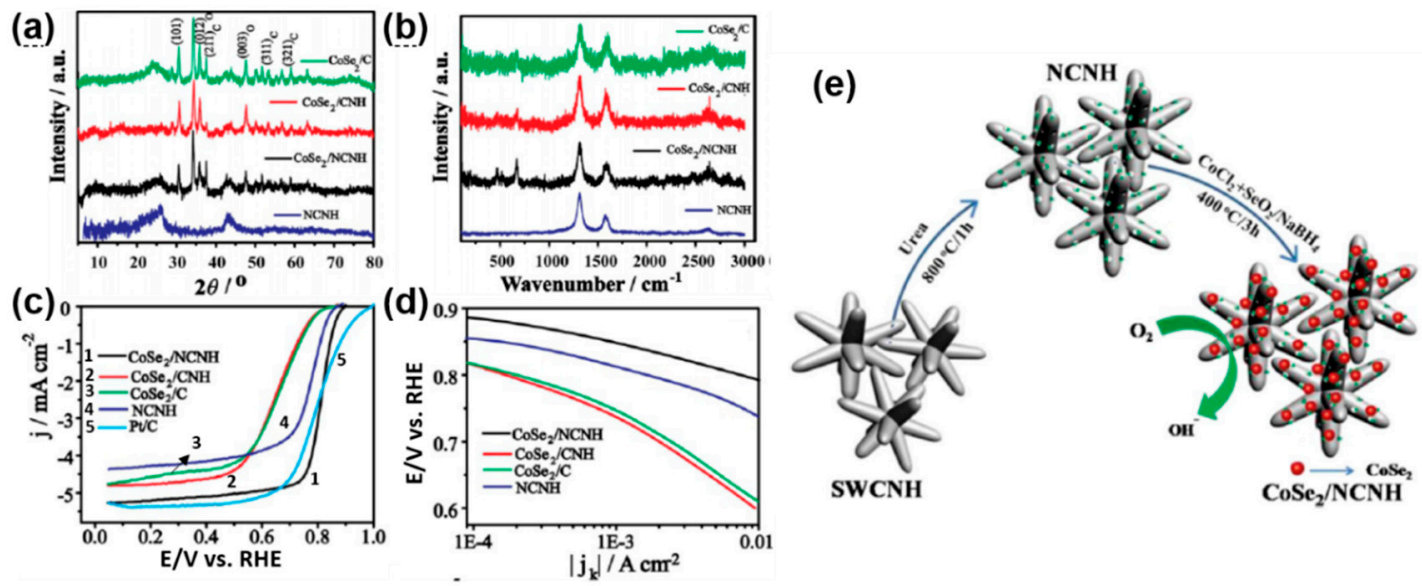

Figure 3. (a) Raman spectra; (b) X-ray diffraction (XRD) patterns; (c) oxygen reduction reaction (ORR) polarization curves of $\mathrm{CoSe}_{2} / \mathrm{N}$-doped carbon nanohorns $(\mathrm{NCNH}), \mathrm{CoSe}_{2} /$ carbon nanohorns $(\mathrm{CNH})$, $\mathrm{CoSe}_{2} / \mathrm{C}, \mathrm{NCNH}$ and $\mathrm{Pt} / \mathrm{C}$ catalysts in $\mathrm{O}_{2}$-saturated $0.1 \mathrm{KOH}$ at $1600 \mathrm{rpm}$ at a scan rate of $5 \mathrm{mV} \mathrm{s}^{-1}$ (cathodic sweep) at $25^{\circ} \mathrm{C}$. The catalyst loading was $0.214 \mathrm{mg} \mathrm{cm}^{-2}$; (d) ORR Tafel plots of supported $\mathrm{CoSe}_{2}$ onto carbon Vulcan, $\mathrm{CNH}$ and $\mathrm{NCNH}$; (e) schematics of the synthesis procedure. Reproduced from [66], Copyright (c) Wiley, 2015.

Similarly, García-Rosado et al. [67] prepared a series of N-doped reduced graphene oxide (N-RGO) as supports for hexagonal cobalt selenide ( $\mathrm{CoSe}$ ) by a $\mathrm{NaBH}_{4}$-assisted chemical reduction, Figure 4 . The carbon support after the surface reduction supplied more available active and anchor sites due to the increase in the pore size and surface area. The ORR performance is concomitant with the properties of the supports. The graphitic and pyridinic nitrogen moieties of N-RGO acted as electrochemical active sites for the ORR in alkaline media.

Additionally, Pan et al. [68] used porous g- $\mathrm{C}_{3} \mathrm{~N}_{4}$ as a template and a $\mathrm{N}$-source to successfully synthesize mesoporous S-, and N-co-doped carbon matrix coupled with $\mathrm{Co} @ \mathrm{Co}_{9} \mathrm{~S}_{8}$ nanoparticles, cf. Figure 5 . Herein, the $\mathrm{g}-\mathrm{C}_{3} \mathrm{~N}_{4}$ carbon matrixes not only enhance the conductivity, but also suppress the aggregation phenomenon during the electrochemical reactions. Besides, the strong coupling between $\mathrm{Co}_{0} \mathrm{Co}_{9} \mathrm{~S}_{8}$ and N-, S-carbon promoted significantly the ORR electrocatalytic performance with a more positive half-wave potential and lower Tafel slope value, as compared with the commercial $\mathrm{Pt} / \mathrm{C}$ catalyst. 
(a)

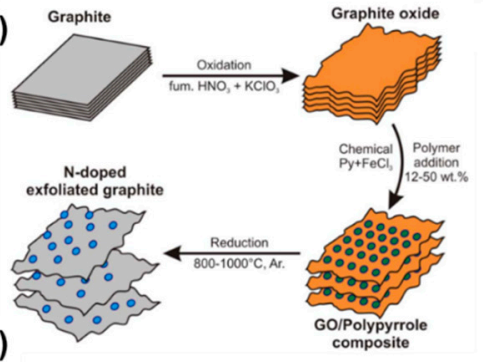

(b)

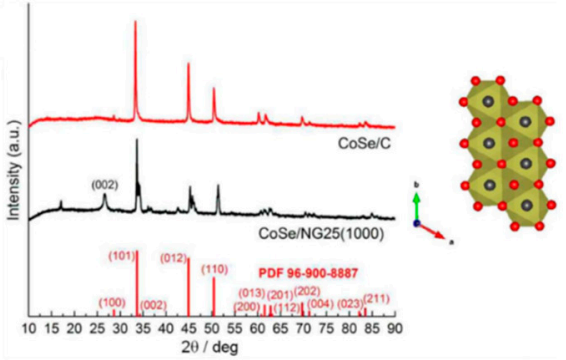

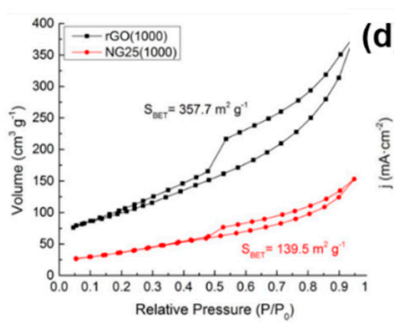
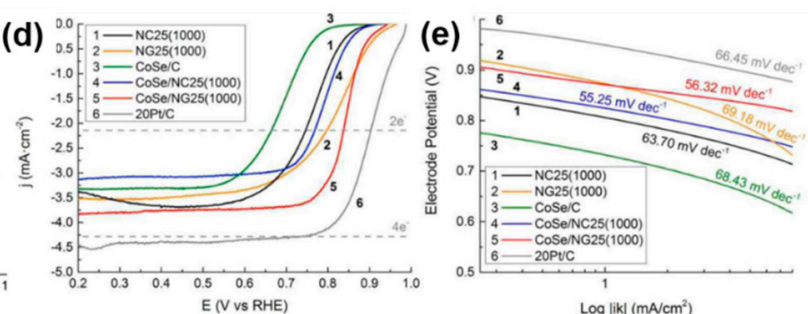

Figure 4. (a) scheme of the synthesis of N-doped reduced graphene oxide (N-RGO); (b) XRD patterns of supported hexagonal CoSe onto GO and N-RGO; (c) BET-nitrogen adsorption-desorption isotherms of rGO(1000), and NG25(1000); (d) ORR polarization curves of NC25(1000), NG25(1000), CoSe/C, CoSe/NC25(1000), CoSe/NG25(1000) and Pt/C electrocatalysts at $900 \mathrm{rpm}$ (cathodic sweep) in $\mathrm{O}_{2}$-saturated $0.1 \mathrm{M} \mathrm{KOH}$ at $25{ }^{\circ} \mathrm{C}$ with the catalyst loading of $0.286 \mathrm{mg} \mathrm{cm}^{-2}$; and (e) ORR Tafel plots of supported CoSe catalysts in alkaline medium. Reproduced from [67], Copyright () The Electrochemical Society, 2017.

\section{(a)}
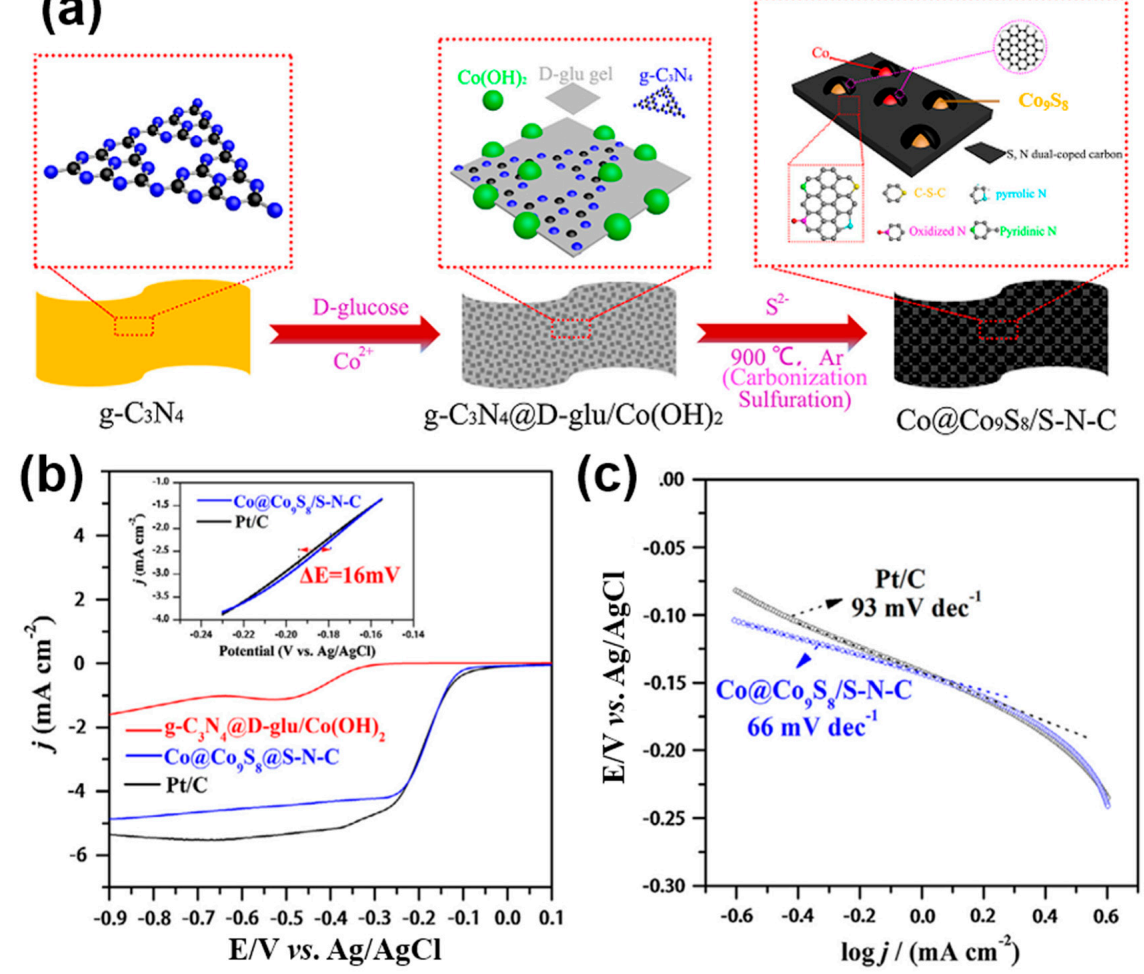

Figure 5. (a) The schematic chemical synthesis route of $\mathrm{Co}_{0} \mathrm{Co} \mathrm{C}_{8} / \mathrm{S}-\mathrm{N}-\mathrm{C}$; (b) linear sweep voltammetry (LSV) curves for the g- $\mathrm{C}_{3} \mathrm{~N}_{4} @ \mathrm{D}-\mathrm{glu} / \mathrm{Co}(\mathrm{OH})_{2}, \mathrm{Co} @ \mathrm{Cog}_{9} \mathrm{~S}_{8} / \mathrm{S}-\mathrm{N}-\mathrm{C}$, and $\mathrm{Pt} / \mathrm{C}$ electrodes recorded in $\mathrm{O}_{2}$-saturated $0.1 \mathrm{KOH}$ solution at $1600 \mathrm{rpm}$ with scan rate of $10 \mathrm{mV} \mathrm{s}^{-1}$ (cathodic sweep) at $25^{\circ} \mathrm{C}$ (catalyst mass loading: $0.2 \mathrm{mg} \mathrm{cm}^{-2}$ ); (c) Tafel plots of $\mathrm{Co}_{0} \mathrm{Cog}_{9} \mathrm{~S}_{8} / \mathrm{S}-\mathrm{N}-\mathrm{C}$ and Pt/C catalysts. Reproduced from [68], Copyright $\odot$ Elsevier, 2018. 


\subsection{Oxygen Reduction on Metal-Organic Frameworks (MOFs) Catalysts}

MOFs and their derivatives have also been used as efficient precursors and self-sacrificing templates because of their well-tunable physical and chemical properties. Benefiting from the unique properties of MOF, such as, large surface area, tailoring porosity, and easy functionalization with other heteroatoms or metal/metal oxides, various carbon-based nanomaterials (as support) have been prepared. Based on organic ligands and cobalt metal centers, MOFs compounds possess special superiority to prepare various cobalt-based functionalized carbon nanomaterials, including heteroatom-doped porous carbons, and metal/metal oxide decorated porous carbons, via thermal decomposition under controlled atmospheres. For instance, Lou et al. [69] used ZIF-67 as a template and thioacetamide as a sulfur source to prepare a double-shelled $\mathrm{Co}-\mathrm{C} @ \mathrm{Co}_{9} \mathrm{~S}_{8}$ nanocages electrocatalyst for the ORR. By adjusting the reaction time, the amorphous CoS nanocages (a-CoS NCs) and ZIF-67@a-CoS yolk-shelled hollow nanostructures were fabricated. The $\mathrm{Co}_{9} \mathrm{~S}_{8}$ shells, served as a nanoreactor, effectively prevented the $\mathrm{Co}-\mathrm{C}$ active centers from aggregation, Figure 6a. Interestingly, the unique $\mathrm{Co}-\mathrm{C}$ hollow cages significantly shortened the diffusion pathway of the electrolyte, and thus promoted the electrocatalytic activity, durability, and tolerant to methanol toward the ORR of $\mathrm{Co}_{-} \mathrm{C} @ \mathrm{Co}_{9} \mathrm{~S}_{8}$ catalyst. In Figure $6 \mathrm{~b}-\mathrm{e}$, the onset potential remarkably reached $0.96 \mathrm{~V}$ vs. RHE with a limiting current of $4.5 \mathrm{~mA} \mathrm{~cm}{ }^{-2}$ and a four-electron transfer route with $\mathrm{OH}^{-}$production in alkaline media.

(a)

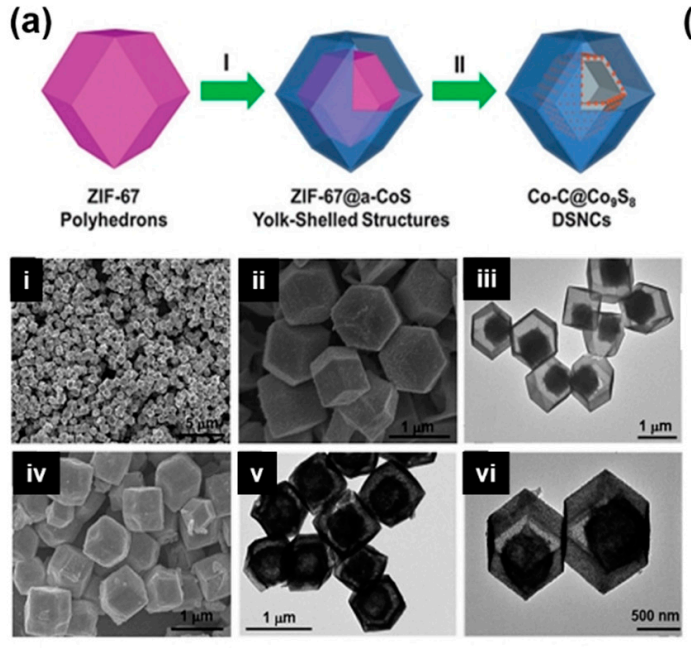

(b)

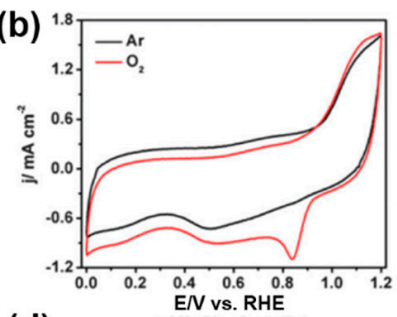

(d)

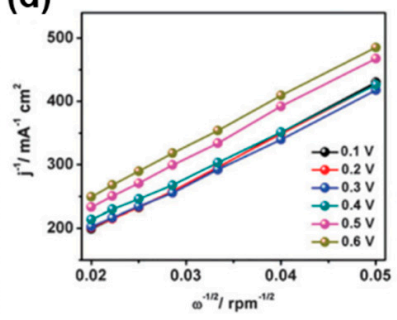

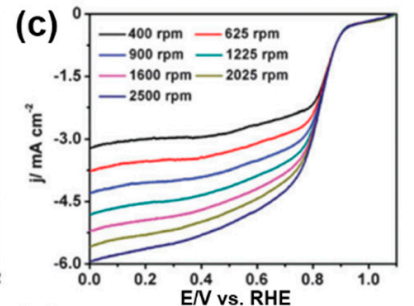

(e)

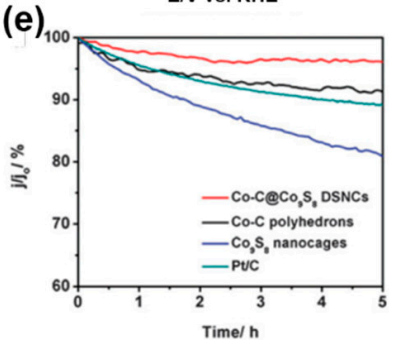

Figure 6. (a) The synthesis route of $\mathrm{Co}-\mathrm{C}_{9} \mathrm{Co}_{9} \mathrm{~S}_{8}$ DSNCs (double-shelled nanocages); (i-vi) field-emission scanning electron microscopy (FESEM) and TEM micrographs of the catalyst; (b) CV curves of Co-C@Co ${ }_{9} \mathrm{~S}_{8}$ DSNCs in Ar- or $\mathrm{O}_{2}$-saturated $0.1 \mathrm{M} \mathrm{KOH}$ electrolyte with a scan rate of $10 \mathrm{mV} \mathrm{cm} \mathrm{s}^{-1}$; (c) LSV (cathodic sweep) curves of $\mathrm{Co}-\mathrm{C}_{0} \mathrm{Co}_{9} \mathrm{~S}_{8}$ DSNCs catalyst recorded at different rotation speeds from 400 to $2500 \mathrm{rpm}$ in $\mathrm{O}_{2}$-saturated $0.1 \mathrm{M} \mathrm{KOH}$; (d) the K-L plots of Co-C@Co $\mathrm{S}_{8}$ DSNCs at various potentials (0.1-0.6 V vs. RHE (Reversible Hydrogen Electrode); (e) the chronoamperometric responses (j/ $\mathrm{j}_{0}(\%)$ vs. $\left.\mathrm{t}\right)$ of $\mathrm{Co}-\mathrm{C} @ \mathrm{Co}_{9} \mathrm{~S}_{8}$ DSNCs, $\mathrm{Co}-\mathrm{C}$ polyhedrons, $\mathrm{Co}_{9} \mathrm{~S}_{8}$ nanocages and $\mathrm{Pt} / \mathrm{C}$ electrodes at $0.5 \mathrm{~V}$ in $\mathrm{O}_{2}$-saturated $0.1 \mathrm{M} \mathrm{KOH}$ solution at $1600 \mathrm{rpm}$. Reproduced from [69], Copyright $\odot$ Royal Society of Chemistry, 2015.

Additionally, a simple and efficient method to produce homogeneously dispersed cobalt sulfide/N-, S-co-doped porous carbon electrocatalysts, using ZIF-67 as precursor and template, was reported by Xia et al. [70]. Due to a unique core-shell structure, high porosity, homogeneous dispersion of active components together with $\mathrm{N}$-, and S-doping effects, the electrocatalyst not only showed an excellent electrocatalytic activity towards ORR with a high onset potential (ca. $-0.04 \mathrm{~V}$ compared with $-0.02 \mathrm{~V}$ for the benchmark $\mathrm{Pt} / \mathrm{C}$ catalyst), but also revealed a superior stability $(92 \%)$ compared with the commercial $\mathrm{Pt} / \mathrm{C}$ catalyst (74\%) in ORR. 
Table 1 summarizes some transition metal chalcogenides as ORR catalysts investigated so far. One can conclude that: (1) Co-based chalcogenides are promising catalysts for the ORR in alkaline media; (2) the carbon support having a pore morphological structure, and hetero-atom doping plays a key role to promote the ORR performance of Co-based chalcogenides.

\subsection{Oxygen Reduction on Cobalt Oxide Catalysts}

\subsubsection{Nanostructure}

Intensive efforts have been devoted to fabricate various surface-tuned cobalt oxides materials with different nanostructures and morphologies, including $\mathrm{Co}_{3} \mathrm{O}_{4}$ nanorods [71], nanowires [72], core-shell [73], and hollow structures [74], which are responsible for the electrochemical performance. For example, Kurungot et al. [75] prepared a series of surface-tuned $\mathrm{Co}_{3} \mathrm{O}_{4}$ nanoparticles with different morphologies (cubic $\left(\mathrm{Co}_{3} \mathrm{O}_{4}-\mathrm{NC} / \mathrm{NGr}-9 \mathrm{~h}\right)$, blunt-edged cubic $\left(\mathrm{Co}_{3} \mathrm{O}_{4}-\mathrm{BC} / \mathrm{NGr}-12 \mathrm{~h}\right)$, and rough edged spherical $\left.\left(\mathrm{Co}_{3} \mathrm{O}_{4}-\mathrm{SP} / \mathrm{NGr}-24 \mathrm{~h}\right)\right)$ dispersed on nitrogen-doped graphene (NGr) electrocatalysts for ORR by varying the reaction time. The transformations of the morphologies of $\mathrm{Co}_{3} \mathrm{O}_{4}$ could be assigned to the transformation of the higher to the lower surface energy crystal plane structure, which was expected to obtain the mixed facets of the exposed Co-oxide crystals. Among them, the NGr supported spherical $\mathrm{Co}_{3} \mathrm{O}_{4}\left(\mathrm{Co}_{3} \mathrm{O}_{4}-\mathrm{SP}\right)$ nanoparticles $\left(\mathrm{Co}_{3} \mathrm{O}_{4}-\mathrm{SP} / \mathrm{NGr}-24 \mathrm{~h}\right)$ with the highest roughness factor and increased surface area exhibited the best activity in alkaline medium, and attributed to: (1) homogenous dispersion of $\mathrm{Co}_{3} \mathrm{O}_{4}$ nanoparticles on NGr support; (2) NGr served as nucleation sites, efficiently controlling the growth kinetics of $\mathrm{Co}_{3} \mathrm{O}_{4}$ nanoparticles; and (3) a strong synergistic interaction between the active sites and the support.

\subsubsection{Particle Size Effect and Chemical Composition}

Different particle size also influences the electrocatalytic active surface. For example, Feng's group [76] synthesized a series of $\mathrm{Co}_{3} \mathrm{O}_{4} / \mathrm{N}-\mathrm{RGO}$ composites with different particle size by controlling $\mathrm{Co}^{2+}$ initial feeding concentrations, and carefully investigated the particle size effect of $\mathrm{Co}_{3} \mathrm{O}_{4}$ nanoparticles on the bifunctional oxygen electrocatalytic performance. The $\mathrm{Co}_{3} \mathrm{O}_{4} / \mathrm{N}-\mathrm{RGO}$ with the smallest particle size of $12.2 \mathrm{~nm}$ revealed the best bifunctional oxygen activity (ORR and OER) with lower $\Delta \mathrm{E}=0.75 \mathrm{~V}\left(\Delta \mathrm{E}=E_{\mathrm{OER}}, \mathrm{j} @ 10 \mathrm{~mA} \mathrm{~cm}^{-2}-E_{\mathrm{ORR}}, \mathrm{j} @-3 \mathrm{~mA} \mathrm{~cm}{ }^{-2}\right)\left(E_{\mathrm{OER}}, \mathrm{j} @ 10 \mathrm{~mA} \mathrm{~cm}^{-2}\right.$, the potential at a current density of $10 \mathrm{~mA} \mathrm{~cm}{ }^{-2}$ for OER; $E_{\mathrm{ORR}, \mathrm{j} @-3 \mathrm{~mA} \mathrm{~cm}}{ }^{-2}$, the potential at a current density of $-3 \mathrm{~mA} \mathrm{~cm}{ }^{-2}$ for ORR) than other larger particle sized samples. Sun and co-workers [77] investigated, on the other hand, the impact of the $\mathrm{CoO}$ particle size on the ORR activity via a combined controllable hydrolysis and thermal treatment process. The promoted ORR current and the increased content of $\mathrm{HO}_{2}{ }^{-}$produced over the smallest $\mathrm{CoO}$ particles benefited from the increase of the interface between carbon support and $\mathrm{CoO}$ nanoparticles (NPs). Thus, the interface between carbon and $\mathrm{CoO}$ NPs could be identified as the most active site.

Besides the control of particles' size, fine-tuning of the chemical composition (e.g., $\mathrm{Co}^{3+} / \mathrm{Co}^{2+}$ ratio) was an effective strategy to boost the electrocatalytic activity of cobalt oxide catalysts. Liu et al. [78] proposed an interesting approach to enhance the electrocatalytic activity of $\mathrm{Co}_{3} \mathrm{O}_{4}$ nanosheets through the modulation of the inner oxygen vacancy concentration, and the $\mathrm{Co}^{3+} / \mathrm{Co}^{2+}$ ratio. Based on the synergistic effect of the fashioned 2D nanosheets, the presence of oxygen vacancies, and the $\mathrm{Co}^{3+} / \mathrm{Co}^{2+}$ ratio, the catalyst showed a much lower overpotential towards ORR and OER for $\mathrm{Li}-\mathrm{O}_{2}$ batteries. Furthermore, Zhao's group [79] reported that the ORR catalytic activity of the prepared catalysts is sensitive to the number and activity of surface-exposed $\mathrm{Co}^{3+}$ ions that could be tailored by the morphology of cobalt oxides.

\subsubsection{Support Effect}

Cobalt oxide $\left(\mathrm{Co}_{3} \mathrm{O}_{4}\right.$ and $\left.\mathrm{CoO}\right)$ nanoparticles are recognized as a class of non-precious catalysts with high activity, stability and durability in alkaline solution. For example, $\mathrm{Co}_{3} \mathrm{O}_{4} /$ graphene 
hybrids had a remarkable ORR performance comparable to that of commercial $\mathrm{Pt} / \mathrm{C}$ in alkaline, which was attributed to the synergistic catalyst-support coupling [25]; as for graphene supported 3D "sheet-on-sheet" interleaved $\mathrm{Co}_{3} \mathrm{O}_{4}$ nanosheets $(\mathrm{Co}-\mathrm{S} / \mathrm{G})$, the strong electron transport and charge transfer from graphene to $\mathrm{Co}_{3} \mathrm{O}_{4}$ nanosheets significantly enhanced the ORR electrocatalytic properties of Co-S/G [80].

Bao et al. [81] proposed that the excessive ascorbic acid (AA) could form abundant negative functional groups on the surface of 3D graphene aerogel (3DG, Figure 7a), with $\mathrm{Co}^{2+}$ ions uniformly anchored on 3DG by electrostatic or coordination interaction. The hollow $\mathrm{Co}_{3} \mathrm{O}_{4} / 3 \mathrm{DG}$ was synthesized by a direct oxidation of $\mathrm{C} @ \mathrm{Co} / 3 \mathrm{DG}$ precursor through the Kirkendall effect, Figure 7b. The prepared $\mathrm{Co}_{3} \mathrm{O}_{4} / 3 \mathrm{DG}\left(22 \mathrm{wt} \% \mathrm{Co}_{3} \mathrm{O}_{4}\right)$ electrocatalyst showed a positive onset potential of $0.82 \mathrm{~V}$ vs. RHE, and a limiting current density of $5.12 \mathrm{~mA} \mathrm{~cm}^{-2}(1600 \mathrm{rpm})$, Figure $7 \mathrm{c}$. The rotating ring disk electrode (RRDE) method further confirmed a charge transfer pathway close to 4-electron with a production of hydrogen peroxide $\left(\mathrm{HO}_{2}{ }^{-}\right)$of $4.27 \%$ to $14.2 \%$ in Figure $7 \mathrm{~d}$.

(a)

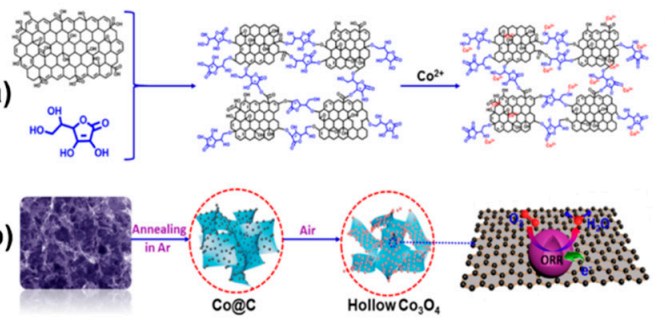

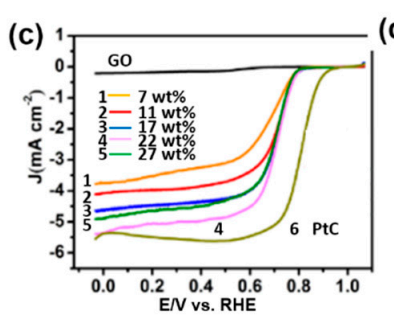

Figure 7. (a) Schematic representation of how an excess of ascorbic acid reduced graphene oxide (GO) and formed 3DG (three-dimensional graphene). The added $\mathrm{Co}^{2+}$ are anchored on 3DG; (b) Schematic showing the formation of HNPs (hollow nanoparticles) $\mathrm{Co}_{3} \mathrm{O}_{4} / 3 \mathrm{DG}$ material; (c) LSVs (cathodic sweep) curves of $\mathrm{GO}, \mathrm{Co}_{3} \mathrm{O}_{4} / 3 \mathrm{DG}$ (with various weight loading) and $\mathrm{Pt} / \mathrm{C}$ electrodes in $\mathrm{O}_{2}$-saturated $0.1 \mathrm{M} \mathrm{KOH}$ electrolyte at $5 \mathrm{mV} \mathrm{s}^{-1}$ at $1600 \mathrm{rpm}$; (d) the transferred electrons and peroxide percentage of $\mathrm{Co}_{3} \mathrm{O}_{4} / 3 \mathrm{DG}(22 \mathrm{wt} \%)$. Reproduced from [81], Copyright (c) Wiley, 2017.

Wang et al. [82] developed a supramolecular gel-assisted method to manufacture N-doped carbon shell coated Co@CoO nanoparticles on carbon Vulcan XC-72 (Co@CoO@N-C/C) for ORR. Herein, melamine not only acted as a chelating agent interacting with $\mathrm{Co}^{2+}$, but also as a nitrogen source to dope at high-temperature pyrolysis treatment. Due to the synergistic effect, the double-shelled

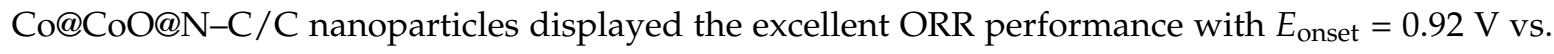
RHE and $E_{1 / 2}=0.81 \mathrm{~V}$ vs. RHE, comparable with the commercial Pt $/ \mathrm{C}$ in $0.1 \mathrm{M} \mathrm{KOH}$.

\subsection{Oxygen Reduction on Cobalt-Based Layered Double-Hydroxides Catalysts}

Synthesis Strategy

Layered double hydroxides (LDHs), a class of two-dimensional (2D) layered material, consist of host sheets with divalent $\left(\mathrm{M}^{\mathrm{II}}\right)$ and trivalent $\left(\mathrm{M}^{\mathrm{III}}\right)$ metal cations coordinated to hydroxide anions, and the guest anions in the interlayer regions. This kind of structure has attracted interest in various energy conversion systems [31]. Generally, hydroxides have a good affinity to aqueous electrolytes and their layered structures offer an enlarged surface area and improved dispersion degree based on the confinement effect. This latter property favors the accessibility of catalytic sites. Nevertheless, the positively charged host sheets in LDHs favor the oxygen adsorption and its oxygen reduction. Currently, Co-containing LDHs, as ORR catalysts, have been the object of intense research [83-85]. For instance, Li et al. [85] investigated the interaction of LDHs with RGO toward the ORR via a four-electron transfer pathway and found that the $\mathrm{Co}^{2+}$ in the LDHs, as active sites, catalyzed the disproportionation of the peroxide species to form $\mathrm{H}_{2} \mathrm{O}$ and $\mathrm{O}_{2}$. Additionally, the RGO support increased the electrical conductivity. 
Apart from the direct preparation of the LDHs precursor, the materials derived from LDHs, after thermal treatment, showed similar promising electrocatalytic activity in alkaline solution. For example, $\mathrm{Co}_{3} \mathrm{Mn}-\mathrm{CO}_{3}-\mathrm{LDH} / \mathrm{RGO}$ precursor was calcined to produce reduced graphene oxide supported $\mathrm{Co}-\mathrm{Mn}$ oxides under nitrogen atmosphere with enhanced catalytic performance ( $E_{\text {onset }}=0.95 \mathrm{~V}$ vs. RHE, $E_{1 / 2}=0.76 \mathrm{~V}$ vs. RHE, and $j_{\text {limit }}=4.2 \mathrm{~mA} \mathrm{~cm}^{-2}$ at $0.2 \mathrm{~V}$ vs. RHE, $1600 \mathrm{rpm}$ ) [84]. Similarly, $\mathrm{Co}_{3} \mathrm{O}_{4} / \mathrm{Co}_{2} \mathrm{MnO}_{4}$ composites, resulting from $\mathrm{CoMn}-\mathrm{LDHs}$ precursor, displayed excellent bifunctional activities for ORR and OER with $\triangle \mathrm{E}=1.09 \mathrm{~V}$.

Herein, the activity of the material was attributed to the large specific surface area and well-dispersed heterogeneous structure [83]. $\mathrm{Xu}$ et al. [86], on the other hand, fabricated a $\mathrm{Co} / \mathrm{CoO} / \mathrm{CoFe}_{2} \mathrm{O}_{4}$ as ORR electrocatalyst based on the utilization of $\mathrm{CoFe}-\mathrm{LDH}$ as precursor by separate nucleation and aging steps (SNAS). The same group later reported Co@N-CNTs obtained by calcination of melamine/CoAl-LDH mixture, cf. Figure 8 [32]. Here, the CoAl-LDH precursor operated as: (i) catalyst for carbonization and formation of N-CNTs; (ii) detacher of active Co nanoparticles from the Co component in the host sheet; (iii) enabler for the growth of long N-CNTs with the aid of the confinement effect of non-active $\mathrm{Al}_{2} \mathrm{O}_{3}$ matrix formed.

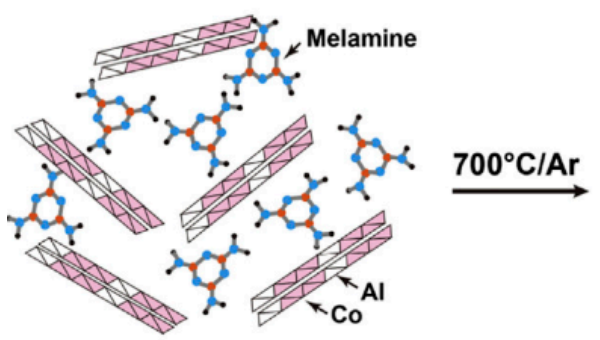

CoAI-LDH/melamine mixture

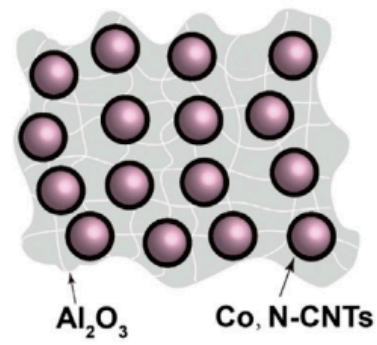

$\mathrm{Al}_{2} \mathrm{O}_{3}$

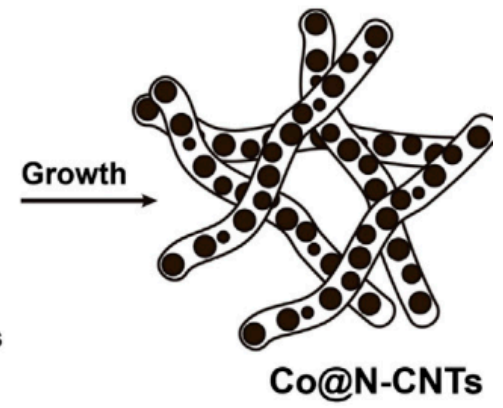

Figure 8. Representation of Co@N-CNTs-m resulting from CoAl-layered double hydroxides (LDH)/melamine mixture. Reproduced from [32], Copyright (C Elsevier, 2016.

\subsection{Oxygen Reduction on $\mathrm{Co}-\mathrm{N}_{x} / \mathrm{C}$ Catalysts}

\subsection{1. $\mathrm{Co}-\mathrm{N}_{x}$ Active center}

Besides the aforementioned Co-based electrocatalysts, $\mathrm{Co}-\mathrm{N}_{x} / \mathrm{C}$ has also been considered as another potential candidate to substitute Pt for ORR. In 1964, Jasinski [87] for the first time found that cobalt-phthalocyanine ( $\mathrm{CoPc}$ ) activated the ORR process in alkaline electrolyte. However, the catalytic sites in macrocyclic cathode catalysts for ORR are still controversial. Apropos $\mathrm{Co}-\mathrm{N}_{x} / \mathrm{C}$ catalysts, various type of active sites were proposed, including $\mathrm{Co}-\mathrm{N}_{4} / \mathrm{C}$ and $\mathrm{Co}-\mathrm{N}_{2} / \mathrm{C}$ [88-92], $\mathrm{N}_{x} \mathrm{C}_{y}$ [93], pyridinic N [91,94], and graphitic N [95,96]. For example, Kiefer et al. [97] explained the origin and mechanism of ORR on Co- $\mathrm{N}_{x}(x=2,4)$ based on self-assembled carbon supported electrocatalysts in alkaline and acidic media via first-principle DFT calculations. The graphitic $\mathrm{Co}-\mathrm{N}_{4}$ defect was energetically more favorable than the graphitic $\mathrm{Co}-\mathrm{N}_{2}$ defects, and the former was predicted to be the dominant in-plane graphitic defect in $\mathrm{Co}-\mathrm{N}_{x} / \mathrm{C}$ electrocatalysts.

Nevertheless, $\mathrm{Li}$ et al. [98] believed that the dominant reactive sites for cobalt single atoms (Co-SAs) in Co-SAs/ $\mathrm{N}-\mathrm{C}$ could be postulated as $\mathrm{Co}-\mathrm{N}_{4}$ and $\mathrm{Co}-\mathrm{N}_{2}$ moieties, and $\mathrm{Co}-\mathrm{N}_{2}$ species had a stronger interaction with peroxide than $\mathrm{Co}-\mathrm{N}_{4}$, promoting the ORR four-electron reduction process. Tang et al. [99] considered that both of $\mathrm{Co}-\mathrm{N}_{x}$ and pyri- $N$ species were very important and their coupling effect (Co-pyri-N) was of paramount importance in the high electrocatalytic activity due to the high lying HOMO energy levels. Besides, Liao et al. [100] proposed that doped transition metals could act, on one hand, as a catalyst for the formation of stable active sites in the pyrolysis process, and on the other hand, the residual metal compounds could serve as active sites. In fact, the ORR catalytic performance improvement of transition metals might be the result of joint effects: (i) the overall $\mathrm{N}$ content/active $\mathrm{N}$ content; (ii) metal residue; and (iii) the surface area and pore structures. Metal-free 
carbon structure was originally suggested as active sites by Wiesener [101]. Yet, Masa et al. [102] argued for the concept of a metal-free catalyst. Indeed, truly metal-free nitrogen-doped carbon demonstrated much lower ORR activity and reduced $\mathrm{O}_{2}$ through a two-electron pathway in acidic solution, so that undetectable metal residues may play a crucial role for the ORR.

\subsubsection{Co- $\mathrm{N}_{x}$ Synthesis Strategy}

Generally, the electrocatalytic activity and stability of $\mathrm{Co}-\mathrm{N}_{x} / \mathrm{C}$, or nitrogen-modified carbon supports (NCSs) or templates materials, basically rely on the morphology, pore structure, dispersion of the active sites, and nitrogen species, which are up to the crucial synthetic route. Traditional methods involving the pyrolysis of carbon-supported cobalt $\mathrm{N}_{4}$-macrocycles, e.g., phthalocyanine (Pc), tetra-azaannulene (TAA), tetra-phenylpophyrin (TPP) and tetra-methoxyphenlyporphyrin (TMPP), at temperatures between $550{ }^{\circ} \mathrm{C}$ and $800^{\circ} \mathrm{C}$ preserved or created $\mathrm{Co}-\mathrm{N}_{x}$ active sites, although the macrocyclic structure of the complex was partially or completely destroyed [103-106]. Above $800{ }^{\circ} \mathrm{C}$, the metal-nitrogen species are known to decompose with a concomitant decrease in the ORR performance. For example, Popov et al. [107] found, via EXAFS, that the content of Co-N species decreased when the heat treatment exceeded $800{ }^{\circ} \mathrm{C}$. Yet, Dodelet's group [108] proposed that Co metal and/or CoPc fragments containing Co could be responsible for the catalytic activity of CoPc/XC-72 pyrolyzed at 600 or $700{ }^{\circ} \mathrm{C}$, a treatment where the maximum of the electrocatalytic activity was obtained [109]. Jahnke et al. [110] improved the stability as well as the electrochemical activity of transition metal porphyrins deposited on carbon support by a pyrolytic treatment step in the range of 450 to $900{ }^{\circ} \mathrm{C}$, in an inert atmosphere. Qiao et al. [35] synthesized carbon-supported cobalt catalysts, namely, Py-CoPc/C, heat-treated at $600-900{ }^{\circ} \mathrm{C}$, and investigated its heat-treatment effect onto the ORR activity in alkaline electrolyte. The catalysts that annealed at $700{ }^{\circ} \mathrm{C}$ exhibited the best activity towards ORR in $0.1 \mathrm{M} \mathrm{KOH}$. Such a phenomenon was related with $\mathrm{Co}-\mathrm{N}_{x} / \mathrm{C}$, pyridinic-N and graphitic- $\mathrm{N}$ active sites. Shan et al. [111] fabricated novel mesoporous $\mathrm{Co}-\mathrm{N}_{x}-\mathrm{C}$, by a nanocasting-pyrolysis method, using $\mathrm{Co}-$ phenanthroline as the only precursor, permitting that abundant $\mathrm{Co}-\mathrm{N}_{x}$ moieties remained embedded in the graphitic framework during pyrolysis.

Recently, most $\mathrm{Co}-\mathrm{N}_{x} / \mathrm{C}$ catalysts were fabricated by pyrolysis treatment of Co salts mixed with carbon support and nitrogen-rich precursor [100]. Zelenay et al. [88] used polyaniline (PANI) as a nitrogen source for high-temperature synthesis of catalysts incorporating iron or cobalt centers. The most active catalysts: $\mathrm{FeCo} / \mathrm{N} / \mathrm{C}$, showed a very positive onset potential of $\sim 0.93 \mathrm{~V}$ with a long-term stability test of $700 \mathrm{~h}$ at a fuel cell voltage of $0.4 \mathrm{~V}$ in $0.5 \mathrm{M} \mathrm{H}_{2} \mathrm{SO}_{4}$. Zhang et al. [112] demonstrated the direct utilization of the intrinsic structural defects in nanocarbon to generate atomically dispersed $\mathrm{Co}-\mathrm{N}_{x}-\mathrm{C}$ active sites via defect engineering. The as-obtained $\mathrm{Co} / \mathrm{N} / \mathrm{O}$ tri-doped graphene mesh (denoted as NGM-Co) were prepared via the carbonization of a mechanical mixture of gelatinized amylopectin, melamine, cobalt nitrate, and in situ generated $\mathrm{Mg}(\mathrm{OH})_{2}$ nanoflakes. The remarkable bifunctional electroactivity for ORR and OER in alkaline medium of NGM-Co catalyst was ascribed to $\mathrm{Co}-\mathrm{N}_{x}-\mathrm{C}$ moieties, nitrogen-doping, oxygen functional groups, and topological defects. Miao et al. [113] reported a noble-free $\mathrm{Co}-\mathrm{N}-\mathrm{C}$ catalyst, derived from cobalt-phenanthroline complexes on CMK-3 under heat-treatment. By careful examination of the $\mathrm{Co}-\mathrm{N}-\mathrm{C}$ catalyst with sub-Ångström-resolution aberration-corrected scanning transmission electron microscopy (HAADF-STEM), the authors suggested that the Co single atoms bonded to $\mathrm{N}$ within the graphitic sheets served as the active sites. Wang's group [114] developed a new type of Co-N/C catalysts that contained two forms of active components, namely, coordinating cobalt moieties $\left(\mathrm{CoC}_{x} \mathrm{~N}_{y}\right.$ or $\left.\mathrm{CoN}_{x}\right)$ and $\mathrm{Co}$ nanoparticles encapsulated in mesoporous $\mathrm{N}$-doped carbon hollow spheres (Co-N-mC) by pyrolyzing the polystyrene@polydopamine-Co (PS/PDA-Co) precursor. The $\mathrm{Co}-\mathrm{N}-\mathrm{mC}$ catalysts revealed striking ORR performance, comparable with commercial $\mathrm{Pt} / \mathrm{C}$, with onset potential of $0.94 \mathrm{~V}$ vs. RHE, half-wave potential of $0.851 \mathrm{~V}$ vs. RHE, and a Tafel slope of $45 \mathrm{mV} \mathrm{dec}^{-1}$ in $0.1 \mathrm{M} \mathrm{KOH}$. Similarly, Tsiakaras et al. [115] designed and fabricated a 3D hollow carbon spheres (HCS) with co-doping of cobalt and nitrogen, using dopamine and poly-methyl-methacrylate 
(PMMA) as a template and a vacuum-assisted impregnation method, Figure 9a. The Co-N@HCS catalyst with a large specific surface area $\left(347.3 \mathrm{~m}^{2} \mathrm{~g}^{-1}\right)$ displayed excellent catalytic activity for both ORR and OER with a $\triangle \mathrm{E}\left(\Delta \mathrm{E}=E_{\mathrm{OER}}\right.$, j@10 $\mathrm{mA} \mathrm{cm}{ }^{-2}-E_{1 / 2}$, ORR $)$ of $0.856 \mathrm{~V}$, much lower than those of the N@HCS (1.233 V) and the benchmark Pt/C catalysts (1.044 V).

(a)

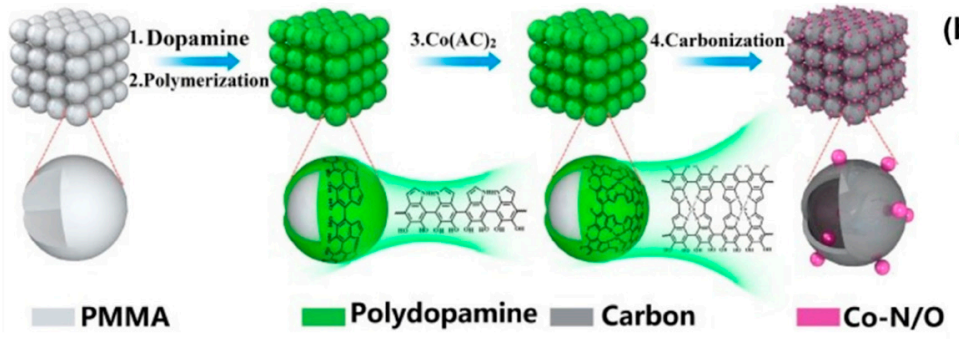

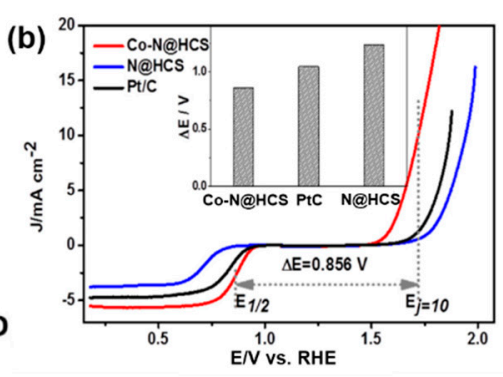

Figure 9. (a) The schematic chemical synthesis route of Co-N@HCS catalyst; (b) the LSV curves within ORR (cathodic sweep) and OER (anodic sweep) potential window of Co-N@HCS, N@HCS and Pt/C catalysts in $\mathrm{O}_{2}$-saturated $0.1 \mathrm{KOH}$ at a rotation speed of $1600 \mathrm{rpm}$ with a mass loading of $0.3 \mathrm{mg} \mathrm{cm}^{-2}$. Inset: the comparison of the $\Delta \mathrm{E}$ values. Reproduced from [115], Copyright $\subset$ Elsevier, 2017.

Besides, more recently, some new synthesis strategies have been proposed to precisely control and fabricate the $\mathrm{Co}-\mathrm{N}_{x}$ catalytic materials, under the confinement effect, with well-engineered nanostructure derived from metal-organic framework precursors (MOFs). The $\mathrm{Co}-\mathrm{N}_{x} / \mathrm{C}$ catalysts synthesized by a simple pyrolysis of MOF precursor, inherited the large surface area and satisfactory porosity of MOFs, which led to dense active sites on the surface of materials. Feng's group [28] fabricated the $\mathrm{Co} / \mathrm{CoN}_{x} / \mathrm{N}-\mathrm{CNT} / \mathrm{C}$ electrocatalysts by heat treatment of MOF (Co-mela-BDC) at different temperatures under $\mathrm{N}_{2}$ atmosphere. The $\mathrm{Co} / \mathrm{CoN}_{x} / \mathrm{N}-\mathrm{CNT} / \mathrm{C}$ catalyst obtained at $800{ }^{\circ} \mathrm{C}$ contained $\mathrm{N}$-doped carbon nanotubes, which were generated by the catalysis of cobalt species. Owing to the synergistic effect between $\mathrm{Co}-\mathrm{N}_{x}-\mathrm{C}$ and NCNTs, the $\mathrm{Co} / \mathrm{CoN}_{x} / \mathrm{N}-\mathrm{CNT} / \mathrm{C}$ composite boosted the much higher ORR performance. Aijaz et al. [116] reported highly active bifunctional electrocatalysts for oxygen electrodes containing core-shell Co@ $\mathrm{Co}_{3} \mathrm{O}_{4}$ nanoparticles embedded in CNT-grafted N-doped carbon-polyhedra from the pyrolysis of ZIF-67, involved in the sequential reduction and oxidation steps. The use of ZIF-67, as sacrificial precursor, was advantageous to build a core-shell nanostructured polyhedral with large surface area, and high dispersion of $\mathrm{Co}-\mathrm{N}_{x}$ and $\mathrm{Co}_{3} \mathrm{O}_{4}-\mathrm{N}_{x}$ active sites. Furthermore, Zheng et al. [117] developed a bimetal ( $\mathrm{Cu}$ and $\mathrm{Co}$ ) embedded $\mathrm{N}$-doped carbon framework, using the in situ growth of ZIF-67 polyhedrons on $\mathrm{Cu}(\mathrm{OH})_{2}$ nanowires, followed by pyrolysis treatment, Figure 10. The pyrolytic decomposition proceeded successively for $\mathrm{Cu}(\mathrm{OH})_{2}$ and ZIF-67, and thus the hierarchical porosity of ZIF-67 enabled the confinement of $\mathrm{Cu}$ nanocrystals and particles' size. The authors proposed that the existence of $\mathrm{Cu}$ ions not only provided extra active sites, but also led to an increased nitrogen content in the carbon frameworks via $\mathrm{Cu}-\mathrm{N}$ coordination, optimized porous structure and large specific surface area, favorable to enhance the ORR electrocatalytic activity, Figure 10b. The CuCo@NC material showed an outstanding ORR activity, with much more positive $E_{\text {onset }}=0.96 \mathrm{~V}$ and $E_{1 / 2}=0.88 \mathrm{~V}$, comparable to commercial $30 \% \mathrm{Pt} / \mathrm{C}(1.04 \mathrm{~V}$ and $0.84 \mathrm{~V}$, for $E_{\text {onset, }}$ and $E_{1 / 2}$, respectively). 
a

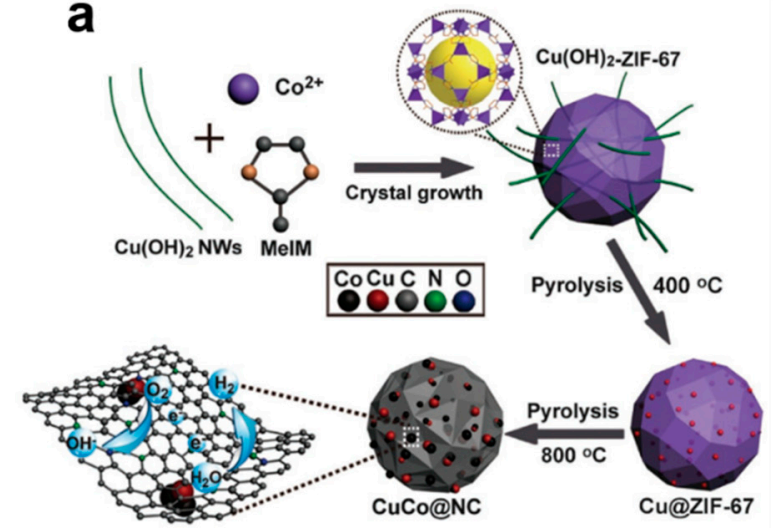

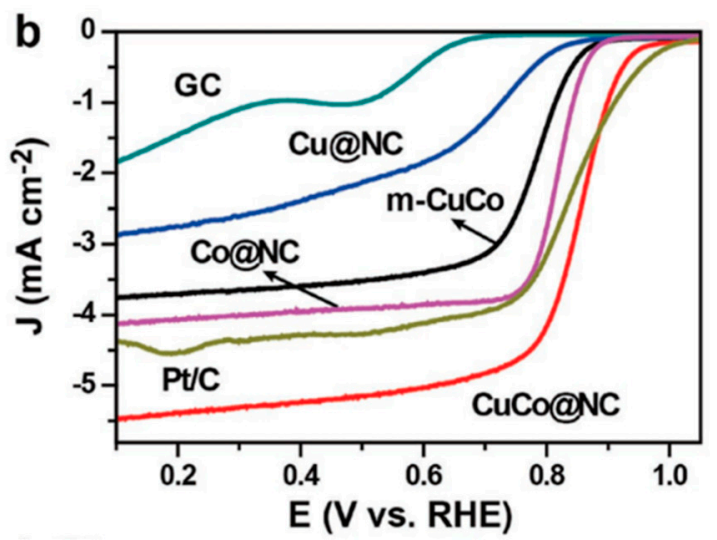

Figure 10. (a) The chemical synthesis route of Co-N@HCS catalyst; (b) ORR current-potential characteristics on $\left(\mathrm{Cu}\right.$ and $\mathrm{Co}$ ) embedded $\mathrm{N}$-doped carbon materials in $\mathrm{O}_{2}$-saturated $0.1 \mathrm{M} \mathrm{KOH}$ solution at a scan rate of $10 \mathrm{mV} \mathrm{s}^{-1}$ and rotation speed of $1600 \mathrm{rpm}$ (cathodic sweep) at room temperature $\left(25 \pm 1{ }^{\circ} \mathrm{C}\right)$. The catalyst loadings of all samples were $0.182 \mathrm{mg} \mathrm{cm}^{-2}$. Reproduced from [117], Copyright (c) Wiley, 2017.

Because of some interesting properties, such as, tunable chemical composition, permanent porosity, and a high thermal/chemical stability, the porous covalent networks (PCNs), also known as covalent organic frameworks (COFs), are chemical precursors of interest for electrocatalysis. In this context, $\mathrm{Bu}$ et al. [118] proved that the porphyrinic conjugated network PCN-FeCo/C, a carbonized product of heterometalloporphyrinic PCN-FeCo at $800^{\circ} \mathrm{C}$, showed a spectacular ORR activity and electrochemical stability in alkaline and acid electrolytes, Figure 11. The PCN-FeCo/C electrode displayed a very positive onset potential (1.00 V vs. RHE), and a half-wave potential of $0.85 \mathrm{~V}$ vs. RHE comparable to that of $\mathrm{Pt} / \mathrm{C}(0.84 \mathrm{~V}$ vs. RHE) in $0.1 \mathrm{M} \mathrm{KOH}$. Again, the binary PCN-FeCo/C catalyst was found to give the highest activity, i.e., the most positive $E_{\text {onset }}=0.90 \mathrm{~V}$ vs. $\mathrm{RHE}$, and $E_{1 / 2}=0.76 \mathrm{~V}$ vs. RHE in $0.1 \mathrm{M} \mathrm{HClO}_{4}$ solution. The prominent performance of $\mathrm{PCN}-\mathrm{FeCo} / \mathrm{C}$ was attributed to the high homogeneity of active components derived from ordered distribution of Fe and Co covalent network, i.e., a generated hierarchical porosity.

Table 1. Selected Co-based catalyst for the oxygen reduction reaction.

\begin{tabular}{|c|c|c|c|c|c|c|c|}
\hline Catalysts & $\begin{array}{l}\text { Mass Loading } \\
\left(\mathrm{mg} \mathrm{cm}^{-2}\right)\end{array}$ & Electrolyte & $\begin{array}{l}\text { RPM } \\
\text { (rpm) }\end{array}$ & $j_{k}\left(\mathrm{~mA} \mathrm{~cm}^{-2}\right)$ & $\begin{array}{c}E_{1 / 2} \\
\text { (V/RHE) }\end{array}$ & $\begin{array}{l}\text { Tafel Slope } \\
\left(\mathrm{mV} \mathrm{dec}^{-1}\right)\end{array}$ & Refs. \\
\hline Cubic $\mathrm{CoSe}_{2} / \mathrm{NCNH}^{\mathrm{a}}$ & 0.214 & $0.1 \mathrm{M} \mathrm{KOH}$ & 1600 & $8.1 @ 0.8 \mathrm{~V}$ & 0.81 & 52 & [66] \\
\hline Hexagonal CoSe/N-RGO ${ }^{\mathrm{b}}$ & 0.286 & $0.1 \mathrm{M} \mathrm{KOH}$ & 1600 & $2.9 @ 0.85 \mathrm{~V}$ & 0.86 & 56 & [67] \\
\hline $\mathrm{Co}_{3} \mathrm{C}-\mathrm{GNRs}^{\mathrm{c}}$ & - & $0.1 \mathrm{M} \mathrm{KOH}$ & 1600 & $4.6 @ 0.5 \mathrm{~V}$ & 0.77 & 41 & [119] \\
\hline Cubic $\mathrm{CoSe}_{2}$ /XC-72 Vulcan & 0.1 & $0.5 \mathrm{M} \mathrm{H}_{2} \mathrm{SO}_{4}$ & 2000 & $0.1 @ 0.8 \mathrm{~V}$ & - & 113 & [120] \\
\hline 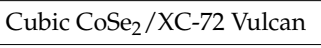 & 0.22 & $0.1 \mathrm{M} \mathrm{KOH}$ & 1600 & - & 0.71 & - & [61] \\
\hline $\mathrm{Co}_{1-x} \mathrm{~S} / \mathrm{RGO}$ & 0.285 & $\begin{array}{c}0.1 \mathrm{M} \mathrm{KOH} \\
0.5 \mathrm{M} \mathrm{H}_{2} \mathrm{SO}_{4}\end{array}$ & 1600 & $\begin{array}{l}3.8 @ 0.7 \mathrm{~V} \\
1.1 @ 0.7 \mathrm{~V}\end{array}$ & $\begin{array}{l}0.75 \\
0.59\end{array}$ & - & [18] \\
\hline $\mathrm{Co}_{1-x} \mathrm{~S} / \mathrm{N}-\mathrm{S}-\mathrm{G}^{\mathrm{d}}$ & 0.5 & $0.1 \mathrm{M} \mathrm{KOH}$ & 1600 & $\begin{array}{c}15 \% \text { higher } \\
\text { than Pt/C @ } \\
0.6 \mathrm{~V}\end{array}$ & 0.86 & 58 & [121] \\
\hline $\mathrm{Co}_{1-x} \mathrm{~S} / \mathrm{SNG} / \mathrm{CF}^{\mathrm{e}}$ & 0.153 & $0.1 \mathrm{M} \mathrm{KOH}$ & 1600 & $4.3 @ 0.2 \mathrm{~V}$ & 0.83 & 85 & [122] \\
\hline Co-S/NS-RGO ${ }^{f}$ & 0.38 & $0.1 \mathrm{M} \mathrm{KOH}$ & 900 & - & 0.81 & - & [123] \\
\hline $\mathrm{CoS}_{2} / \mathrm{NS}-\mathrm{GO}$ & 0.25 & $0.1 \mathrm{M} \mathrm{KOH}$ & 1600 & 7.7 & 0.79 & 30 & [124] \\
\hline $\mathrm{CoS}_{2} / \mathrm{XC}-72$ & 0.1 & $0.1 \mathrm{M} \mathrm{KOH}$ & 1600 & $4.2 @ 0.4 \mathrm{~V}$ & 0.71 & 73 & [46] \\
\hline $\mathrm{Co}_{3} \mathrm{~S}_{4} / \mathrm{G}^{\mathrm{g}}$ & 0.051 & $0.1 \mathrm{M} \mathrm{KOH}$ & 1600 & $\begin{array}{c}4.5 @-1.1 \mathrm{~V} \\
\text { (vs. Ag/AgCl) }\end{array}$ & - & - & [125] \\
\hline
\end{tabular}


Table 1. Cont.

\begin{tabular}{|c|c|c|c|c|c|c|c|}
\hline Catalysts & $\begin{array}{l}\text { Mass Loading } \\
\quad\left(\mathrm{mg} \mathrm{cm}^{-2}\right)\end{array}$ & Electrolyte & $\begin{array}{l}\text { RPM } \\
\text { (rpm) }\end{array}$ & $j_{k}\left(\mathrm{~mA} \mathrm{~cm}^{-2}\right)$ & $\begin{array}{c}E_{1 / 2} \\
(\mathrm{~V} / \mathrm{RHE})\end{array}$ & $\begin{array}{l}\text { Tafel Slope } \\
\left(\mathrm{mV} \mathrm{dec}{ }^{-1}\right)\end{array}$ & Refs. \\
\hline $\mathrm{Co}_{3} \mathrm{~S}_{4}$ nanosheets & - & $0.1 \mathrm{M} \mathrm{KOH}$ & 1600 & - & $\begin{array}{l}-0.19 \text { (vs. } \\
\mathrm{Hg} / \mathrm{HgO} \text { ) }\end{array}$ & - & [126] \\
\hline $\mathrm{Co}_{3} \mathrm{~S}_{4} / \mathrm{C}$ & 0.011 & $0.5 \mathrm{M} \mathrm{H}_{2} \mathrm{SO}_{4}$ & 1600 & - & 0.26 & - & {$[60]$} \\
\hline $\mathrm{Co}_{9} \mathrm{~S}_{8} / \mathrm{G}$ & 0.6 & $0.5 \mathrm{M} \mathrm{H}_{2} \mathrm{SO}_{4}$ & 1600 & $\begin{array}{c}3.7 @-0.1 \mathrm{~V} \\
\text { (vs. } \mathrm{Ag} / \mathrm{AgCl} \text { ) }\end{array}$ & $\begin{array}{l}-0.11 \text { (vs. } \\
\mathrm{Ag} / \mathrm{AgCl})\end{array}$ & 52 & [127] \\
\hline $\mathrm{Cog}_{8} / \mathrm{N}-\mathrm{S}-\mathrm{C}^{\mathrm{h}}$ & 0.1 & $0.1 \mathrm{M} \mathrm{KOH}$ & 1600 & - & 0.90 & 74 & {$[128]$} \\
\hline $\begin{array}{l}\text { Hollow } \mathrm{Co}_{9} \mathrm{~S}_{8} \\
\text { microspheres }\end{array}$ & 0.61 & $0.5 \mathrm{M} \mathrm{H}_{2} \mathrm{SO}_{4}$ & 1600 & - & $\sim 0.18$ & - & [129] \\
\hline $\mathrm{Co}_{9} \mathrm{~S}_{8} / \mathrm{N}-\mathrm{S}-\mathrm{G}_{\mathrm{gC} 3 \mathrm{~N} 4}$ & 0.612 & $0.1 \mathrm{M} \mathrm{KOH}$ & 1600 & - & $\begin{array}{l}-0.10 \text { (vs. } \\
\mathrm{Ag} / \mathrm{AgCl})\end{array}$ & - & [130] \\
\hline $\mathrm{Co}_{3} \mathrm{O}_{4} / \mathrm{N}-\mathrm{rmGO}^{\mathrm{i}}$ & 0.24 & $0.1 \mathrm{M} \mathrm{KOH}$ & 1600 & $5.0 @ 0.4 \mathrm{~V}$ & 0.83 & 42 & {$[25]$} \\
\hline Co@N-CNTs-m ${ }^{j}$ & 0.6 & $0.1 \mathrm{M} \mathrm{KOH}$ & 1600 & 6.0 & 0.85 & - & {$[32]$} \\
\hline $\mathrm{Co}-\mathrm{S} / \mathrm{G}-3$ & 0.08 & $0.1 \mathrm{M} \mathrm{KOH}$ & 1600 & $7.0 @ 0.85 \mathrm{~V}$ & 0.83 & 38 & [80] \\
\hline $\mathrm{Co}_{3} \mathrm{O}_{4}-\mathrm{SP} / \mathrm{NGr}-24 \mathrm{~h}^{\mathrm{k}}$ & - & $0.1 \mathrm{M} \mathrm{KOH}$ & 1600 & - & 0.82 & 76 & {$[75]$} \\
\hline Co@CoO@N-C/C & - & $0.1 \mathrm{M} \mathrm{KOH}$ & 1600 & - & 0.81 & 69 & [82] \\
\hline $\mathrm{Co}_{3} \mathrm{O}_{4} / \mathrm{N}-\mathrm{RGO}-3$ & 0.1 & $0.1 \mathrm{M} \mathrm{KOH}$ & 1600 & 5.24 & 0.82 & 55 & [76] \\
\hline $\mathrm{L}_{1} \mathrm{G}_{5}{ }^{\mathrm{l}} \mathrm{CoAl}-\mathrm{LDHs} / \mathrm{RGO}$ & 0.255 & $0.1 \mathrm{M} \mathrm{KOH}$ & 1600 & $5.1 @ 0.2 \mathrm{~V}$ & 0.71 & - & {$[85]$} \\
\hline $\mathrm{CoPc} / \mathrm{C}$ & 0.071 & $0.1 \mathrm{M} \mathrm{KOH}$ & 1500 & - & $\begin{array}{l}0.03 \text { (vs. } \\
\text { SHE) }\end{array}$ & 62 & [35] \\
\hline NGM-Co & 0.25 & $0.1 \mathrm{M} \mathrm{KOH}$ & 1600 & - & - & 58 & [112] \\
\hline $\mathrm{Co}-\mathrm{N}-\mathrm{mC}$ & 0.285 & $0.1 \mathrm{M} \mathrm{KOH}$ & 1600 & $4.5 @ 0.8 \mathrm{~V}$ & 0.85 & 45 & [114] \\
\hline Co-N@HCS m & 0.3 & $0.1 \mathrm{M} \mathrm{KOH}$ & 1600 & $4.8 @ 0.8 \mathrm{~V}$ & - & 56 & [115] \\
\hline MOFs-800 & 0.335 & $0.1 \mathrm{M} \mathrm{KOH}$ & 1600 & $3.7 @ 0.7 \mathrm{~V}$ & 0.80 & 42 & [28] \\
\hline $\mathrm{Co} @ \mathrm{Co}_{3} \mathrm{O}_{4} / \mathrm{NC}-1$ & 0.21 & $0.1 \mathrm{M} \mathrm{KOH}$ & 1600 & - & 0.80 & 92 & [116] \\
\hline CuCo@NC & 0.182 & $0.1 \mathrm{M} \mathrm{KOH}$ & 1600 & $4.4 @ 0.8 \mathrm{~V}$ & 0.88 & 80 & [117] \\
\hline
\end{tabular}

$j_{\mathrm{k}}$ : kinetically current density; $E_{1 / 2}$ : half-wave potential. ${ }^{a} \mathrm{NCNH}, \mathrm{N}$-doped carbon nanohorns; ${ }^{\mathrm{b}} \mathrm{N}-\mathrm{RGO}, \mathrm{N}$-doped reduced graphene oxides; ${ }^{c}$ GNRs, graphene nanoribbons; ${ }^{d} \mathrm{~N}-\mathrm{S}-\mathrm{G}, \mathrm{N}$, S-doped graphene; ${ }^{\mathrm{e}} \mathrm{CF}$, carbon fiber; ${ }^{\mathrm{f}}$ NS-RGO, N, S-doped reduced graphene oxides; ${ }^{\mathrm{g}} \mathrm{G}$, graphene; ${ }^{\mathrm{h}} \mathrm{N}-\mathrm{S}-\mathrm{C}, \mathrm{N}$, S-doped carbon; ${ }^{\mathrm{i}} \mathrm{N}-\mathrm{rmGO}$, N-doped reduced mildly graphene oxides; ${ }^{j} \mathrm{~N}-\mathrm{CNTs}-\mathrm{m}, \mathrm{N}$-doped carbon nanotubes mixture; ${ }^{\mathrm{k}} \mathrm{NGr}-24 \mathrm{~h}, \mathrm{~N}$-doped graphene; ${ }^{1} \mathrm{~L}_{1} \mathrm{G}_{5}$, the mass ratio of LDHs/GO (1:5); ${ }^{\mathrm{m}}$ HCS, hollow carbon spheres. 


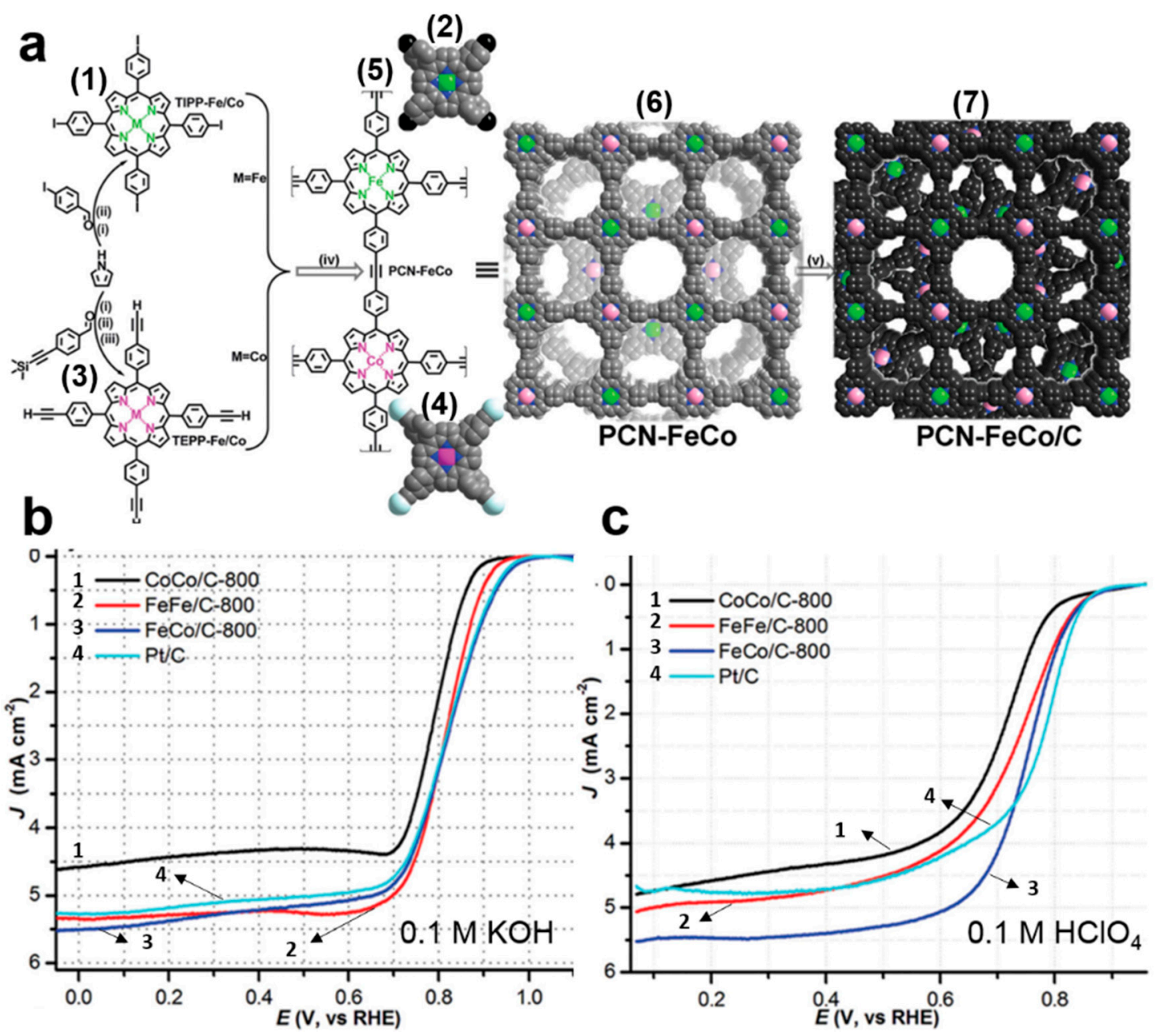

Figure 11. (a) Synthesis representation of porous covalent network (PCN)-FeCo/C by carbonization. Monomers: $(1,2)$ TIPP-M, and $(3,4)$ TEPP-M $(\mathrm{M}=\mathrm{Fe}, \mathrm{Co})$. $(5,6)$ porphyrinic conjugated network $\mathrm{PCN}-\mathrm{FeCo}$, and (7) the $\mathrm{PCN}-\mathrm{FeCo} / \mathrm{C}$ product. The reagents and conditions were: (i) propionic acid, reflux, $3 \mathrm{~h}$; (ii) $\mathrm{Co}(\mathrm{OAc})_{2} \cdot 4 \mathrm{H}_{2} \mathrm{O}$ or $\mathrm{FeCl}_{2} \cdot 4 \mathrm{H}_{2} \mathrm{O}, \mathrm{CHCl}_{3} \cdot \mathrm{CH}_{3} \mathrm{OH}$, reflux, $12 \mathrm{~h}$; (iii) tetrabutylammonium fluoride (TBAF), THF- $\mathrm{CH}_{2} \mathrm{Cl}_{2}$, at R.T. 1 h; (iv) $\mathrm{Pd}_{2}(\mathrm{dba})_{3}, \mathrm{AsPh}_{3}, \mathrm{THF} / \mathrm{Et}_{3} \mathrm{~N}, 50{ }^{\circ} \mathrm{C}, 72 \mathrm{~h}$. TIPP stands for: 5, 10, 15, 20-tetrakis (4-iodophenyl) porphyrin, and TEPP for: 5, 10, 15, 20-tetrakis (4-ethynylphenyl) porphyrin; (b) ORR current-potential curves on PCN/C and 20\% Pt/C (Alfa) at $1600 \mathrm{rpm}$ (cathodic sweep) in $\mathrm{O}_{2}$-saturated $0.1 \mathrm{M} \mathrm{KOH}$ solution, with the catalyst loading on PCN/C electrode of $0.2 \mathrm{mg}$ $\mathrm{cm}^{-2}$ and on $\mathrm{Pt} / \mathrm{C}$ electrode of $0.1 \mathrm{mg} \mathrm{cm}^{-2}$; (c) in $\mathrm{O}_{2}$-saturated $0.1 \mathrm{M} \mathrm{HClO}_{4}$ with the catalyst loading on PCN/C electrode of $0.6 \mathrm{mg} \mathrm{cm}^{-2}$ and on Pt/C electrode of $0.1 \mathrm{mg} \mathrm{cm}^{-2}$. Reproduced from [118], Copyright $@$ Wiley, 2015.

\section{Electrocatalysts for Oxygen Evolution Reaction (OER)}

\subsection{Mechanistic Approach of OER}

OER kinetics are also a multi-electron charge transfer process in acid and alkaline media. The kinetic parameters such as overpotential $(\eta)$, exchange current density $(i)$, Tafel slope $(b)$, turnover frequency (TOF), and so on, are employed to evaluate the OER performance of electrocatalytic materials. Particularly, the overpotential at a current density of $10 \mathrm{~mA} \mathrm{~cm}^{-2}$ is a crucial criterion to examine the OER performance (indicated as $\eta_{@ 10}$ ). These parameters play a key role for obtaining an insight into the mechanism of this electrocatalytic process. In general, the electrochemical reaction that occurs at the anode (OER) in acid, and alkaline electrolytes are: 
Acid medium:

$$
2 \mathrm{H}_{2} \mathrm{O}_{(a q)} \rightarrow 4 \mathrm{H}^{+}(a q)+4 \mathrm{e}^{-}+\mathrm{O}_{2(g)}
$$

Alkaline medium:

$$
4 \mathrm{OH}^{-}(a q) \rightarrow 2 \mathrm{H}_{2} \mathrm{O}_{(a q)}+4 \mathrm{e}^{-}+\mathrm{O}_{2(g)},
$$

Various research groups have proposed possible OER mechanisms in acid (Equations (9)-(13)) and alkaline medium (Equations (14)-(18)). Most of the proposed mechanisms involve $\mathrm{MOH}$ and $\mathrm{MO}$ intermediates. The diagram in Figure 12 displays two different routes to form oxygen from a $\mathrm{MO}$ intermediate. One, the green route, via the direct combination of $2 \mathrm{MO}$ to produce $\mathrm{O}_{2(\mathrm{~g})}$ (Equation (11)), and that involving the generation of the $\mathrm{MOOH}$ intermediate (Equations (12) and (17)) which subsequently decomposes, black route, to $\mathrm{O}_{2(\mathrm{~g})}$ (Equations (13) and (18)). During the heterogeneous OER process, all the bonding interactions $(\mathrm{M}-\mathrm{O})$ within the intermediates $(\mathrm{MOH}, \mathrm{MO}$ and $\mathrm{MOOH}$ ) are crucial to determining the overall electrocatalytic performance.

Acid medium:

$$
\begin{aligned}
\mathrm{M}+\mathrm{H}_{2} \mathrm{O}_{(l)} & \rightarrow \mathrm{MOH}+\mathrm{H}^{+}+\mathrm{e}^{-} \\
\mathrm{MOH}+\mathrm{OH}^{-} & \rightarrow \mathrm{MO}+\mathrm{H}_{2} \mathrm{O}_{(l)}+\mathrm{e}^{-} \\
\mathrm{MO} & \rightarrow 2 \mathrm{M}+\mathrm{O}_{2(g)} \\
\mathrm{MO}+\mathrm{H}_{2} \mathrm{O}_{(l)} & \rightarrow \mathrm{MOOH}+\mathrm{H}^{+}+\mathrm{e}^{-} \\
\mathrm{MOOH}+\mathrm{H}_{2} \mathrm{O}_{(l)} & \rightarrow \mathrm{M}+\mathrm{O}_{2(g)}+\mathrm{H}^{+}+\mathrm{e}^{-}
\end{aligned}
$$

Alkaline medium:

$$
\begin{gathered}
\mathrm{M}+\mathrm{OH}^{-} \rightarrow \mathrm{MOH} \\
\mathrm{MOH}+\mathrm{OH}^{-} \rightarrow \mathrm{MO}+\mathrm{H}_{2} \mathrm{O}_{(l)} \\
2 \mathrm{MO} \rightarrow 2 \mathrm{M}+\mathrm{O}_{2(g)} \\
\mathrm{MO}+\mathrm{OH}^{-} \rightarrow \mathrm{MOOH}+\mathrm{e}^{-} \\
\mathrm{MOOH}+\mathrm{OH}^{-} \rightarrow \mathrm{M}+\mathrm{O}_{2(g)}+\mathrm{H}_{2} \mathrm{O}_{(l)}
\end{gathered}
$$

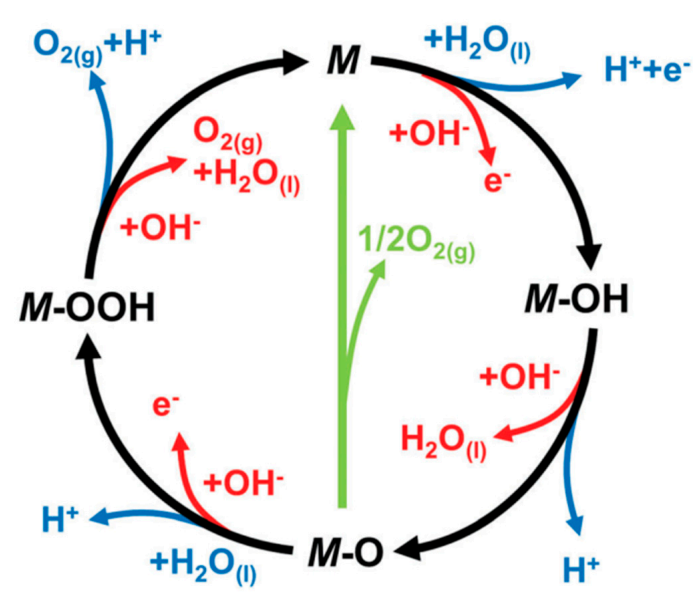

Figure 12. The oxygen evolution reaction (OER) mechanism in acid (blue line) and alkaline (red line) medium. Two reaction routes of oxygen evolution take place: (1) black line indicates that the process involves the formation of a peroxide $(\mathrm{M}-\mathrm{OOH})$ intermediate; (2) green line indicates that the direct reaction of two adjacent oxo (M-O) intermediates to produce molecular oxygen. Reproduced from [4], Copyright (C) Royal Society of Chemistry, 2017. 
Until now, the Ni- and Co-based materials (both free support and supported on, e.g., carbon) have been intensively investigated as promising non-precious OER electrocatalysts. The catalysts derived from cobalt metal centers can activate the OER in alkaline medium rather than in acid medium. Particularly for $\mathrm{CoO}_{x}$ and $\mathrm{CoOOH}$, the nature of their OER activities, stabilities in alkaline solution and OER mechanism have been thoroughly investigated [131-133]. For example, Mattioli group [131] provided insightful information into the pathways towards oxygen evolution of a cobalt-based catalyst (CoCat) by performing ab initio DFT $+\mathrm{U}$ molecular dynamics calculations of cluster models in water solution. The reaction pathways of CoCat were proposed as follows: (1) the fast $\mathrm{H}^{+}$mobility at the CoCat/water interface is responsible for an optimal distribution of terminal $\mathrm{Co}(\mathrm{III})-\mathrm{OH}$ groups, as sites of injected holes. These sites are preferred in the case of complete cubane units; (2) the oxygen evolution process starts with the release of a proton from one of such terminal $\mathrm{Co}-\mathrm{OH}$ sites, a process favored by the proton-acceptor species in solution, leading to the formation of a $\mathrm{Co}(\mathrm{IV})=\mathrm{O}^{\bullet}$ oxyl radical; (3) the coupling of $\mathrm{Co}=\mathrm{O}$ radicals with germinal (i.e., bonded to the same $\mathrm{Co}$ atom) $\mathrm{Co}-\mathrm{OH}$ or $\mathrm{Co}-\mu \mathrm{O}-\mathrm{Co}$ groups to form hydroperoxo and peroxo intermediates.

\subsection{Oxygen Evolution on Cobalt Chalcogenides Catalysts}

\subsubsection{Synthesis Strategy}

One of the attractive electrocatalysts surface engineering strategies, e.g., etching and edging, could greatly improve the catalytic performance. Dai et al. [19], for the first time, developed an novel bifunctional oxygen electrode catalysts by using $\mathrm{NH}_{3}$-plasma to simultaneously etch and dope the cobalt sulfides-graphene hybrid $\left(\mathrm{N}-\mathrm{Co}_{9} \mathrm{~S}_{8} / \mathrm{G}\right)$. $\mathrm{NH}_{3}$-plasma treatment, not only could induce the $\mathrm{N}$ doping into both $\mathrm{Co}_{9} \mathrm{~S}_{8}$ and graphene to enhance the activity, but also realized etching on the surface to expose more active sites for electrocatalysis. The $\mathrm{N}-\mathrm{Co}_{9} \mathrm{~S}_{8} / \mathrm{G}$ catalyst exhibited a low onset potential at ca. $1.51 \mathrm{~V}$ vs. RHE and a small Tafel slope of $82.7 \mathrm{mV} \mathrm{dec}^{-1}$. Notably, the required overpotential of $\mathrm{N}-\mathrm{Co}_{9} \mathrm{~S}_{8} / \mathrm{G}$ catalyst to reach the current density of $10 \mathrm{~mA} \mathrm{~cm}^{-2}$ was only $0.409 \mathrm{~V}$ in $0.1 \mathrm{M} \mathrm{KOH}$. Additionally, Xie's group [134] proposed that reducing the thickness of bulk $\mathrm{CoSe}_{2}$ into the atomic scale, rather than doping or hybridizing, was inclined to form a great deal of exposed active sites e.g., $\mathrm{V}_{\mathrm{Co}}$ " vacancies, which could effectively catalyze the OER process evidenced by the positron annihilation spectrometry, XAFS (X-ray Absorption Fine Structure) spectra and DFT calculations. The ultrathin $\mathrm{CoSe}_{2}$ nanosheets with rich $\mathrm{V}_{\mathrm{Co}}$ " vacancies manifested an OER overpotential of $0.32 \mathrm{~V}$ at $10 \mathrm{~mA} \mathrm{~cm}^{-2}$ in alkaline electrolyte $(\mathrm{pH}=13)$ much less than that of the bulk $\mathrm{CoSe}_{2}$.

\subsubsection{Support Effect}

Clear evidence of the strong metal-support interaction (SMSI) was given by Gao et al. [135] with synthesized $\mathrm{CoSe}_{2}$ nanobelts on $\mathrm{N}$-doped reduced graphene oxide (RGO) sheets. This system showed an exceptional OER activity and stability in alkaline environment, with a Tafel slope of $40 \mathrm{mV}$ $\mathrm{dec}^{-1}$ and $\eta_{@ 10}$ (the overpotential required to achieve the current density of $10 \mathrm{~mA} \mathrm{~cm}^{-2}$ ) of $0.366 \mathrm{~V}$. The authors concluded that the high performance is dependent on the interaction between $\mathrm{N}$-doped carbon domains and $\mathrm{CoSe}_{2}$ nanobelts. Similarly, Liao et al. [121] embedded $\mathrm{Co}_{1-x} \mathrm{~S}$ hollow nanospheres in $\mathrm{N}$ and $\mathrm{S}$ co-doped graphene holes to create an efficient bifunctional catalysts $\left(\mathrm{Co}_{1-x} \mathrm{~S} / \mathrm{N}-\mathrm{S}-\mathrm{G}\right)$ with hierarchical meso-macroporous structures for ORR and OER. The $\mathrm{Co}_{1-x} \mathrm{~S} / \mathrm{N}-\mathrm{S}-\mathrm{G}$ material with a large specific surface area $\left(390.6 \mathrm{~m}^{2} \mathrm{~g}^{-1}\right)$, showed a small overpotential of $371 \mathrm{mV}$ for $10 \mathrm{~mA} \mathrm{~cm} \mathrm{~cm}^{-2}$ in $0.1 \mathrm{KOH}$, and the $\Delta \mathrm{E}$ value is $0.706 \mathrm{~V}$, which was much smaller than those of many reported non-precious metal catalysts. The investigated results demonstrated that the excellent bifunctional performance was mainly attributed to a synergistic effect of the multiple active sites consisting of $\mathrm{Co}_{1-x} \mathrm{~S}, \mathrm{~N}$ and $\mathrm{S}$ dopants, and possible $\mathrm{Co}-\mathrm{N}-\mathrm{C}$ sites. Interestingly, Guo et al. [136] used $\mathrm{CoSe}_{2}$ nanosheets as support to grow $\mathrm{Co}_{2} \mathrm{~B}$ at room temperature. The resulting $\mathrm{Co}_{2} \mathrm{~B} / \mathrm{CoSe}_{2}$ hybrid catalysts showed $\eta_{@ 10}$ values for OER and HER in alkaline of $0.32 \mathrm{~V}$, and $0.30 \mathrm{~V}$, respectively. Apparently, $\mathrm{CoSe}_{2}$ 
nanosheets supplied nucleation sites for $\mathrm{Co}_{2} \mathrm{~B}$, as well as high electrical conductivity that promoted a high stability through water splitting reactions in alkaline medium.

\subsection{Oxygen Evolution on Cobalt Oxides Catalysts}

\subsubsection{Mechanism of Cobalt Oxides}

Cobalt (II) commonly undergoes the oxidation $\left(\mathrm{CO}^{\mathrm{II}} \rightarrow \mathrm{Co}^{\mathrm{III}}\right)$ under an anodic potential prior to the OER in an aqueous solution, forming a layered oxidic cobalt species [137,138]. Some researchers pointed out that $\mathrm{Co}^{\mathrm{IV}}$ species were generated on the outermost surface of the electrode $[137,139]$. So that the catalytic site formed on the $\mathrm{Co}_{3} \mathrm{O}_{4}$ electrode was the quasi-reversible redox couple $\mathrm{Co}{ }^{\mathrm{III}} / \mathrm{Co}^{\mathrm{IV}}$ that accelerated the one-step or two-step OER $[131,133,140,141]$. In order to investigate the role of the peroxo process in the oxygen evolution reaction, $\mathrm{Fu}$ et al. [142] prepared ultrathin $\mathrm{Co}_{3} \mathrm{O}_{4}$ nanosheets (NSs) with abundant active centers with a large electroactive surface to gain an insight into the OER performance of $\mathrm{Co}_{3} \mathrm{O}_{4}$ NSs. The possible mechanism of $\mathrm{Co}_{3} \mathrm{O}_{4}$ nanosheets towards OER included essentially double two-electron steps: (1) oxidation of $\mathrm{OH}^{-}$to $\mathrm{OOH}_{a d}$ (thermodynamic rate-limiting step); and (2) fast oxidation of the intermediate $\mathrm{OOH}_{\mathrm{ad}}$ to $\mathrm{O}_{2}^{\text {ad }}$ by $\mathrm{Co}{ }^{\mathrm{III}} / \mathrm{Co}^{\mathrm{IV}}$ surface redox couple (kinetic process), Figure 13. The apparent OER on $\mathrm{Co}_{3} \mathrm{O}_{4} \mathrm{NSs}$ that proceeded via a four-electron pathway, corresponding to a double two-electron one, ascribed to $\mathrm{Co}{ }^{\mathrm{III}} / \mathrm{Co}^{\mathrm{IV}}$ sites acting efficiently to oxidize the generated $\mathrm{OOH}_{\mathrm{ad}}$, and facilitating the formation of $\mathrm{O}_{2, \mathrm{ad}}$.

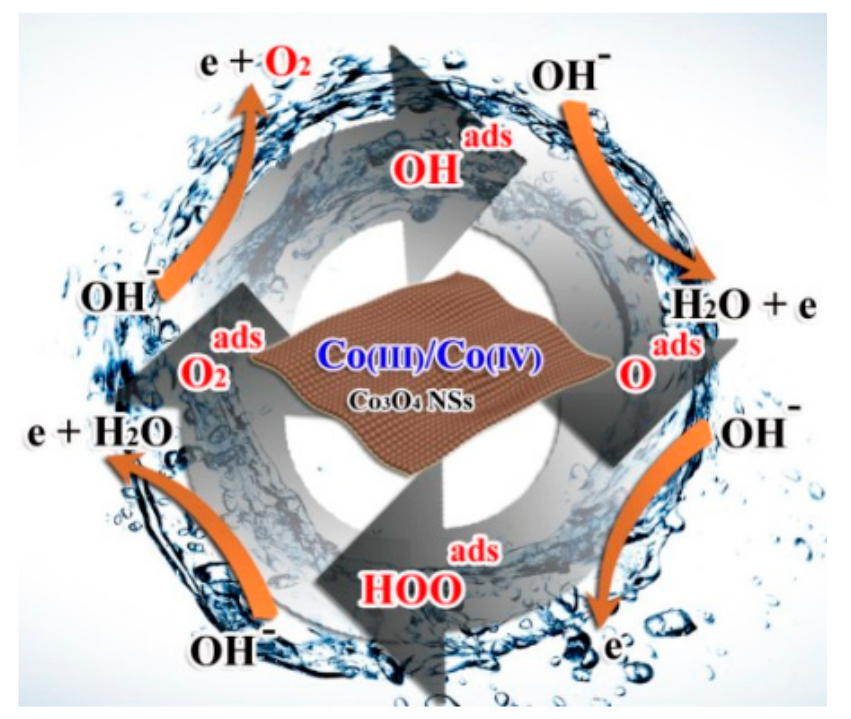

Figure 13. The scheme exemplifying the proposed OER electrocatalytic mechanism on $\mathrm{Co}_{3} \mathrm{O}_{4} \mathrm{NSs}$. Reproduced from [142], Copyright (C) Royal Society of Chemistry, 2016.

\subsubsection{Chemical Composition}

As mentioned above, the electrocatalytic performance of $\mathrm{Co}_{3} \mathrm{O}_{4}$ nanoparticles mainly depends on the surface area, the oxidation charge of the cobalt atoms, and the oxygen vacancies. Hence, a reasonable tuning of the surface electronic states of undoped $\mathrm{Co}_{3} \mathrm{O}_{4}$ can provide more electrochemically active sites to favor the OER. The preparation of mesoporous $\mathrm{Co}_{3} \mathrm{O}_{4}$ nanowires $\left(\mathrm{Co}_{3} \mathrm{O}_{4} \mathrm{NWs}\right)$ by Zheng et al. [143], through a facile $\mathrm{NaBH}_{4}$ reduction method led to seven-fold activity enhancement of OER, as compared to pristine $\mathrm{Co}_{3} \mathrm{O}_{4}$, Figure 14. As shown in Figure 14a, the peak current density observed in the cyclic voltammetry curves increased dramatically, after the chemical reduction process, signifying the existence of more active sites as a result of the oxygen vacancies, confirmed by DFT calculations. The increased $\mathrm{Co}^{4+} / \mathrm{Co}^{3+}$ redox peaks $(1.4-1.5 \mathrm{~V})$ was ascribed to the formation of $\left[\mathrm{Co}^{4+}-\mathrm{O}\right]$ intermediate, involved in the turnover-limiting chemical step of oxygen evolution. The onset potential of the reduced $\mathrm{Co}_{3} \mathrm{O}_{4} \mathrm{NWs}$ was ca. $1.52 \mathrm{~V}$ vs. RHE, i.e., ca. $50 \mathrm{mV}$ 
and $100 \mathrm{mV}$ more negative than pristine $\mathrm{Co}_{3} \mathrm{O}_{4} \mathrm{NWs}$ and $\mathrm{Pt} / \mathrm{C}$ catalyst, respectively, Figure $14 \mathrm{~b}$. Besides reduction post-treatment, $\mathrm{Xia}$ et al. [144] fabricated 3D ordered mesoporous cubic $\mathrm{Co}_{3} \mathrm{O}_{4}$ implementing hard-templating strategies. X-ray photoelectron spectroscopy (XPS) analysis revealed that the molar surface ratio $\mathrm{Co}^{\mathrm{III}+} / \mathrm{CO}^{\mathrm{II}+}$ of ordered mesoporous $\mathrm{CO}_{3} \mathrm{O}_{4}$ was much lower than that of bulk-Co, suggesting more surface oxygen vacancies on the former, which benefited the adsorption and activation of molecular oxygen.
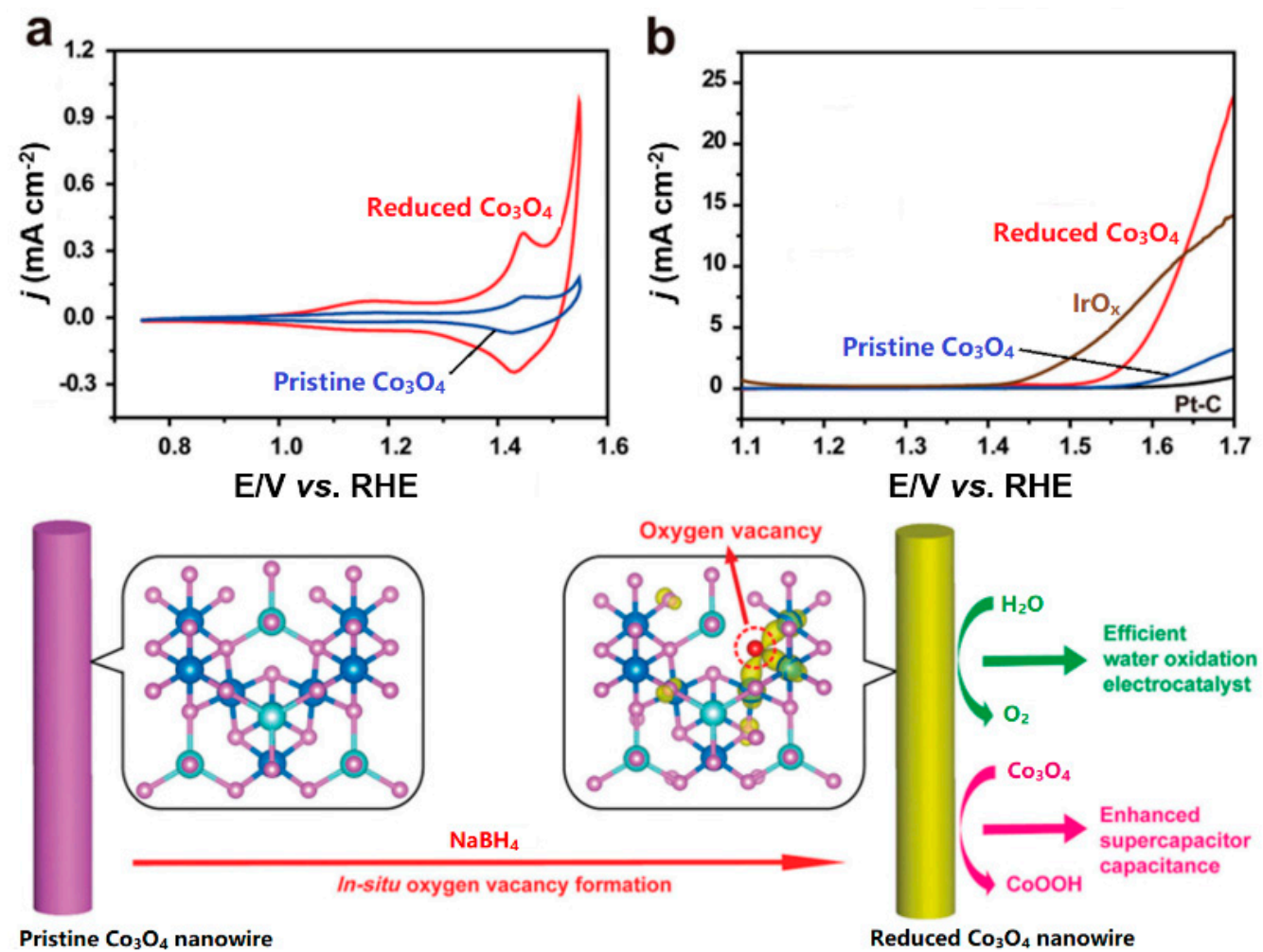

Figure 14. (a) Cyclic voltammograms of reduced $\mathrm{Co}_{3} \mathrm{O}_{4}$, and pristine $\mathrm{Co}_{3} \mathrm{O}_{4}$ NWs deposited on glassy carbon electrodes in $\mathrm{O}_{2}$-saturated $1 \mathrm{M} \mathrm{KOH}$ at $5 \mathrm{mV} \mathrm{s}^{-1}$; (b) water oxidation current-potential characteristic of reduced $\mathrm{Co}_{3} \mathrm{O}_{4} \mathrm{NWs}$ (red curve), pristine $\mathrm{Co}_{3} \mathrm{O}_{4} \mathrm{NWs}$ (blue curve), $\mathrm{IrO}_{x}$ (brown curve) and $\mathrm{Pt} / \mathrm{C}$ (black curve) in $\mathrm{O}_{2}$-saturated $1 \mathrm{M} \mathrm{KOH}$ at a scan rate $5 \mathrm{mV} \mathrm{s}^{-1}$ at $1600 \mathrm{rpm}$ (anodic sweep) at $25 \pm 1{ }^{\circ} \mathrm{C}$ with $i R$-compensation. The catalyst mass loadings in all cases was $0.136 \mathrm{mg} \mathrm{cm}^{-2}$; The bottom panel shows the ins situ chemical reduction via $\mathrm{NaBH}_{4}$ to form oxygen vacancies in $\mathrm{Co}_{3} \mathrm{O}_{4}$ NWs. Reproduced from [143], Copyright @ Wiley, 2014.

\subsubsection{Synthesis Strategy}

The synthesis of graphene- $\mathrm{Co}_{3} \mathrm{O}_{4}\left(\mathrm{G}-\mathrm{Co}_{3} \mathrm{O}_{4}\right)$ composite having a unique sandwich-architecture was reported by Zhao et al. [145]. The large amount of tiny $\mathrm{Co}_{3} \mathrm{O}_{4}$ nanocrystals, uniformly dispersed on both sides of graphene sheets, allowed for a favorable electron transfer kinetics. The onset potential of $\mathrm{G}-\mathrm{Co}_{3} \mathrm{O}_{4}$ was $0.406 \mathrm{~V}$ vs. $\mathrm{Ag} / \mathrm{AgCl}$ in $1 \mathrm{M} \mathrm{KOH}$, and $0.858 \mathrm{~V}$ vs. $\mathrm{Ag} / \mathrm{AgCl}$ in neutral phosphate buffer solution (PBS). The overpotential at a current density of $10 \mathrm{~mA} \mathrm{~cm}^{-2}\left(\eta_{@ 10}\right)$ was $313 \mathrm{mV}$ in $1 \mathrm{M}$ $\mathrm{KOH}$, and $498 \mathrm{mV}$ in PBS, respectively. Kim et al. [146], on the other hand, used dextrose as chemical source to obtain mesoporous carbon, and urea together with $\mathrm{CoCl}_{2} \cdot 6 \mathrm{H}_{2} \mathrm{O}$ in a hydrothermal treatment to obtain carbon-cobalt oxide-nanorods $\left(\mathrm{C}^{-} \mathrm{Co}_{3} \mathrm{O}_{4}-\mathrm{NRs}\right)$. This latter provided an overpotential at a current density of $10 \mathrm{~mA} \mathrm{~cm}{ }^{-2}\left(\eta_{@ 10}\right)$ of $415 \mathrm{mV}$, a value much lower than that of carbon free $\mathrm{Co}_{3} \mathrm{O}_{4}$ nanorods. The OER activity of the $\mathrm{C}-\mathrm{Co}_{3} \mathrm{O}_{4}-\mathrm{NRs}$ electrode was significantly increased with a low onset potential of $356 \mathrm{mV}$ and Tafel slope of $53 \mathrm{mV} \mathrm{dec}^{-1}$.

Additionally, materials with high conductivity and mobility, e.g., Co foil, Ni foam and carbon fiber paper, were employed as support grown on non-precious metal electrocatalysts to facilitate the 
electrolyte diffusion, drive off the as-formed gas bubbles from the electrode surface during the oxygen evolution process, favoring the kinetics, and the chemical stability. In this connection, a simple and reasonable method to synthesize self-supported $\mathrm{Co}_{3} \mathrm{O}_{4}$ nanocrystal/carbon fiber paper via thermal decomposition of the $\left[\mathrm{Co}\left(\mathrm{NH}_{3}\right)_{\mathrm{n}}\right]^{2+}$-oleic acid complex and subsequent spray deposition was done by Fu et al. [147]. The $\mathrm{Co}_{3} \mathrm{O}_{4} \mathrm{NCs}$ with a loading of $0.35 \mathrm{mg} \mathrm{cm}^{-2}$ showed a current density of $16.5 \mathrm{~mA} \mathrm{~cm}^{-2}$ at $\eta_{@ 10}$ of $350 \mathrm{mV}$ in $1 \mathrm{M} \mathrm{KOH}$. With the same perspective, Wei et al. [148] reported the synthesis of $\mathrm{Co}_{3} \mathrm{O}_{4}$ nanorods array on $\mathrm{Co}$ foil $\left(\mathrm{Co}_{3} \mathrm{O}_{4} \mathrm{NA} / \mathrm{CF}\right)$ oxygen-evolving catalyst using the so-called in situ self-standing method, Figure $15 \mathrm{a}$. The $1 \mathrm{D} \mathrm{Co}_{3} \mathrm{O}_{4}$ NA/CF OER material only needed $\eta=308 \mathrm{mV}$ to drive a geometrical current density of $15 \mathrm{~mA} \mathrm{~cm}^{-2}$ in $1 \mathrm{M} \mathrm{KOH}$, exceeding the value reported so far on $\mathrm{Co}_{3} \mathrm{O}_{4}$-based electrocatalysts. The electrocatalyst delivered an excellent long-term durability of $22 \mathrm{~h}$, and a turnover frequency of $0.646 \mathrm{~mol} \mathrm{O}_{2} \mathrm{~s}^{-1}$ at $\eta=410 \mathrm{mV}$ in Figure $15 \mathrm{~b}$. The suggested OER high activity of $\mathrm{Co}_{3} \mathrm{O}_{4} \mathrm{NA} / \mathrm{CF}$ was thought to be the formation of $\mathrm{Co}^{\mathrm{III}}$ (in an octahedral environment) on $\mathrm{CoOOH}$ as a result of $\mathrm{Co}_{3} \mathrm{O}_{4}$ oxidation. The surface $\mathrm{Co}^{\mathrm{III}}$-containing octahedral forms $\mathrm{Co}^{\mathrm{III}}-\mathrm{OH}$, which was further oxidized to form the active catalytic center: $\mathrm{Co}^{\mathrm{IV}}-\mathrm{O}$ for OER. A further coupling of $\mathrm{Co}^{\mathrm{IV}}-\mathrm{O}$ with neighboring species formed hydroperoxo $\left(\mathrm{Co}^{\mathrm{IV}}-\mathrm{OOH}\right)$ to peroxo $\left(\mathrm{Co}^{\mathrm{IV}}-\mathrm{OO}\right)$ species, leading to the release of $\mathrm{O}_{2}$ and initial $\mathrm{Co}^{\mathrm{III}}$, see scheme in Figure $15 \mathrm{c}$.

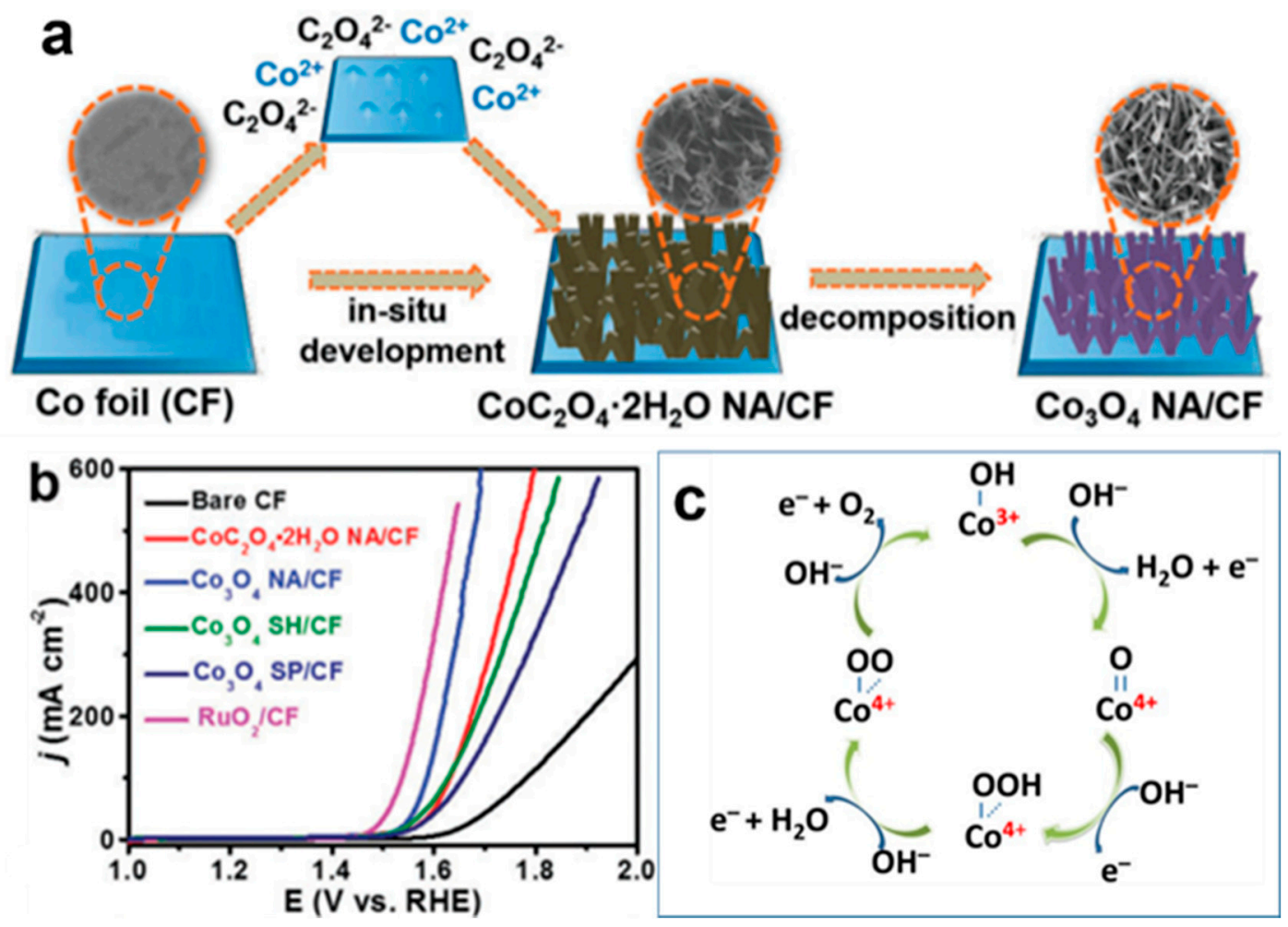

Figure 15. (a) Two-step manufacture of $\mathrm{Co}_{3} \mathrm{O}_{4} \mathrm{NA} / \mathrm{CF}$; (b) LSV curves (anodic sweep) of $\mathrm{RuO}_{2} / \mathrm{CF}$, $\mathrm{Co}_{3} \mathrm{O}_{4} \mathrm{NA} / \mathrm{CF}, \mathrm{CoC}_{2} \mathrm{O}_{4} \cdot 2 \mathrm{H}_{2} \mathrm{O} \mathrm{NA} / \mathrm{CF}$, and bare Co catalysts in $\mathrm{O}_{2}$-saturated $1 \mathrm{M} \mathrm{KOH}$ at $5 \mathrm{mV} \mathrm{s}^{-1}$ at a rotation speed of $1600 \mathrm{rpm}$ at $25^{\circ} \mathrm{C}$. The constant catalyst loading was $1.9 \mathrm{mg} \mathrm{cm}^{-2}$; (c) Suggested OER mechanism on $\mathrm{Co}_{3} \mathrm{O}_{4}$. Reproduced from [148], Copyright (C Royal Society of Chemistry, 2018.

\subsection{Oxygen Evolution on Cobalt-Based Layered Double-Hydroxides Catalysts}

The use of LDH materials for OER has been recently promoted, see Table 2. Cobalt-containing LDHs composed of edge-sharing octahedral $\mathrm{MO}_{6}$ layers, which are OER active sites, were successfully synthesized and showed an unusual catalytic activity and stability [149-151]. Li et al. [15] presented a strategy for a direct nucleation and growth of CoMn-LDH material on modified multiwall carbon nanotubes (MWCNTs) with three-dimensional hierarchical configuration. This approach afforded an intimate chemical and electrical coupling between LDH nanoplates and carbon materials, to allow 
for a rapid electron charge transfer from the active sites to the support. By tuning $\mathrm{Co} / \mathrm{Mn}$ ratio, the $\mathrm{Co}_{5} \mathrm{Mn}-\mathrm{LDH} / \mathrm{MWCNT}$ activated the reaction at a low overpotential of $\eta_{@ 10} \sim 300 \mathrm{mV}$ in $1 \mathrm{M}$ $\mathrm{KOH}$. Ren et al. [152] designed and synthesized randomly cross-linked $\mathrm{CoNi}-\mathrm{LDH} / \mathrm{CoO}$ via an in situ reduction and interface-directed assembly in air. Owing to the orbital hybridization between metal $3 d$ and $\mathrm{O} 2 p$ orbitals, and electron transfer between metal atoms through $\mathrm{Ni}-\mathrm{O}-\mathrm{Co}$, some $\mathrm{Co}$ and $\mathrm{Ni}$ atoms in the $\mathrm{CoNi}$ LDH underwent a high +3 valence. For transition metals, highly oxidized redox couples, e.g., $\mathrm{Co}^{4+/ 3+}$ and $\mathrm{Ni}^{4+/ 3+}$ were considered as active centers for OER [153].

The specific activity of the material for the target reaction is usually highly dependent on the chemical composition and electronic structure. The higher conductivity induced by modifying the electronic structure of $\mathrm{Co}$ is applicable for the electrochemical catalysis, such as de-lithiated hexagonal $\mathrm{LiCO}_{2}$ for OER, and spinel $\mathrm{LiCO}_{2}$ for ORR [153]. For the OER, a small amount of Fe doping was effective for enhancing the OER activities of Ni hydroxides or oxides, possibly due to the enhanced structure disorder and conductivity. Inspired by this, Sun et al. [154] systematically investigated the ORR and OER activities of ternary NiCoFe-LDHs and observed that a peroxidation treatment of NiCoFe-LDHs led to obtain o-NiCoFe-LDHs that significantly enhanced the corresponding bifunctional performance of (ORR/OER), as shown in Figure 16a. The XPS results and Zeta potential measurements evidenced that $\mathrm{Co}^{2+}$ was partially oxidized to a higher $\mathrm{Co}^{3+}$ state, while negligible chemical state change of $\mathrm{Ni}$ and Fe elements was observed in o-NiCoFe-LDHs. The partial conversion of $\mathrm{Co}^{2+}$ to $\mathrm{Co}^{3+}$ state stimulated the charge transfer to the catalyst surface, which could lead to the enhancement of the conductivity. In the Figure 16b, in $6 \mathrm{M} \mathrm{KOH}$ medium, the o-NiCoFe-LDHs afforded a high ORR current density of $-20 \mathrm{~mA} \mathrm{~cm}^{-2}$ at a required potential of $0.65 \mathrm{~V}$ vs. RHE. Moreover, there was a negligible ORR current density degradation of o-NiCoFe-LDHs for $40 \mathrm{~h}$. The higher conductivity induced from the higher valence state of $\mathrm{Co}$, might enhance the electrophilicity of the adsorbed $\mathrm{O}$ and thus facilitating the reaction of an $\mathrm{OH}^{-}$anion with an adsorbed $\mathrm{O}$ atom on the catalytic active sites to form adsorbed -OOH species, which was considered as the rate-limiting step for OER $[138,155]$.
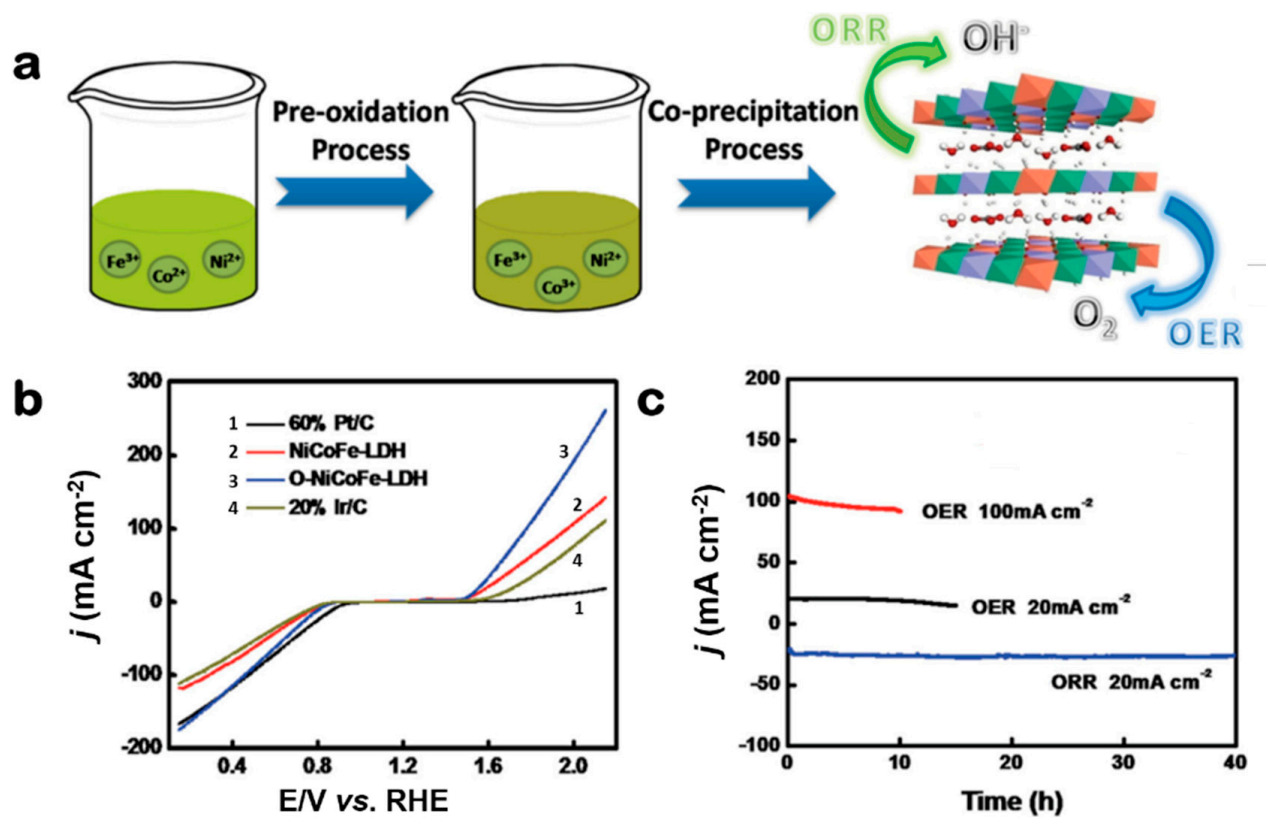

Figure 16. (a) Schematic chemical synthesis route and crystal structure of peroxidized ternary LDH bifunctional catalyst; (b) The global polarization curves of various catalysts loaded onto Teflon-treated carbon fiber paper (T-CFP) in $\mathrm{O}_{2}$-saturated $6 \mathrm{M} \mathrm{KOH}$ electrolyte with a scan rate of $1 \mathrm{mV} \mathrm{s}^{-1}$, the mass-loading of $1 \mathrm{mg} \mathrm{cm}^{-2}$ without $i R$-compensation; (c) ORR (cathodic sweep) and OER (anodic sweep) stability measurements of o-NiCoFe-LDH/Y-CFP electrode in $\mathrm{O}_{2}$-saturated $6 \mathrm{M}$ $\mathrm{KOH}$ electrolyte with a constant potential, the mass-loading of $1 \mathrm{mg} \mathrm{cm}^{-2}$. Reproduced from [154], Copyright (C) Wiley, 2015. 
It is fascinating to design and build a bifunctional oxygen electrode catalyst based on the combination of highly OER-active Ni-Fe hydroxides or oxides, and highly ORR-active Co, Fe-based compounds. Feng's group [33] designed and obtained a bifunctional electrocatalyst based on $\mathrm{NiFeO}_{x} / \mathrm{Co}-\mathrm{N}_{y}-\mathrm{C}$ by a simple calcination of $\mathrm{Ni}_{2} \mathrm{Fe}-\mathrm{CoPcTs}-\mathrm{LDH}$ precursor based on the intercalation of cobalt phthalocyanine tetrasulfonate (CoPcTs) into $\mathrm{Ni}_{2} \mathrm{Fe}-\mathrm{LDHs}$ under $\mathrm{N}_{2}$ atmosphere at $600{ }^{\circ} \mathrm{C}$. The key aspects of this bifunctional electrocatalyst, for the reversible oxygen electrode, was the mutual incorporation of the ORR-active centers (Co-based compound), and OER-active ones (spinel $\mathrm{NiFe}_{2} \mathrm{O}_{4}$ ). Particularly, the CoPcTs-intercalated structure and $\mathrm{Ni}_{2} \mathrm{Fe}-\mathrm{LDH}$ host sheet significantly enhanced the immobilization of CoPcTs and improved the dispersion degree of catalytic sites, respectively.

Moreover, the surface area of lamellar architecture materials can be further enlarged by swelling and exfoliating into individually single layers by mechanical, chemical or electrochemical means [156-159]. The exfoliated single-layered nanosheets revealed significantly higher oxygen evolution activity than the corresponding bulk LDH in alkaline conditions. Hu et al. [159] inferred that the higher OER activities of exfoliated LDHs (CoCo, NiCo, and NiFe-LDH) were mainly attributed to the increase in the number of active edge sites and to higher electronic conductivity. Analogously, Jin et al. [160] selected NiCo LDH as a representative material to demonstrate the concept of the amplified influence of exfoliation using a newly developed high-temperature high-pressure hydrothermal continuous flow reactor (HCFR), see Figure 17. The major findings were presented as follows: (1) the utilized HCFR technology effectively maintain the supersaturation to control the morphology and size of the product; (2) the exfoliation not only resulted in thinner layers with reduced size, but it was also caused by a change in the electronic structure; (3) the increase in the number of edge sites to activate OER; and (4) the increase in the electrochemical active surface area (ECSA) upon the exfoliation was not the only important factor that led to the enhanced OER performance. This work provided a general strategy to enhance the electrocatalytic performance of layered materials by chemical exfoliation.
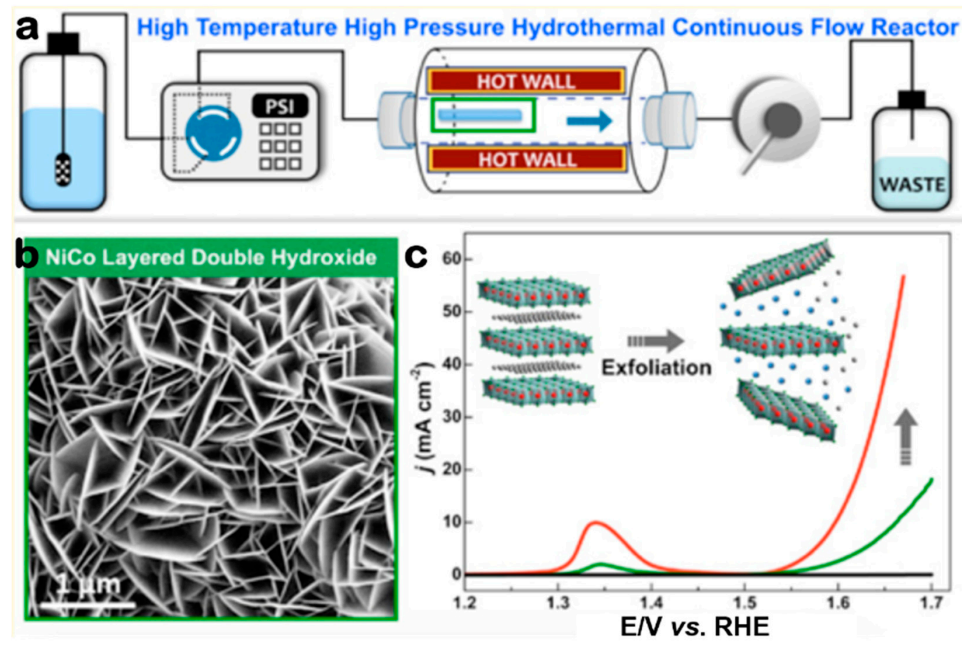

Figure 17. (a) The high-temperature high-pressure continuous flow reactor (HCFR) scheme; (b) scanning electron microscope (SEM) image of exfoliated NiCo LDH from HCFR; (c) iR-corrected and background subtracted polarization curves (anodic sweep) of NiCo LDH nanoplates (green curve) made of HCFR with mass catalyst loading of $\sim 0.23 \mathrm{mg} \mathrm{cm}^{-2}$, NiCo LDH nanosheets (red curve) synthesized nanoplates from exfoliated HCFR with a mass catalyst loading of $\sim 0.17 \mathrm{mg} \mathrm{cm}^{-2}$, and carbon paper (black curve) in $\mathrm{O}_{2}$-saturated $1 \mathrm{M} \mathrm{KOH}$ at a scan rate of $0.5 \mathrm{mV} \mathrm{s}^{-1}$. All experiments were conducted at room temperature $\left(25^{\circ} \mathrm{C}\right)$. Reproduced from [160], Copyright $\odot$ American Chemical Society, 2015. 
Table 2. Selected Co-based catalyst towards the oxygen evolution reaction.

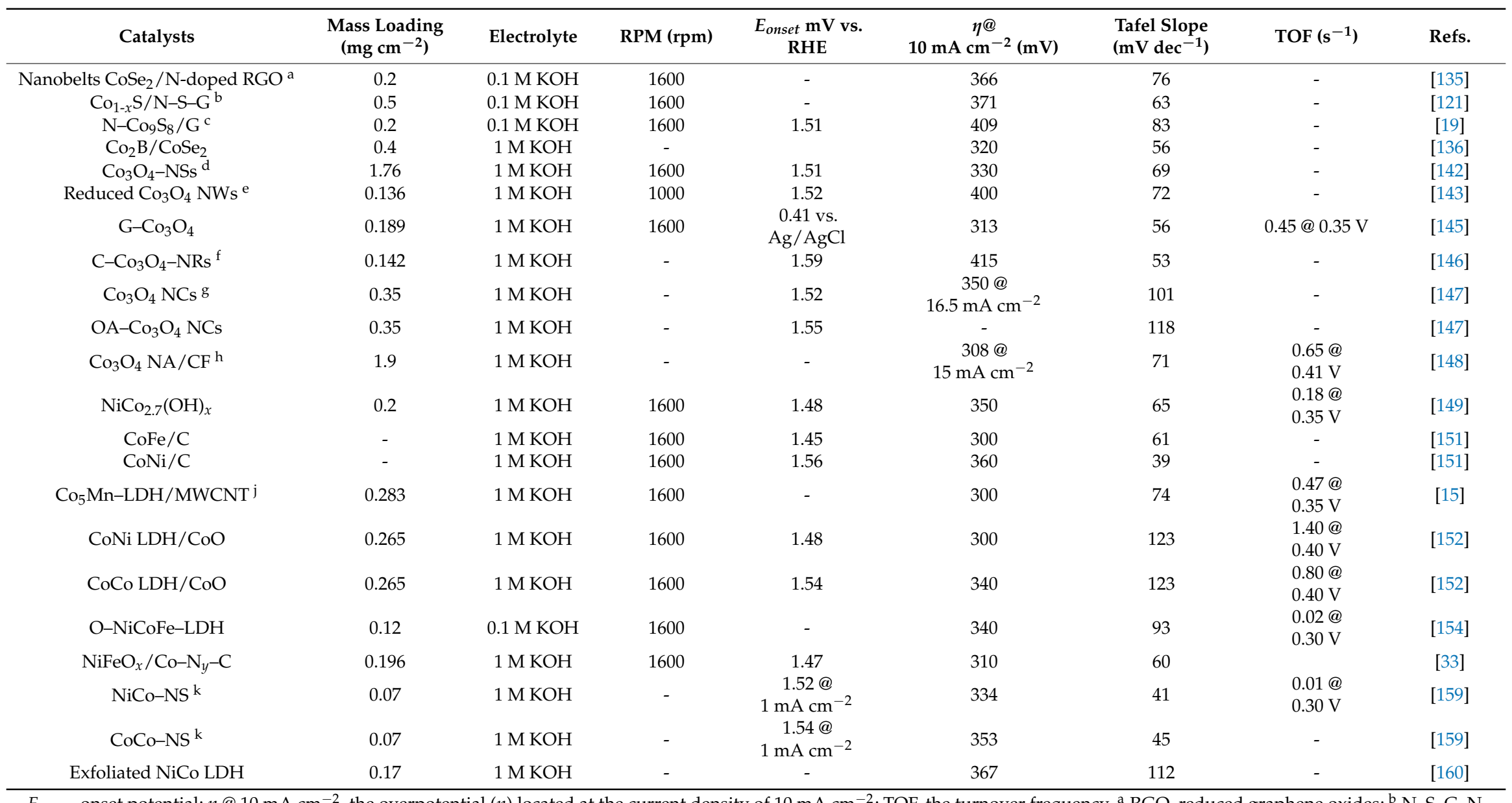

$E_{\text {onset, }}$ onset potential; $\eta @ 10 \mathrm{~mA} \mathrm{~cm}{ }^{-2}$, the overpotential $(\eta)$ located at the current density of $10 \mathrm{~mA} \mathrm{~cm}{ }^{-2}$; TOF, the turnover frequency. ${ }^{a}$ RGO, reduced graphene oxides; ${ }^{\mathrm{b}} \mathrm{N}-\mathrm{S}-\mathrm{G}, \mathrm{N}$

S-doped graphene; ${ }^{\mathrm{c}} \mathrm{G}$, graphene; ${ }^{\mathrm{d}} \mathrm{NSs}$, nanosheets; ${ }^{\mathrm{e}} \mathrm{NWs}$, nanowires; ${ }^{\mathrm{f}} \mathrm{NRs}$, nanorods; ${ }^{\mathrm{g}} \mathrm{NCs}$, nanocrystals; ${ }^{\mathrm{h}} \mathrm{CF}$, carbon fiber; ${ }^{j}$ MWCNT, multiwall carbon nanotubes; ${ }^{\mathrm{k}} \mathrm{NS}$, nanosheets. 


\subsection{Cobalt-Based Bifunctional Catalysts in Assembled Unitized Regenerative Fuel Cells}

Bifunctional oxygen electrode catalysts play a vital role in the development of unitized regenerative fuel cells (URFCs). URFC, a compact energy storage and conversion device, can simultaneously work in a fuel cell mode to produce electricity, and as a water electrolyzer mode to store off-peak electricity in the form of hydrogen. In this closed-loop system, the essential component is the desired bifunctional oxygen electrode catalysts with high catalytic activity, long-term durability, and strongly resistance to anodic corrosion. To date, several previous studies have reported cobalt-based materials as promising bifunctional ORR/OER electrocatalysts for a URFC system [161]. Scott's group used cobalt-based ORR catalysts as the cathodes and demonstrated high and stable power density performance $\left(>200 \mathrm{~mW} \mathrm{~cm}^{-2}\right)$ in alkaline anion exchange membrane fuel cells (AAEMFCs) [162]. They further [163] modified the ORR and OER electrode with $\mathrm{Cu}_{0.6} \mathrm{Mn}_{0.3} \mathrm{Co}_{2.1} \mathrm{O}_{4}$ catalyst for regenerative $\mathrm{H}_{2}-\mathrm{O}_{2}$ fuel cell. In water electrolyzer mode, the onset voltage for water electrolysis (deionized water as electrolyte) was ca. $1.55 \mathrm{~V}$. At $100 \mathrm{~mA} \mathrm{~cm}^{-2}$, the voltages of fuel cell mode and electrolyzer mode were $0.58 \mathrm{~V}$ and $1.82 \mathrm{~V}$, respectively, indicating that the fuel cell to electrolyzer voltage ratio was ca. $31.87 \%$. However, the current densities in both modes were much lower than those cells with $\mathrm{KOH}$ as electrolyte, probably because of the large electrolytic resistance.

$\mathrm{Xu}$ et al. [161] measured the performance of a unitized regenerative anion exchange membrane fuel cells (UR-AEMFCs), using a bifunctional ORR/OER catalysts, $\mathrm{Co}_{3} \mathrm{O}_{4} / \mathrm{oCNT}$, (oCNT stands for oxidized CNTs) on the oxygen electrode. The obtained performance in fuel cell mode was basically consistent with the result in half-cell mode, while the electrolyzer performance was poor. Likewise, $0.1 \mathrm{M} \mathrm{KOH}$ solution in the cell, significantly improved the performance of electrolysis.

Our group designed a self-assembly laminar flow unitized regenerative micro-cell (LFURMC) without gas separator, which was provided with $\mathrm{Pt} / \mathrm{C}$ as the hydrogen catalyst, bifunctional oxygen $\mathrm{NiFeOx} / \mathrm{CoNy}-\mathrm{C}$ catalyst and $3 \mathrm{M} \mathrm{KOH}$ electrolyte [33]. In the fuel cell mode, Figure 18, the $\mathrm{NiFeO}_{x} / \mathrm{CoN}_{y}-\mathrm{C}$ electrode showed the maximum power density of $56 \mathrm{~mW} \mathrm{~cm}^{-2}$, which was very close to that of $\mathrm{Pt} / \mathrm{C}\left(63 \mathrm{~mW} \mathrm{~cm}^{-2}\right)$ and $\mathrm{IrO}_{x} / \mathrm{C}\left(58 \mathrm{~mW} \mathrm{~cm}^{-2}\right)$; in the electrolyzer mode, the maximum electrical power consumed on $\mathrm{NiFeO}_{x} / \mathrm{CoN}_{y}-\mathrm{C}\left(237 \mathrm{~mW} \mathrm{~cm}{ }^{-2}\right)$, was more than three times that on $\mathrm{Pt} / \mathrm{C}\left(73 \mathrm{~mW} \mathrm{~cm}{ }^{-2}\right.$ ). Moreover, the calculated round-trip efficiency (RTE) of $\mathrm{NiFeO}_{x} / \mathrm{CoN}_{y}-\mathrm{C}$ catalyst nearly held a level of ca. 52\% during three cycles, evaluating a super reversibility of the $\mathrm{NiFeO}_{x} / \mathrm{CoN}_{y}-\mathrm{C}$ electrode. 

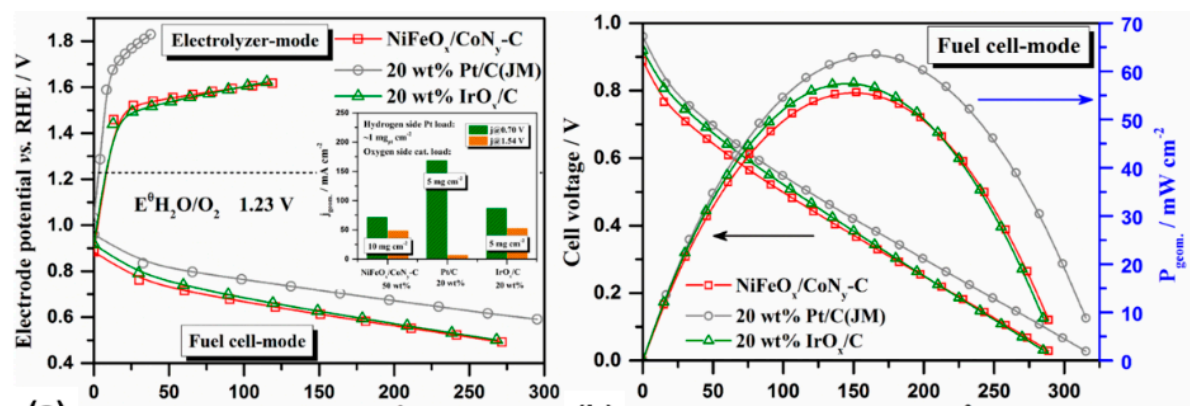

(a)

$\mathbf{j}_{\text {geom. }} / \mathbf{m A ~ c m}^{-2}$

(b)
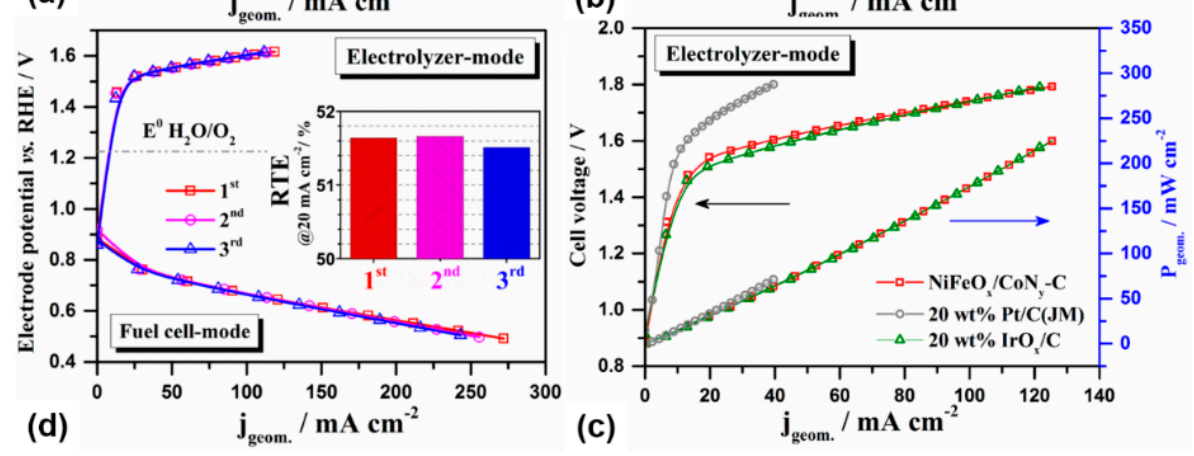

Figure 18. Alkaline laminar flow unitized regenerative micro-cell (LFURMC) experiment. (a) Current-potential of the material as anode (electrolyzer mode) and cathode (fuel cell mode). inset: The geometric activities comparison of three LFURMC; (b) the cell voltage and power density curves of the fuel cell with platinum as the hydrogen catalyst, and $\mathrm{NiFeO}_{x} / \mathrm{CoN}_{y}-\mathrm{C}, 20 \mathrm{wt} \% \mathrm{Pt} / \mathrm{C}$ and $20 \mathrm{wt} \% \mathrm{IrO}_{x} / \mathrm{C}$ cathode catalysts; (c) the cell voltage and power density curves of the electrolyzer with platinum as the hydrogen catalyst, and $\mathrm{NiFeO}_{x} / \mathrm{CoN}_{y}-\mathrm{C}, 20 \mathrm{wt} \% \mathrm{Pt} / \mathrm{C}$ and $20 \mathrm{wt} \% \mathrm{IrO}_{x} / \mathrm{C}$ cathode catalysts; (d) Stability tests of LFURMC based on the $\mathrm{NiFeO}_{x} / \mathrm{CoN}_{y}-\mathrm{C}$ catalyst (three runs), inset: round-trip-efficiency (RTE) for the three cycles. All measurements were conducted at room temperature $\left(25^{\circ} \mathrm{C}\right)$. Remark: no Ohmic-drop correction was made for all determinations. Reproduced from [33], Copyright (C) Elsevier, 2017.

\section{Electrocatalysts for Hydrogen Evolution Reaction (HER)}

\subsection{Mechanism of HER}

The hydrogen evolution reaction (HER) is the half-reaction carried out at the cathode of an electrolyzer, in which protons (acidic environment) or water molecules (alkaline environment) are reduced, accompanied by the subsequent evolution of gaseous hydrogen through the water splitting process. The overall HER proceeds as follow (in all cases, any catalytic site is denoted as "**"):

Acid medium:

$$
2 \mathrm{H}^{+}+2 \mathrm{e}^{-} \rightarrow \mathrm{H}_{2(g)}
$$

Alkaline medium:

$$
2 \mathrm{H}_{2} \mathrm{O}+2 \mathrm{e}^{-} \rightarrow \mathrm{H}_{2(g)}+2 \mathrm{OH}^{-}
$$

The standard potentials $\left(\mathrm{E}^{\circ}\right)$ are different due to the nature of the active ions in the reaction. As we can expect, the HER as any electrochemical reaction possesses a certain activation energy barrier to promote the reaction, usually denoted as overpotential $\eta$. Therefore, the HER usually demands the assistance of electrocatalytic materials to lower $\eta$, and consequently to increase the reaction rate and efficiency. The mechanisms to achieve the HER can be Volmer-Heyrovsky or Volmer-Tafel. In acid medium, the HER proceeds according to the following steps: 
i. A hydrogen atom adsorption, which is the result of the combination of a proton and an electron on the electrode surface (proton discharge) is the Volmer reaction:

$$
*+\mathrm{H}^{+}+\mathrm{e}^{-} \rightleftharpoons * \mathrm{H}_{\mathrm{ad}}
$$

ii. The adsorbed hydrogen atom interacting with a proton and an electron leads to an electrochemical desorption. This reaction is the Heyrovsky reaction:

$$
* \mathrm{H}_{\mathrm{ad}}+\mathrm{H}^{+}+\mathrm{e}^{-} \rightleftharpoons \mathrm{H}_{2}+*
$$

iii. The coupling of the two adsorbed hydrogen atoms leads to a dissociative desorption of hydrogen, the Tafel reaction:

$$
2 * \mathrm{H}_{\mathrm{ad}} \rightleftharpoons \mathrm{H}_{2}+2 *
$$

In alkaline electrolyte, due to the $\mathrm{OH}^{-}$abundance, the HER proceeds according to the following steps. For the Volmer reaction, the molecular water couples with an electron, leading in an adsorbed hydrogen atom at the electrode surface:

$$
*+\mathrm{H}_{2} \mathrm{O}+\mathrm{e}^{-} \rightleftharpoons * \mathrm{H}_{\mathrm{ad}}+\mathrm{OH}^{-}
$$

i. For the Heyrovsky reaction, the adsorbed hydrogen atom combines with molecular water and an electron, allowing the electrochemical desorption of hydrogen:

$$
* \mathrm{H}_{\mathrm{ad}}+\mathrm{H}_{2} \mathrm{O}+\mathrm{e}^{-} \rightleftharpoons \mathrm{H}_{2}+*+\mathrm{OH}^{-}
$$

ii. The Tafel reaction is similar to that of the acidic medium.

In acid and alkaline media, for the HER, the hydrogen adsorption starts via the Volmer reaction, Equations (21) or (24). The successive hydrogen desorption can proceed via the Heyrovsky reaction, Equations (22) or (25) or the dissociative desorption via the Tafel reaction, Equation (23). On the other hand, the HER can be proposed by the Tafel slope, as derived from the HER polarization curves. The Tafel slope analysis represents the intrinsic nature of the electrocatalytic material, and the empirical magnitude of the Tafel slope can provide information to distinguish the mechanism. For a Tafel rate determining step (RDS), the slope is $30 \mathrm{mV} \mathrm{dec}^{-1}$, whereas for Heyrovsky and Volmer RDS, slopes are 40 , and $120 \mathrm{mV} \mathrm{dec}^{-1}$, respectively.

The HER mechanism on Co-based catalysts follows the Volmer-Heyrovsky mechanism, where normally the Heyrovsky step is the RDS in acid medium [164,165]; whereas the Volmer step is considered the RDS in alkaline medium [165].

\subsection{Hydrogen Evolution on Cobalt Chalcogenides Catalysts}

\subsubsection{Synthesis Strategy}

Co-based catalysts are potential materials for the HER. Considerable research efforts were devoted to synthesizing cobalt chalcogenides as catalysts for HER. Those dichalcogenides are in the pyrite/marcasite phase. The metal atoms are octahedrally coordinated to adjacent S/Se atoms. Kong et al. [164] claimed that $\mathrm{CoSe}_{2}$ possessed one of the best HER performance among the first raw transition-metal chalcogenides, because of the partially filled $\mathrm{e}_{g}$ band of $\mathrm{CoSe}_{2}$. With this knowledge, Liu et al. [166] developed $\mathrm{CoSe}_{2}$ nanowire arrays on carbon cloth $\left(\mathrm{CoSe}_{2} \mathrm{NW} / \mathrm{CC}\right)$ through a facile two-step hydrothermal preparative strategy. The hydrogen evolution reaction performance was tested in $0.5 \mathrm{M} \mathrm{H}_{2} \mathrm{SO}_{4}$. Current densities of 10 and $100 \mathrm{~mA} \mathrm{~cm}^{-2}$ at overpotentials of 130 and $164 \mathrm{mV}$ were maintained for at least $48 \mathrm{~h}$. The excellent HER activity and durability for $\mathrm{CoSe}_{2} \mathrm{NW} / \mathrm{CC}$ were explained as follows. (1) The nanoarray allows for the exposure of more active sites; (2) The direct 
growth of $\mathrm{CoSe}_{2}$ on CC offers intimate contact, good mechanical adhesion and excellent electrical connection between them; and (3) The absence of polymer binder for catalyst immobilization.

Vertical-aligned graphene nanoribbons (VA-GNRs) were used as a support for cobalt carbide nanocrystals, e.g., $\mathrm{Co}_{3} \mathrm{C} / \mathrm{VA}-\mathrm{GNRs}$ by Fan et al. [119]. The HER performance in acid medium revealed a Tafel slope of $57 \mathrm{mV} \mathrm{dec}^{-1}$ and $\eta_{@ 10}$ of ca. $0.125 \mathrm{~V}$. Zhang et al. [167] synthesized by a hydrothermal procedure polymorphic $\mathrm{CoSe}_{2}$ supported onto graphite with promising HER performance, Figure 19. These authors observed that the optimized calcination temperature of $\mathrm{CoSe}_{x}$ was $30{ }^{\circ} \mathrm{C}$. This treatment allowed the change of a mixed orthorhombic to cubic phase of $\mathrm{CoSe}_{2}$. The polymorphic $\mathrm{CoSe}_{2}$ catalytic center showed higher HER performance compared to $\mathrm{CoSe}_{x}$, cubic $\mathrm{CoSe}_{2}$ and CoSe synthesized under the same conditions. The high performance observed in polymorphic $\mathrm{CoSe}_{2}$ was attributed to the enhanced chemisorption of $\mathrm{H}$ atoms onto the mixed-phase in the Tafel step.

(a)

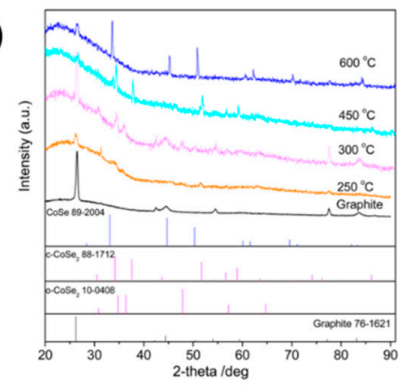

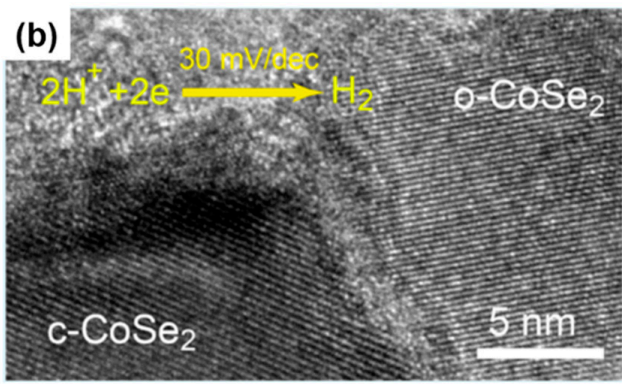

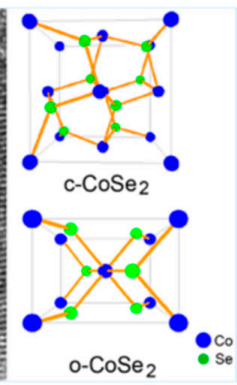

(c)
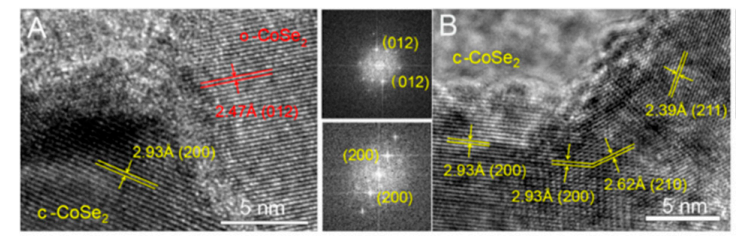

(d)
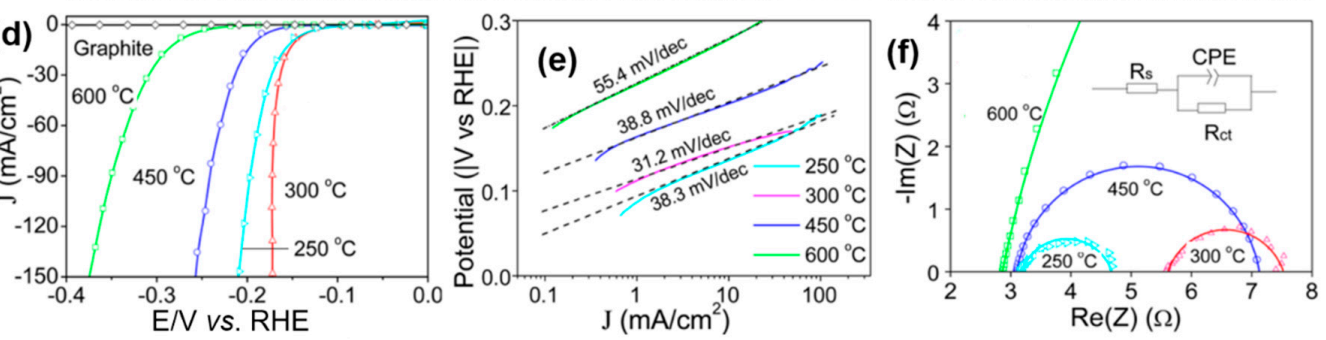

Figure 19. (a) XRD patterns of the as-prepared $\mathrm{CoSe}_{x} / \mathrm{GD}$ samples calcined at different temperatures; (b) the crystal structures of cubic $\mathrm{CoSe}_{2}\left(\mathrm{c}-\mathrm{CoSe}_{2}\right)$ and orthorhombic $\mathrm{CoSe}_{2}\left(\mathrm{o}-\mathrm{CoSe}_{2}\right)$; (c) HRTEM micrographs and electron-diffraction patterns of c-CoSe $e_{2}$ annealed at $300^{\circ} \mathrm{C}(\mathrm{A}), \mathrm{c}-\mathrm{CoSe}_{2}$ annealed at $450{ }^{\circ} \mathrm{C}(\mathrm{B})$ and CoSe annealed at $600{ }^{\circ} \mathrm{C}(\mathrm{C})$, respectively; (d) $i R$-corrected hydrogen evolution reaction (HER) polarization curves (cathodic sweep) of $\mathrm{CoSe}_{x}\left(250^{\circ} \mathrm{C}\right), \mathrm{c}-\mathrm{CoSe}_{2}\left(300^{\circ} \mathrm{C}\right), \mathrm{c}-\mathrm{CoSe}_{2}\left(450^{\circ} \mathrm{C}\right)$ and CoSe $\left(600{ }^{\circ} \mathrm{C}\right)$ in $\mathrm{H}_{2}$-saturated $0.5 \mathrm{M} \mathrm{H}_{2} \mathrm{SO}_{4}$ solution with a scan rate of $3 \mathrm{mV} \mathrm{s}^{-1}$; (e) Tafel slopes analysis of polymorphic $\mathrm{CoSe}_{2} / \mathrm{GD}$ catalysts; (f) Nyquist plots for the HER at an overpotential of $-0.5 \mathrm{~V}$ vs. SCE from $200 \mathrm{kHz}$ to $50 \mathrm{mHz}$, the data were fitted by the simplified Randles equivalent circuit (inset). Reproduced from [167], Copyright @ American Chemical Society, 2015.

\subsubsection{Crystal Structure and Nanostrcuture}

Tuning the crystal structure and surface morphology, a catalytic center can enhance its performance for electrochemical energy conversion devices. For example, the combined effect of morphology and phase of $\mathrm{CoSe}_{2}$ was studied by Li et al. [168]. These authors fashioned $\mathrm{CoSe}_{2}$ nanotubes with orthorhombic- (o-CoSe $)_{2}$ and cubic-phases (c-CoSe $\left.{ }_{2}\right)$ by a facile precursor transformation method, Figure 20a. In the synthetic process, the crystal structure and surface morphology of $\mathrm{CoSe}_{2}$ were adjusted by the calcination temperature. Benefiting from the advantageous tubular structure, including the functional shells and well-defined interior voids, $\mathrm{CoSe}_{2}$ nanotubes 
showed a clear HER performance in alkaline medium. Interestingly, the authors observed that the orthorhombic phase $\left(\mathrm{o}-\mathrm{CoSe}_{2}\right)$ possessed the highest HER performance in terms of lowest onset overpotential $(\sim 54 \mathrm{mV})$ and smallest Tafel slope $\left(\sim 65.9 \mathrm{mV}\right.$ decade $\left.^{-1}\right)$ in alkaline medium, see Figure 20b,c. Another approach where the morphology effect towards the HER was observed were given by $\mathrm{CoSe}_{2}$ nanoparticles [21], nanowires [166,169], interwoven [170], nanocomposites [171], hollow microspheres [172], and nanosheets [173].
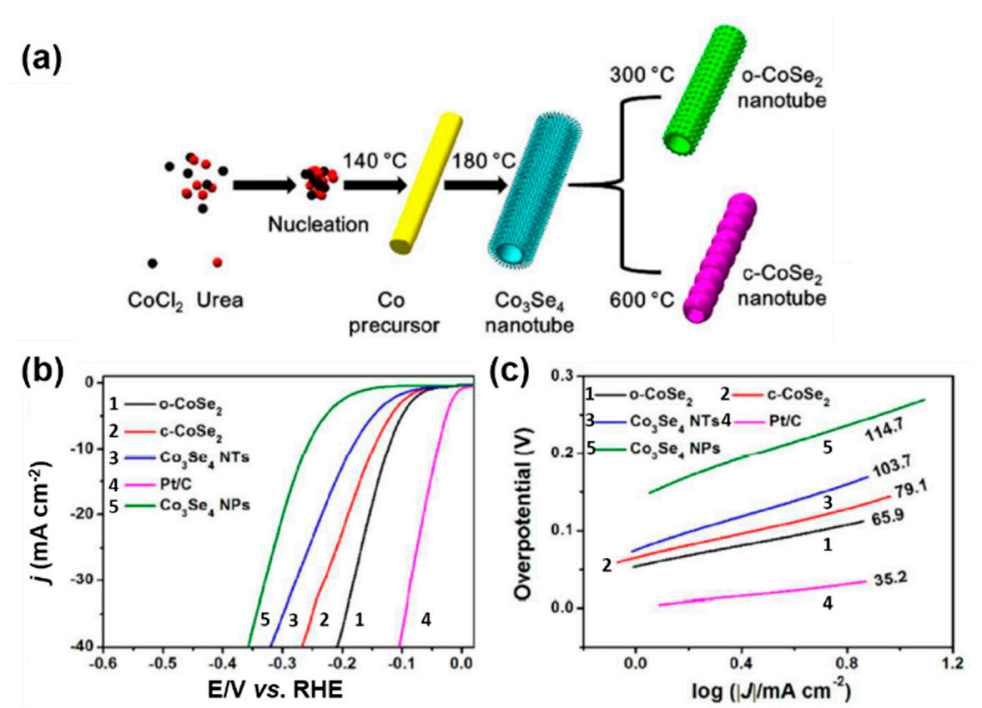

Figure 20. (a) Synthesis route of $\mathrm{CoSe}_{2}$ nanotubes; (b) $i R$-corrected HER polarization curves (cathodic sweep) of o-CoSe $2, \mathrm{c}-\mathrm{CoSe}_{2}, \mathrm{Co}_{3} \mathrm{Se}_{4} \mathrm{NTs}, \mathrm{Pt} / \mathrm{C}$ and $\mathrm{Co}_{3} \mathrm{Se}_{4}$ nanoparticles (NPs) catalysts at a scan rate of $5 \mathrm{mV} \mathrm{s}^{-1}$ in $1 \mathrm{M} \mathrm{KOH}$ solution; and (c) Tafel slopes analysis of all the catalysts. The mass loading of the catalyst was $\sim 0.283 \mathrm{mg} \mathrm{cm}^{-2}$. Reproduced from [168], Copyright (C) Royal Society of Chemistry, 2017.

On the other hand, the construction of the ultra-thin two-dimensional (2D) nanostructure have become an promising approach to tailor novel high active electrocatalytic centers, due to the confined charge interaction in the planar dimension with minimum interlayer interaction (which in fact hinders the electrical conductivity), thus improving catalytic properties [174]. An ultrathin 2D structure with abundant low-coordinated surface atoms offers adequate active sites for hydrogen evolution reactions. Liu group [175], prepared the $\mathrm{Mn}_{0.05} \mathrm{Co}_{0.95} \mathrm{Se}_{2}$ ultrathin nanosheets with $1.2 \mathrm{~nm}$ thickness by usual liquid exfoliation of homogeneous $\mathrm{Mn}$ doped $\mathrm{CoSe}_{2} / \mathrm{DETA}$ hybrid nanosheets. The subtle distortion of atomic arrangement was induced after the incorporation of $\mathrm{Mn}^{2+}$ into $\mathrm{CoSe}_{2}$, which boosted the exposure of more active edge Se sites, optimizing the HER activity. Since the chalcogenide atoms at the edges of pyrite catalyst have been verified to be HER active sites analogous to $\mathrm{MoS}_{2}$, the authors proposed that the edge Se sites in the $\mathrm{CoSe}_{2}$ probably were responsible for HER as the active sites. The Mn-doped $\mathrm{CoSe}_{2}$ ultrathin nanosheets displayed outstanding HER performance, with a low overpotential of $174 \mathrm{mV}$, and a Tafel slope of $36 \mathrm{mV} \mathrm{dec}^{-1}$.

\subsection{Hydrogen Evolution on MOFs Catalysts}

Regarding derived-MOF electrocatalysts, the porous ZIF-9 was used as a cobalt source and sacrificial template to synthesize $\mathrm{CoS}_{2}$, see Figure 21a [176]. The ZIF-9 presented very weak HER electrocatalytic performance, the benzimidazole ligands of ZIF-9 were substituted by $S$ ions after adding sulfur sources in the appropriate mention of $200{ }^{\circ} \mathrm{C}$ and $1 \mathrm{~atm}$ hydrothermal temperature and pressure, the resulting $\mathrm{CoS}_{2}$ had excellent HER activity. The introduction of graphene to further enhance the conductivity of the material, and improve the dispersion of cobalt disulfide, on RGO $\left(\mathrm{CoS}_{2} / \mathrm{RGO}\right)$ was necessary. In Figure 21b, the HER performance of the material with an overpotential of $180 \mathrm{mV}$ at $10 \mathrm{~mA} \mathrm{~cm}-2$ was smaller than those of ZIF-9, and ZIF-9/RGO. The Tafel slope of $\mathrm{CoS}_{2} / \mathrm{RGO}$ 
was $75 \mathrm{mV}$ decade $^{-1}$. This slope was near that obtained on $\mathrm{Pt} / \mathrm{C}$ electrode. Zhang et al. [177] synthesized the core-shell structure $\mathrm{Co} / \mathrm{Co}_{9} \mathrm{~S}_{8}$ anchored onto $\mathrm{S}-, \mathrm{N}$ - co-doped porous graphene sheet (Co/Cog $\left.\mathrm{S}_{8} @ S N G S\right)$. They employed thiophene-2,5-dicarboxylate (Tdc), and 4,4-bipyridine (Bpy) organic ligands assembled Co-based metal-organic frameworks in situ grown on graphene oxide sheets. The S-containing Tdc, and the N-containing Bpy did not only trigger the growth of Co-MOF nanocrystals but also fixed the $\mathrm{S} / \mathrm{N}$ atomic ratio of 1:2.4 on graphene oxide sheets. After pyrolysis of $\mathrm{Co}-\mathrm{MOF}$ at $1000{ }^{\circ} \mathrm{C}$ the catalyst showed high bifunctional catalytic activities for the OER, and HER in $0.1 \mathrm{M} \mathrm{KOH}$ electrolyte, with an overpotential of $290 \mathrm{mV}$ for OER at a current density of $10 \mathrm{~mA} \mathrm{~cm}{ }^{-2}$, and $350 \mathrm{mV}$ for HER at a current density of $20 \mathrm{~mA} \mathrm{~cm}^{-2}$.

Besides the cobalt sulfide, cobalt selenide could also be synthesized using MOFs.CoSe ${ }_{2}$ nanoparticles embedded in defective carbon nanotubes ( $\left.\mathrm{CoSe}_{2} @ \mathrm{DC}\right)$ was produced by carbonoxidation-selenization procedure of Co-based MOFs [64], Figure 22. The pre-oxidation treatment was a crucial step in introducing an increasing number of defects into carbon nanotubes, which promoted the reaction between Co@Carbon and selenium. The authors associated the enhanced HER performance to the induced carbon-surface defect density, which favored the diffusion of Se atoms through Co atoms, and made the best use of the exposed active surface area. Lin et al. [178] synthesized MOF-derived cobalt diselenide (MOF-CoSe 2 ) built with $\mathrm{CoSe}_{2}$ nanoparticles anchored into nitrogen-doped graphitic carbon through in situ selenization of Co-based MOFs. The N-doped MOFs derived architecture benefited of the high conductivity provided by the abundant active reaction sites, ensuring a robust contact between $\mathrm{CoSe}_{2}$ nanoparticles and $\mathrm{N}$-doped carbon support.

(a)

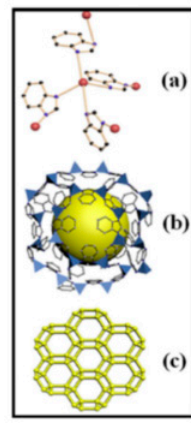

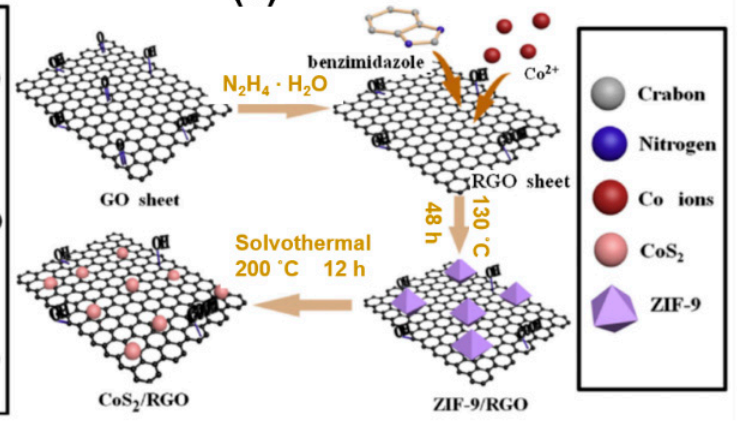

(b)

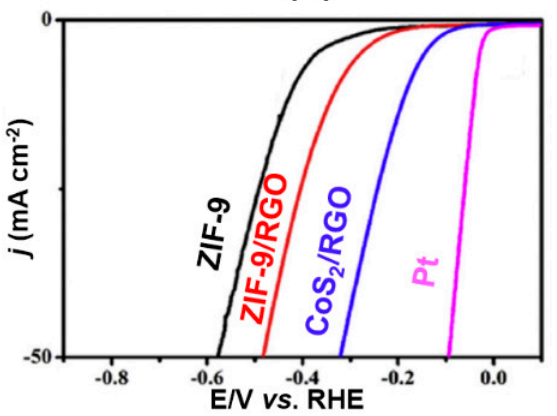

Figure 21. (a) Schematic illustration of the synthesis of $\mathrm{CoS}_{2} / \mathrm{RGO}$; and (b) HER polarization curves (cathodic sweep) collected on different catalysts with mass loading of $0.285 \mathrm{mg} \mathrm{cm}^{-2}$ in $0.5 \mathrm{M} \mathrm{H}_{2} \mathrm{SO}_{4}$ acidic solution at a scan rate of $5 \mathrm{mV} \mathrm{s}^{-1}$ at room temperature. Reproduced from [176], Copyright $\odot$ Elsevier, 2017.

Table 3 summarizes the relevant contributions regarding the HER Co-based catalysts, wherein it is possible to highlight that these catalysts present considerable performance in acid and in alkaline media. One can stress some remarkable parameters regarding the HER electrocatalytic performance, namely, (1) among non-precious catalysts, Co-based catalytic centers are one potential candidate to replace Pt-based electrodes for the water-splitting cathodic reaction, their high activity and stability; (2) since cobalt selenides catalytic centers boost the HER in acidic and in alkaline media, the chemical coordination of Co with sulfides and phosphides showed considerable performance in acid media; (3) the crystalline structure, due to the exposed active sites and electronic properties are crystalline-phase dependent; (4) the surface morphology can expose active sites; (5) the electrical coupling with conductive supports; in as much as the coupling of Co-based catalytic centers with high surface area and high electrical conductive supports modulate the dispersion of the catalytic centers and the interfacial charge-transfer. Doped carbon supports (mainly N-doped graphitic surfaces) could modify the electronic structure of the anchored catalytic centers; and (6) the synthesis route and metal source; e.g., MOFs, could provide hybrid materials which combine the surface properties of the 
porous carbon network and the catalytic properties of Co domains. Those parts are critical points to be considered in tailoring HER advanced materials.

(a)
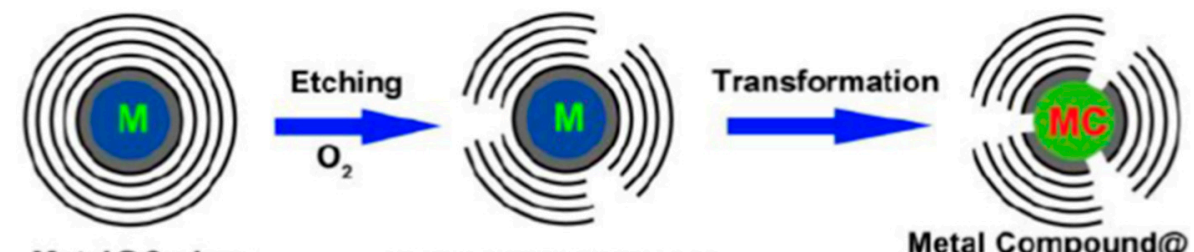

Metal@Carbon

Metal@Defect Carbon

Metal Compound@

Defect Carbon

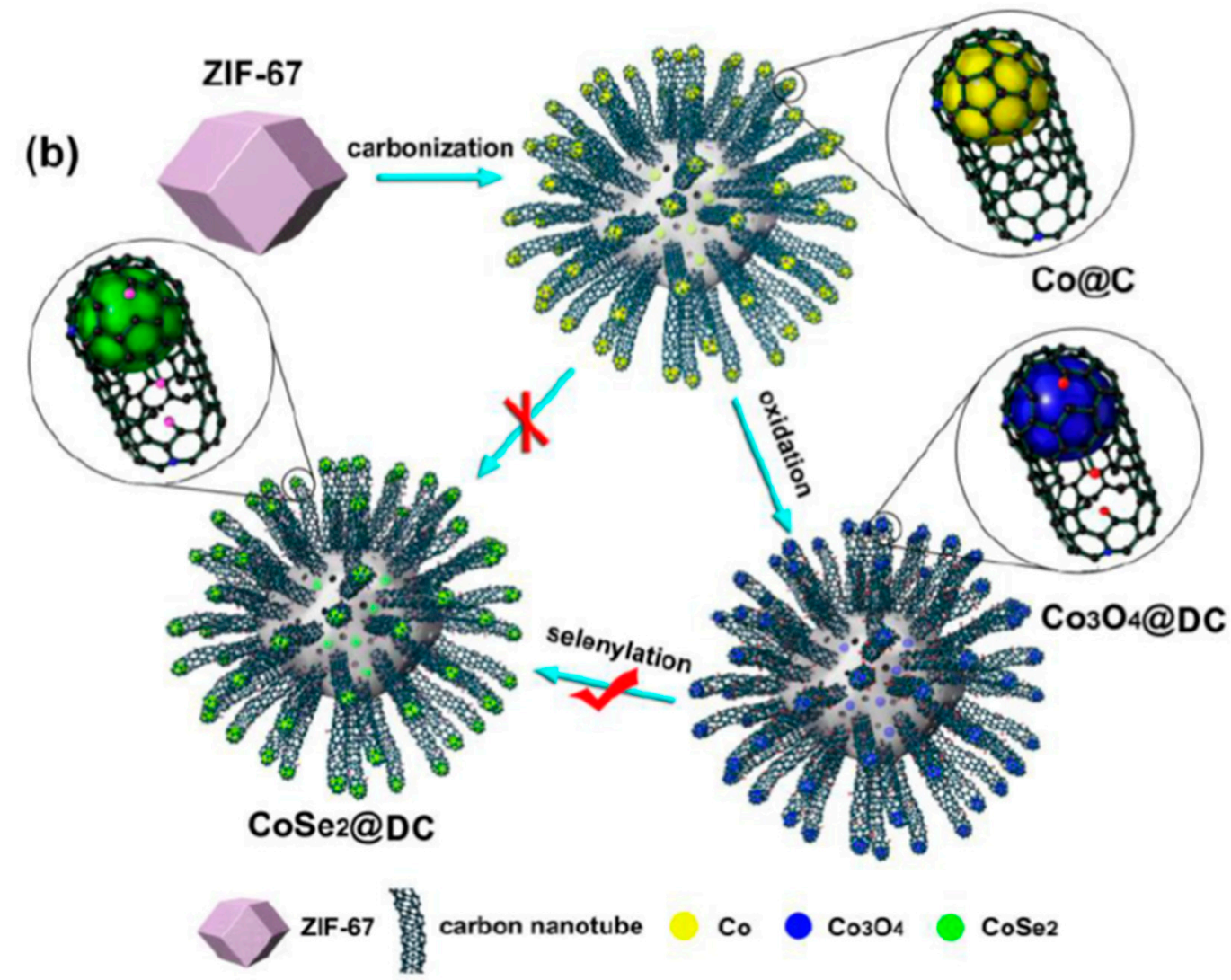

Figure 22. Schematic representation of (a) the etching process of metal@carbon by pre-oxidation; (b) the synthetic chemical route for $\mathrm{CoSe}_{2} @ D C$. Reproduced from [64], Copyright (c) Elsevier, 2016. 
Table 3. Selected state-of-the-art Co-based catalyst towards the hydrogen evolution reaction.

\begin{tabular}{|c|c|c|c|c|c|c|}
\hline Catalysts & $\begin{array}{l}\text { Mass Loading } \\
\left(\mathrm{mg} \mathrm{cm}^{-2}\right)\end{array}$ & Electrolyte & RPM (rpm) & $\begin{array}{c}\eta @ 10 \mathrm{~mA} \\
\mathrm{~cm}^{-2}(\mathrm{mV})\end{array}$ & $\begin{array}{l}\text { Tafel Slope } \\
\left(\mathrm{mV} \mathrm{dec}^{-1}\right)\end{array}$ & Refs. \\
\hline $\mathrm{CoSe}_{2} @ \mathrm{DC}^{\mathrm{a}}$ & 0.357 & $0.5 \mathrm{M} \mathrm{H}_{2} \mathrm{SO}_{4}$ & - & 132 & 82 & [64] \\
\hline $\mathrm{Co}_{3} \mathrm{C}-\mathrm{GNRs}{ }^{\mathrm{b}}$ & 0.142 & $0.5 \mathrm{M} \mathrm{H}_{2} \mathrm{SO}_{4}$ & 1600 & 125 & 57 & [119] \\
\hline $\mathrm{Co}_{2} \mathrm{~B} / \mathrm{CoSe}_{2}$ & 0.4 & $1 \mathrm{M} \mathrm{KOH}$ & - & 300 & 76 & [136] \\
\hline Cubic $\mathrm{CoSe}_{2} / \mathrm{GD}^{\mathrm{c}}$ & 2.8 & $0.5 \mathrm{M} \mathrm{H}_{2} \mathrm{SO}_{4}$ & - & 200 & 42 & [179] \\
\hline Cubic $\mathrm{CoSe}_{2}$ nanoparticles $/ \mathrm{CF}^{\mathrm{d}}$ & 0.26 & $0.5 \mathrm{M} \mathrm{H}_{2} \mathrm{SO}_{4}$ & - & 137 & 42 & [21] \\
\hline Interwoven $\mathrm{CoSe}_{2} / \mathrm{CNT}^{\mathrm{e}}$ & 0.54 & $0.5 \mathrm{M} \mathrm{H}_{2} \mathrm{SO}_{4}$ & - & 186 & 32 & {$[170]$} \\
\hline $\mathrm{CoSe}_{2}-\mathrm{CNT}^{\mathrm{e}}$ & 0.255 & $0.5 \mathrm{M} \mathrm{H}_{2} \mathrm{SO}_{4}$ & 2000 & 174 & 38 & [171] \\
\hline Orthorhombic $\mathrm{CoSe}_{2}$ nanotubes & 0.283 & $1 \mathrm{M} \mathrm{KOH}$ & - & 124 & 66 & [168] \\
\hline Cubic $\mathrm{CoSe}_{2}$ nanotubes & 0.283 & $1 \mathrm{M} \mathrm{KOH}$ & - & 149 & 79 & [168] \\
\hline Polymorphic CoSe/GD ${ }^{c}$ & - & $0.5 \mathrm{M} \mathrm{H}_{2} \mathrm{SO}_{4}$ & - & 150 & 31 & [167] \\
\hline $\mathrm{CoSe}_{2}$ hollow microspheres/rGO & 0.277 & $0.5 \mathrm{M} \mathrm{H}_{2} \mathrm{SO}_{4}$ & - & 250 & 55 & [172] \\
\hline CoPS/NC ${ }^{f}$ & 0.17 & $0.5 \mathrm{M} \mathrm{H}_{2} \mathrm{SO}_{4}$ & 2000 & 80 & 68 & [180] \\
\hline $\mathrm{CoPS} / \mathrm{NC}^{\mathrm{f}}$ & 0.17 & $1 \mathrm{M} \mathrm{KOH}$ & 2000 & 148 & 78 & [180] \\
\hline Nanowires $\mathrm{CoSe}_{2} / \mathrm{CF}^{\mathrm{d}}$ & - & $0.5 \mathrm{M} \mathrm{H}_{2} \mathrm{SO}_{4}$ & - & 150 & 34 & [169] \\
\hline Nanowires $\mathrm{CoSe}_{2} / \mathrm{CC} g$ & - & $0.5 \mathrm{M} \mathrm{H}_{2} \mathrm{SO}_{4}$ & - & 150 & 32 & [166] \\
\hline Nanosheets $\mathrm{CoSe}_{2} /$ Ti plate & 0.16 & $0.5 \mathrm{M} \mathrm{H}_{2} \mathrm{SO}_{4}$ & - & 165 & 39 & [173] \\
\hline \multirow{2}{*}{$\mathrm{CoS} / \mathrm{CC}^{\mathrm{g}}$} & \multirow[b]{2}{*}{3.77} & $1 \mathrm{M} \mathrm{KOH}$ & - & 197 & 98 & \multirow[b]{2}{*}{ [181] } \\
\hline & & $0.5 \mathrm{M} \mathrm{H}_{2} \mathrm{SO}_{4}$ & - & 212 & 112 & \\
\hline $\mathrm{CoS}_{2} / \mathrm{RGO}^{\mathrm{h}}$ & 0.285 & $0.5 \mathrm{M} \mathrm{H}_{2} \mathrm{SO}_{4}$ & - & 18 & 75 & [176] \\
\hline \multirow[t]{2}{*}{$\mathrm{CoS}_{2} / \mathrm{P}$} & - & $0.5 \mathrm{M} \mathrm{H}_{2} \mathrm{SO}_{4}$ & - & 67 & 50 & \multirow[t]{2}{*}[182]{} \\
\hline & \multirow{3}{*}{0.283} & $1 \mathrm{M} \mathrm{KOH}$ & - & 67 & 60 & \\
\hline \multirow[t]{2}{*}{$\mathrm{Co}_{9} \mathrm{~S}_{8} / \mathrm{NC}^{\mathrm{e}} @ \mathrm{MoS}_{2}$} & & $0.5 \mathrm{M} \mathrm{H}_{2} \mathrm{SO}_{4}$ & - & 117 & 69 & \multirow[t]{2}{*}{ [183] } \\
\hline & & 1 M PBS & - & 267 & 126 & \\
\hline
\end{tabular}

$\eta @ 10 \mathrm{~mA} \mathrm{~cm}{ }^{-2}$, the overpotential $(\eta)$ located at the current density of $10 \mathrm{~mA} \mathrm{~cm}{ }^{-2} ;{ }^{a} \mathrm{DC}$, defective carbon nanotubes; ${ }^{\mathrm{b}} \mathrm{GNRs}$, graphene nanoribbons; ${ }^{\mathrm{c}} \mathrm{GD}$, graphite disk; ${ }^{\mathrm{d}} \mathrm{CF}$, carbon fiber; ${ }^{\mathrm{e}} \mathrm{CNT}$, carbon nanotubes; ${ }^{\mathrm{f}} \mathrm{NC}$, $\mathrm{N}$-doped carbon, ${ }^{\mathrm{g}} \mathrm{CC}$, carbon cloth; ${ }^{\mathrm{h}} \mathrm{RGO}$, reduced graphene oxides.

\section{Summary and Outlook}

This review mainly focused on novel cobalt-based catalysts (CoCat) for electrochemical processes, e.g., ORR, OER and HER in acid and alkaline electrolyte, categorized into five groups, namely, cobalt chalcogenides (selenides, sulfides), cobalt oxides, $\mathrm{Co}-\mathrm{LDH}, \mathrm{Co}-\mathrm{MOFs}$, and $\mathrm{Co}-\mathrm{N}_{x} / \mathrm{C}$. Tables 1-3 summarize the corresponding electrocatalytic parameters such as onset potential, half-wave potential, Tafel slope, and so on. Based on those results, we assess that cobalt-based materials have emerged as interesting and potential alternatives because of their activities, superior electrochemical stability, and durability compared with precious metals (e.g., Pt, Ir and $\mathrm{Ru}$ ). While loading cobalt metal compounds on conducting carbonaceous materials, the cobalt-carbon hybrids showed enhanced electrochemical performance. With respect to the electrocatalytic performance of cobalt-based catalysts, the surface engineering (e.g., doping, etching and edging), the structural properties and morphologies (e.g., specific surface area, porosity, core-shell and hollow), anionic substitution (S, Se and Te), defects (e.g., vacancies, topological defects, lattice defects and edge sites), and support materials (e.g., RGO, CNTs, CNHs, and Vulcan-XC-72) were discussed in detail. Furthermore, these catalysts achieved desired catalytic activities towards ORR, OER and HER, as a result of the following strategies: (1) enhancing the SMSI effect, and the synergistic coupling of catalyst-support, resulting in faster electron transport and charge transfer; (2) modulation of the active sites $\mathrm{Co}^{3+} / \mathrm{Co}^{2+}$ ratio via the $\mathrm{NaBH}_{4}$-assisted route; (3) elucidation of active sites and building well-engineered architecture under the confinement effect; (4) exfoliating the bulk catalysts into atomic level thickness, boosted the exposure and generation of active sites; (5) the direct growth of cobalt-based catalysts on 3D conductive support, e.g., Co foil, Ni foam, and carbon fiber paper, avoided the use of polymer binders, facilitating the electrolyte diffusion, and driving off the as-formed gas bubbles from the electrode surface.

In search of potentially promising and suitable candidates to replace precious catalyst centers for energy conversion and storage systems, a series of cobalt-based materials has been developed. The last 10 years of research on such materials, there has been a boom in the number of publications, that helped to highlight the assembly of unitized regenerated cells based on bifunctional ORR and OER catalysts by exchanging the fuel cell mode to electrolyzer mode. Taking advantage of the exceptional 
properties which can be achieved by the rational design of materials, such as a large specific surface area, ultrathin/atomic level thickness, optimized porous structure for the exposure of active sites, high conductivity, and a high uniform dispersion, the Co-based nanomaterials will continue to open new avenues to further enhance electrocatalytic activity and stability. Among these Co-based catalysts, due to the coexistence of the diverse active sites including doping via nitrogen, $\mathrm{Co}-\mathrm{N}_{x} / \mathrm{C}$ derived from $\mathrm{LDH}$, $\mathrm{MOF}$ and other precursor used as templates were considered to substitute $\mathrm{Pt}, \mathrm{Ru}$, and Ir-based catalysts in acidic and alkaline medium. Last but not least, in-depth studies and interdisciplinary cooperation are still urgently required. Therefore, the design and development of cobalt-based electrocatalysts should be concentrated on the following aspects in the future: (1) understanding the fundamental reaction mechanisms of ORR, OER and HER by virtue of theoretical prediction and simulation; (2) probing and identifying the ideal active sites, and then integrating the different types of active sites to develop the so-called bifunctional oxygen electrode electrocatalysts or bifunctional HER-OER electrocatalysts; (3) gaining insights into the active sites involved such as metal species, oxygen vacancies, and topological defects, by using various advanced characterization techniques, e.g., X-ray absorption near edge structure spectroscopy (XANES), sub-Ångström-resolution aberration-corrected scanning transmission electron microscopy (HAADF-STEM), and in situ Raman; (4) developing simple and low-cost approaches to synthesize the catalysts with satisfactory activity and stability is expected to achieve the mass-production and high quality required for large-scale applications.

Author Contributions: H.Z. searched the literature, and wrote the main part of the current work; C.A.C.-R. contributed with the data analysis, writing and revision of the current literature; Y.Z. wrote part of this work; S.Z. redacted and corrected the references; Y.F. and N.A.-V. organized, supervised and reviewed the work.

Funding: This research received no external funding.

Acknowledgments: This work is supported by National Key R\&D Program of China (No. 2016YFB0301600), the National Natural Science Foundation of China (No. 21571015, 21627813), Program for Changjiang Scholars and Innovative Research Team in University (No. IRT1205), China Scholarship Council (H.Z.), The Priority Academic Program Development of Jiangsu Higher Education Institutions (Y.Z.), and CONACyT-Mexico Scholarship (C.A.C.-R.).

Conflicts of Interest: The authors declare no conflict of interest.

\section{References}

1. Park, S.; Shao, Y.Y.; Liu, J.; Wang, Y. Electrocatalysts for Water Electrolyzers and Reversible Fuel Cells: Status and Perspective. Energy Environ. Sci. 2012, 5, 9331-9344. [CrossRef]

2. Carrette, L.; Friedrich, K.A.; Stimming, U. Fuel Cells -Fundamentals and Applications. Fuel Cells 2001, 1, 5-39. [CrossRef]

3. Jiao, Y.; Zheng, Y.; Jaroniec, M.; Qiao, S.Z. Design of Electrocatalysts for Oxygen- and Hydrogen-Involving Energy Conversion Reactions. Chem. Soc. Rev. 2015, 44, 2060-2086. [CrossRef] [PubMed]

4. Suen, N.T.; Hung, S.F.; Quan, Q.; Zhang, N.; Xu, Y.J.; Chen, H.M. Electrocatalysis for the Oxygen Evolution Reaction: Recent Development and Future Perspectives. Chem. Soc. Rev. 2017, 46, 337-365. [CrossRef] [PubMed]

5. Ge, X.; Sumboja, A.; Wuu, D.; An, T.; Li, B.; Goh, F.W.T.; Hor, T.S.A.; Zong, Y.; Liu, Z. Oxygen Reduction in Alkaline Media: From Mechanisms to Recent Advances of Catalysts. ACS Catal. 2015, 5, 4643-4667. [CrossRef]

6. Shao, M.H.; Chang, Q.W.; Dodelet, J.P.; Chenitz, R. Recent Advances in Electrocatalysts for Oxygen Reduction Reaction. Chem. Rev. 2016, 116, 3594-3657. [CrossRef] [PubMed]

7. Dai, L.M.; Xue, Y.H.; Qu, L.T.; Choi, H.J.; Baek, J.B. Metal-Free Catalysts for Oxygen Reduction Reaction. Chem. Rev. 2015, 115, 4823-4892. [CrossRef] [PubMed]

8. Liu, Q.; Jin, J.T.; Zhang, J.Y. $\mathrm{NiCo}_{2} \mathrm{~S}_{4} @ G r a p h e n e$ as a Bifunctional Electrocatalyst for Oxygen Reduction and Evolution Reactions. ACS Appl. Mater. Interfaces 2013, 5, 5002-5008. [CrossRef] [PubMed]

9. Gong, M.; Li, Y.G.; Wang, H.L.; Liang, Y.Y.; Wu, J.Z.; Zhou, J.G.; Wang, J.; Regier, T.; Wei, F.; Dai, H.J. An Advanced Ni-Fe Layered Double Hydroxide Electrocatalyst for Water Oxidation. J. Am. Chem. Soc. 2013, 135, 8452-8455. [CrossRef] [PubMed] 
10. Zhao, A.Q.; Masa, J.; Xia, W.; Maljusch, A.; Willinger, M.G.; Calavel, G.; Xie, K.P.; Schlogl, R.; Schuhmann, W.; Muhlert, M. Spinel Mn-Co Oxide in N-Doped Carbon Nanotubes as a Bifunctional Electrocatalyst Synthesized by Oxidative Cutting. J. Am. Chem. Soc. 2014, 136, 7551-7554. [CrossRef] [PubMed]

11. Xie, R.F.; Fan, G.L.; Ma, Q.; Yang, L.; Li, F. Facile Synthesis and Enhanced Catalytic Performance of Graphene-Supported Ni Nanocatalyst from a Layered Double Hydroxide-Based Composite Precursor. J. Mater. Chem. A 2014, 2, 7880-7889. [CrossRef]

12. Sumboja, A.; An, T.; Goh, H.Y.; Lubke, M.; Howard, D.P.; Xu, Y.; Handoko, A.D.; Zong, Y.; Liu, Z. One-Step Facile Synthesis of Cobalt Phosphides for Hydrogen Evolution Reaction Catalysts in Acidic and Alkaline Medium. ACS Appl. Mater. Interfaces 2018, 10, 15673-15680. [CrossRef] [PubMed]

13. Pramana, S.S.; Cavallaro, A.; Li, C.; Handoko, A.D.; Chan, K.W.; Walker, R.J.; Regoutz, A.; Herrin, J.S.; Yeo, B.S.; Payne, D.J.; et al. Crystal Structure and Surface Characteristics of Sr-Doped $\mathrm{GdBaCo}_{2} \mathrm{O}_{6}-\delta$ Double Perovskites: Oxygen Evolution Reaction and Conductivity. J. Mater. Chem. A 2018, 6, 5335-5345. [CrossRef]

14. Lübke, M.; Sumboja, A.; McCafferty, L.; Armer, C.F.; Handoko, A.D.; Du, Y.H.; McColl, K.; Cora, F.; Brett, D.; Liu, Z.L.; et al. Transition-Metal-Doped $\alpha-\mathrm{MnO}_{2}$ Nanorods as Bifunctional Catalysts for Efficient Oxygen Reduction and Evolution Reactions. ChemistrySelect 2018, 3, 2613-2622. [CrossRef]

15. Jia, G.; Hu, Y.; Qian, Q.; Yao, Y.; Zhang, S.; Li, Z.; Zou, Z. Formation of Hierarchical Structure Composed of (Co/Ni)Mn-LDH Nanosheets on MWCNT Backbones for Efficient Electrocatalytic Water Oxidation. ACS Appl. Mater. Interfaces 2016, 8, 14527-14534. [CrossRef] [PubMed]

16. Yang, Z.; Yao, Z.; Li, G.; Fang, G.Y.; Nie, H.G.; Liu, Z.; Zhou, X.M.; Chen, X.A.; Huang, S.M. Sulfur-Doped Graphene as an Efficient Metal-Free Cathode Catalyst for Oxygen Reduction. ACS Nano 2012, 6, $205-211$. [CrossRef] [PubMed]

17. Gago, A.S.; Gochi-Ponce, Y.; Feng, J.Y.; Esquivel, J.P.; Sabate, N.; Santander, J.; Alonse-Vante, N. Tolerant Chalcogenide Cathodes of Membraneless Micro Fuel Cells. ChemSusChem 2012, 5, 1488-1494. [CrossRef] [PubMed]

18. Wang, H.L.; Liang, Y.Y.; Li, Y.G.; Dai, H.J. $\mathrm{Co}_{1-x}$ S-Graphene Hybrid: A High-Performance Metal Chalcogenide Electrocatalyst for Oxygen Reduction. Angew. Chem. Int. Ed. Engl. 2011, 50, 10969-10972. [CrossRef] [PubMed]

19. Dou, S.; Tao, L.; Hou, J.; Wang, S.Y.; Dai, L.M. Etched and Doped Cog $\mathrm{S}_{8} /$ Graphene Hybrid for Oxygen Electrocatalysis. Energy Environ. Sci. 2016, 9, 1320-1326. [CrossRef]

20. Chao, Y.S.; Tsai, D.S.; Wu, A.P.; Tseng, L.W.; Huang, Y.S. Cobalt Selenide Electrocatalyst Supported by Nitrogen-Doped Carbon and its Stable Activity toward Oxygen Reduction Reaction. Int. J. Hydrogen Energy 2013, 38, 5655-5664. [CrossRef]

21. Kong, D.S.; Wang, H.T.; Lu, Z.Y.; Cui, Y. CoSe 2 Nanoparticles Grown on Carbon Fiber Paper: An Efficient and Stable Electrocatalyst for Hydrogen Evolution Rreaction. J. Am. Chem. Soc. 2014, 136, 4897-4900. [CrossRef] [PubMed]

22. Zhang, H.; Wang, H.H.; Sumboja, A.; Zang, W.J.; Xie, J.P.; Gao, D.Q.; Pennycook, S.J.; Liu, Z.L.; Guan, C.; Wang, J. Integrated Hierarchical Carbon Flake Arrays with Hollow P-Doped CoSe $_{2}$ Nanoclusters as an Advanced Bifunctional Catalyst for Zn-Air Batteries. Adv. Funct. Mater. 2018, 28, 1804846. [CrossRef]

23. Chen, P.R.; Yang, F.K.; Kostka, A.; Xia, W. Interaction of Cobalt Nanoparticles with Oxygen- and Nitrogen-Functionalized Carbon Nanotubes and Impact on Nitrobenzene Hydrogenation Catalysis. ACS Catal. 2014, 4, 1478-1486. [CrossRef]

24. Mao, S.; Wen, Z.H.; Huang, T.Z.; Hou, Y.; Chen, J.H. High-Performance Bi-Functional Electrocatalysts of 3D Crumpled Graphene-Cobalt Oxide Nanohybrids for Oxygen Reduction and Evolution Reactions. Energy Environ. Sci. 2014, 7, 609-616. [CrossRef]

25. Liang, Y.Y.; Li, Y.G.; Wang, H.L.; Zhou, J.G.; Wang, J.; Regier, T.; Dai, H.J. $\mathrm{Co}_{3} \mathrm{O}_{4}$ Nanocrystals on Graphene as a Synergistic Catalyst for Oxygen Reduction Reaction. Nat. Mater. 2011, 101, 780-786. [CrossRef] [PubMed]

26. Chen, Y.Z.; Wang, C.M.; Wu, Z.Y.; Xiong, Y.J.; Xu, Q.; Yu, Y.H.; Jiang, H.L. From Bimetallic Metal-Organic Framework to Porous Carbon: High Surface Area and Multicomponent Active Dopants for Excellent Electrocatalysis. Adv. Mater. 2015, 27, 5010-5016. [CrossRef] [PubMed]

27. Ma, T.Y.; Dai, S.; Jaroniec, M.; Qiao, S.Z. Metal-Organic Framework Derived Hybrid $\mathrm{Co}_{3} \mathrm{O}_{4}$-Carbon Porous Nanowire Arrays as Reversible Oxygen Evolution Electrodes. J. Am. Chem. Soc. 2014, 136, 13925-13931. [CrossRef] [PubMed] 
28. Zhong, H.H.; Lou, Y.; He, S.; Tang, P.G.; Li, D.Q.; Alonso-Vante, N.; Feng, Y.J. Electrocatalytic Cobalt Nanoparticles Interacting with Nitrogen-Doped Carbon Nanotube in Situ Generated from a Metal-Organic Framework for the Oxygen Reduction Reaction. ACS Appl. Mater. Interfaces 2017, 9, 2541-2549. [CrossRef] [PubMed]

29. Zhang, W.J.; Sumboja, A.; Ma, Y.Y.; Zhang, H.; Wu, Y.; Wu, S.S.; Wu, H.J.; Liu, Z.L.; Guan, C.; Wang, J.; et al. Single Co Atoms Anchored in Porous N-Doped Carbon for Efficient Zinc-Air Battery Cathodes. ACS Catal. 2018, 8, 8961-8969. [CrossRef]

30. Guan, C.; Sumboja, A.; Zang, W.J.; Qian, Y.H.; Zhang, H.; Liu, X.M.; Liu, Z.L.; Zhao, D.; Pennycook, S.J.; Wang, J. Decorating $\mathrm{Co} / \mathrm{CoN}_{\mathrm{x}}$ Nanoparticles in Nitrogen-Doped Carbon Nanoarrays for Flexible and Rechargeable Zinc-Air Batteries. Energy Storage Mater. 2018, 16, 243-250. [CrossRef]

31. Fan, G.L.; Li, F.; Evans, D.G.; Duan, X. Catalytic Applications of Layered Double Hydroxides: Recent Advances and Perspectives. Chem. Soc. Rev. 2014, 43, 7040-7066. [CrossRef] [PubMed]

32. Zhang, S.L.; Zhang, Y.; Jiang, W.J.; Liu, X.; Xu, S.L.; Hou, R.J.; Zhang, F.Z.; Hu, J.S. Co@N-CNTs Derived from Triple-Role CoAl-Layered Double Hydroxide as an Efficient Catalyst for Oxygen Reduction Reaction. Carbon 2016, 107, 162-170. [CrossRef]

33. Zhong, H.H.; Tian, R.; Gong, X.M.; Li, D.Q.; Tang, P.G.; Alonso-Vante, N.; Feng, Y.J. Advanced Bifunctional Electrocatalyst Generated through Cobalt Phthalocyanine Tetrasulfonate Intercalated $\mathrm{Ni}_{2} \mathrm{Fe}$-Layered Double Hydroxides for a Laminar Flow Unitized Regenerative Micro-Cell. J. Power Sources 2017, 361, 21-30. [CrossRef]

34. Wang, J.H.; Cui, W.; Liu, Q.; Xing, Z.C.; Asiri, A.M.; Sun, X.P. Recent Progress in Cobalt-Based Heterogeneous Catalysts for Electrochemical Water Splitting. Adv. Mater. 2016, 28, 215-230. [CrossRef] [PubMed]

35. Dai, X.F.; Qiao, J.L.; Zhou, X.J.; Shi, J.J.; Xu, P.; Zhang, L.; Zhang, J.J. Effects of Heat-Treatment and Pyridine Addition on the Catalytic Activity of Carbon-Supported Cobalt-Phthalocyanine for Oxygen Reduction Reaction in Alkaline Electrolyte. Int. J. Electrochem. Sci. 2013, 8, 3160-3175.

36. Zhao, S.; Rasimick, B.; Mustain, W.; Xu, H. Highly Durable and Active $\mathrm{Co}_{3} \mathrm{O}_{4}$ Nanocrystals Supported on Carbon Nanotubes as Bifunctional Electrocatalysts in Alkaline Media. Appl. Catal. B 2017, 203, 138-145. [CrossRef]

37. Liu, S.Y.; Li, L.J.; Ahnb, H.S.; Manthiram, A. Delineating the Roles of $\mathrm{Co}_{3} \mathrm{O}_{4}$ and N-Doped Carbon Nanoweb $(\mathrm{CNW})$ in Bifunctional $\mathrm{Co}_{3} \mathrm{O}_{4} / \mathrm{CNW}$ Catalysts for Oxygen Reduction and Oxygen Evolution Reactions. J. Mater. Chem. A 2015, 3, 11615-11623. [CrossRef]

38. Wu, Z.S.; Ren, W.C.; Wen, L.; Gao, L.B.; Zhao, J.P.; Chen, Z.P.; Zhou, G.M.; Li, F.; Cheng, H.M. Graphene Anchored with $\mathrm{Co}_{3} \mathrm{O}_{4}$ Nanoparticles as Anode of Lithium Ion Batteries with Enhanced Reversible Capacity and Cyclic Performance. ACS Nano 2010, 4, 3187-3194. [CrossRef] [PubMed]

39. Subramanian, N.P.; Kumaraguru, S.P.; Colon-Mercado, H.; Kim, H.; Popov, B.N.; Black, T.; Chen, D.A. Studies on Co-Based Catalysts Supported on Modified Carbon Substrates for PEMFC Cathodes. J. Power Sources 2006, 157, 56-63. [CrossRef]

40. Khan, M.; Tahir, M.N.; Adil, S.F.; Khan, H.U.; Siddiqui, M.R.H.; Al-Warthan, A.A.; Tremel, W. Graphene Based Metal and Metal Oxide Nanocomposites: Synthesis, Properties and their Applications. J. Mater. Chem. A 2015, 3, 18753-18808. [CrossRef]

41. Alonso-Vante, N. Platinum and Non-Platinum Nanomaterials for the Molecular Oxygen Reduction Reaction. Chemphyschem 2010, 11, 2732-2744. [CrossRef] [PubMed]

42. Tributsch, H.; Alonso-Vante, N. Energy Conversion Catalysis Using Semiconducting Transition Metal Cluster Compounds. Nature 1986, 323, 431-432.

43. Higgins, D.C.; Hassan, F.M.; Seo, M.H.; Choi, J.Y.; Hoque, M.A.; Lee, D.U.; Chen, Z. Shape-Controlled Octahedral Cobalt Disulfide Nanoparticles Supported on Nitrogen and Sulfur-Doped Graphene/Carbon Nanotube Composites for Oxygen Reduction in Acidic Electrolyte. J. Mater. Chem. A 2015, 3, 6340-6350. [CrossRef]

44. Delacôte, C.; Lewera, A.; Pisarek, M.; Kulesza, P.J.; Zelenay, P.; Alonso-Vante, N. The Effect of Diluting Ruthenium by Iron in $\mathrm{Ru}_{\mathrm{x}} \mathrm{Se}_{\mathrm{y}}$ Catalyst for Oxygen Reduction. Electrochim. Acta 2010, 55, 7575-7580. [CrossRef]

45. Lee, K.; Zhang, L.; Zhang, J.J. Ternary Non-Noble Metal Chalcogenide (W-Co-Se) as Electrocatalyst for Oxygen Reduction Reaction. Electrochem. Commun. 2007, 9, 1704-1708. [CrossRef] 
46. Zhao, C.; Li, D.Q.; Feng, Y.J. Size-Controlled Hydrothermal Synthesis and High Electrocatalytic Performance of $\mathrm{CoS}_{2}$ Nanocatalysts as Non-Precious Metal Cathode Materials for Fuel Cells. J. Mater. Chem. A 2013, 1, 5741-5746. [CrossRef]

47. Alonso-Vante, N.; Malakhov, I.V.; Nikitenko, S.G.; Savinova, E.R.; Kochubey, D.I. The Structure Analysis of the Active Centers of Ru-containing Electrocatalysts for the Oxygen Reduction. An in Situ EXAFS Study. Electrochim. Acta 2002, 47, 3807-3814. [CrossRef]

48. Behret, H.; Binder, H.; Sandstede, G. Electrocatalytic Oxygen Reduction with Thiospinels and Other Sulphides of Transition Metals. Electrochim. Acta 1975, 20, 111-117. [CrossRef]

49. Vayner, E.; Sidik, R.A.; Anderson, A.B.; Popov, B.N. Experimental and Theoretical Study of Cobalt Selenide as a Catalyst for $\mathrm{O}_{2}$ Electroreduction. J. Phys. Chem. C 2017, 111, 10508-10513. [CrossRef]

50. Baresel, D.; Sarholz, W.; Scharner, P.; Schmitz, J. Transition MetalChalcogenides as Oxygen Catalysts for Fuel Cells. Ber. Bunsenges. Phys. Chem. 1974, 78, 608-618.

51. Sidik, R.A.; Anderson, A.B. $\mathrm{Co}_{9} \mathrm{~S}_{8}$ as a Catalyst for Electroreduction of $\mathrm{O}_{2}$ : Quantum Chemistry Predictions. J. Phys. Chem. B 2006, 110, 936-941. [CrossRef] [PubMed]

52. Zhu, C.Y.; Aoki, Y.; Habazaki, H. $\mathrm{Co}_{9} \mathrm{~S}_{8}$ Nanoparticles Incorporated in Hierarchically Porous 3D Few-Layer Graphene-Like Carbon with S, N-Doping as Superior Electrocatalyst for Oxygen Reduction Reaction. Part. Part. Syst. Charact. 2017, 34, 1700296. [CrossRef]

53. Feng, Y.J.; Alonso-Vante, N. Structure Phase Transition and Oxygen Reduction Activity in Acidic Medium of Carbon-Supported Cobalt Selenide Nanoparticles. ECS Trans. 2009, 25, 167-173.

54. Feng, Y.J.; Alonso-Vante, N. Carbon-Supported CoSe 2 Nanoparticles for Oxygen Reduction Reaction in Acid Medium. Fuel Cells 2010, 10, 77-83.

55. Wu, G.; Chung, H.T.; Nelson, M.; Artyushkova, K.; More, K.L.; Johnston, C.M.; Zelenay, P. Graphene-Enriched $\mathrm{Cog}_{8} \mathrm{~S}_{8} \mathrm{~N}-\mathrm{C}$ Non-Precious Metal Catalyst for Oxygen Reduction in Alkaline Media. ECS Trans. 2011, 41, 1709-1717.

56. Apostolova, R.D.; Shembel, E.M.; Talyosef, I.; Grinblat, J.; Markovsky, B.; Aurbach, D. Study of Electrolytic Cobalt Sulfide $\mathrm{Co}_{9} \mathrm{~S}_{8}$ as an Electrode Material in Lithium Accumulator Prototypes. Russ. J. Electrochem. 2009, 45, 311-319. [CrossRef]

57. Handoko, A.D.; Deng, S.; Deng, Y.; Cheng, A.W.F.; Chan, K.W.; Tan, H.R.; Pan, Y.; Tok, E.S.; Sow, C.H.; Yeo, B.S. Enhanced Activity of $\mathrm{H}_{2} \mathrm{O}_{2}$-Treated Copper(II) Oxide Nanostructures for the Electrochemical Evolution of Oxygen. Catal. Sci. Technol. 2016, 6, 269-274. [CrossRef]

58. Antolini, E. Structural Parameters of Supported Fuel Cell Catalysts: The Effect of Particle Size, Inter-Particle Distance and Metal Loading on Catalytic Activity and Fuel Cell Performance. Appl. Catal. B 2016, 181, 298-313. [CrossRef]

59. Wang, J.X.; Inada, H.; Wu, L.J.; Zhu, Y.M.; Choi, Y.M.; Liu, P.; Zhou, W.P.; Adzic, R.R. Oxygen Reduction on Well-Defined Core-Shell Nanocatalysts: Particle Size, Facet, and Pt Shell Thickness Effects. J. Am. Chem. Soc. 2009, 131, 17298-17302. [CrossRef] [PubMed]

60. Feng, Y.J.; He, T.; Alonso-Vante, N. In Situ Free-surfactant Synthesis and ORR-electrochemistry of Carbon-Supported $\mathrm{Co}_{3} \mathrm{~S}_{4}$ and $\mathrm{CoSe}_{2}$ Nanoparticles. Chem. Mater. 2008, 20, 26-28. [CrossRef]

61. Feng, Y.J.; Alonso-Vante, N. Carbon-Supported Cubic CoSe ${ }_{2}$ Catalysts for Oxygen Reduction Reaction in Alkaline Medium. Electrochim. Acta 2012, 72, 129-133. [CrossRef]

62. Feng., Y.J.; He, T.; Alonso-Vante, N. Oxygen Reduction Reaction on Carbon-Supported CoSe ${ }_{2}$ Nanoparticles in an Acidic Medium. Electrochim. Acta 2009, 54, 5252-5256. [CrossRef]

63. Wood, K.N.; O'Hayre, R.; Pylypenko, S. Recent Progress on Nitrogen/Carbon Structures Designed for Use in Energy and Sustainability Applications. Energy Environ. Sci. 2014, 7, 1212-1249. [CrossRef]

64. Zhou, W.J.; Lu, L.; Zhou, K.; Yang, L.J.; Ke, Y.T.; Tang, Z.H.; Chen, S.W. CoSe 2 Nanoparticles Embedded Defective Carbon Nanotubes Derived from MOFs as Efficient Electrocatalyst for Hydrogen Evolution Reaction. Nano Energy 2016, 28, 143-150. [CrossRef]

65. Alonso-Vante, N. Photocatalysis an Enhancer of Electrocatalytic Process, Current Opinion in Electrochemistry. Curr. Opin. Electrochem. 2018, 9, 114-120. [CrossRef]

66. Unni, S.M.; Mora-Hernandez, J.M.; Kurungot, S.; Alonso-Vante, N. CoSe 2 Supported on Nitrogen-Doped Carbon Nanohorns as a Methanol-Tolerant Cathode for Air-Breathing Microlaminar Flow Fuel Cells. ChemElectroChem 2015, 2, 1339-1345. [CrossRef] 
67. García-Rosado, I.J.; Uribe-Calderón, J.; Alonso-Vante, N. Nitrogen-Doped Reduced Graphite Oxide as a Support for CoSe Electrocatalyst for Oxygen Reduction Reaction in Alkaline Media. J. Electrochem. Soc. 2017, 164, F658-F666. [CrossRef]

68. Zhu, A.Q.; Tan, P.F.; Qiao, L.L.; Liu, Y.; Ma, Y.J.; Pan, J. Sulphur and Nitrogen Dual-Doped Mesoporous Carbon Hybrid Coupling with Graphite Coated Cobalt and Cobalt Sulfide Nanoparticles: Rational Synthesis and Advanced Multifunctional Electrochemical Properties. J. Colloid Interface Sci. 2018, 509, 254-264. [CrossRef] [PubMed]

69. Hu, H.; Han, L.; Yu, M.; Wang, Z.Y.; Lou, X.W. Metal-Organic-Framework-Engaged Formation of Co Nanoparticle-Embedded Carbon@Co $\mathrm{S}_{8}$ Double-Shelled Nanocages for Efficient Oxygen Reduction. Energy Environ. Sci. 2016, 9, 107-111. [CrossRef]

70. Chen, B.L.; Li, R.; Ma, G.P.; Gou, X.L.; Zhu, Y.Q.; Xia, Y.D. Cobalt Sulfide/N, S Codoped Porous Carbon Core-Shell Nanocomposites as Superior Bifunctional Electrocatalysts for Oxygen Reduction and Evolution Reactions. Nanoscale 2015, 7, 20674-20684. [CrossRef] [PubMed]

71. Tao, L.Q.; Zai, J.T.; Wang, K.X.; Zhang, H.J.; Xu, M.; Shen, J.; Su, Y.Z.; Qian, X.F. $\mathrm{Co}_{3} \mathrm{O}_{4}$ Nanorods/Graphene Nanosheets Nanocomposites for Lithium Ion Batteries with Improved Reversible Capacity and Cycle Stability. J. Power Sources 2012, 202, 230-235. [CrossRef]

72. Bai, G.M.; Dai, H.X.; Deng, J.G.; Liu, Y.X.; Wang, F.; Zhao, Z.X.; Qiu., W.G.; Au, C.T. Porous $\mathrm{Co}_{3} \mathrm{O}_{4} \mathrm{Nannowires}$ and Nanorods: Highly Active Catalysts for the Combustion of Toluene. Appl. Catal. A 2013, 450, 42-49. [CrossRef]

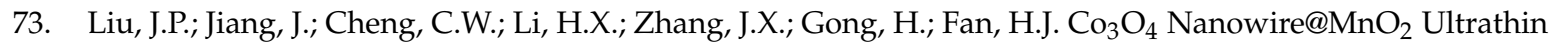
Nanosheet Core/Shell Arrays: A New Class of High-Performance Pseudocapacitive Materials. Adv. Mater. 2011, 23, 2076-2081. [CrossRef] [PubMed]

74. Wang, Y.Y.; Lei, Y.; Li, J.; Gu, L.; Yuan, H.Y.; Xiao, D. Synthesis of 3D-Nanonet Hollow Structured $\mathrm{Co}_{3} \mathrm{O}_{4}$ for High Capacity Supercapacitor. ACS Appl. Mater. Interfaces 2014, 6, 6739-6747. [CrossRef] [PubMed]

75. Singh, S.K.; Dhavale, V.M.; Kurungot, S. Surface-Tuned $\mathrm{Co}_{3} \mathrm{O}_{4}$ Nanoparticles Dispersed on Nitrogen-Doped Graphene as an Efficient Cathode Electrocatalyst for Mechanical Rechargeable Zinc-Air Battery Application. ACS Appl. Mater. Interfaces 2015, 7, 21138-21149. [CrossRef] [PubMed]

76. Jia, X.D.; Gao, S.J.; Liu, T.Y.; Li, D.Q.; Tang, P.G.; Feng, Y.J. Controllable Synthesis and Bi-Functional Electrocatalytic Performance towards Oxygen Electrode Reactions of $\mathrm{Co}_{3} \mathrm{O}_{4} / \mathrm{N}-\mathrm{RGO}$ Composites. Electrochim. Acta 2017, 226, 104-112. [CrossRef]

77. Liu, J.; Jiang, L.H.; Zhang, B.S.; Jin, J.T.; Su, D.S.; Wang, S.L.; Sun, G.Q. Controllable Synthesis of Cobalt Monoxide Nanoparticles and the Size-Dependent Activity for Oxygen Reduction Reaction. ACS Catal. 2014, 4, 2998-3001. [CrossRef]

78. Wang, J.K.; Gao, R.; Zhou, D.; Chen, Z.j.; Wu, Z.H.; Schumacher, G.; Hu, Z.B.; Liu, X.F. Boosting the Electrocatalytic Activity of $\mathrm{Co}_{3} \mathrm{O}_{4}$ Nanosheets for a $\mathrm{Li}^{-\mathrm{O}_{2}}$ Battery through Modulating Inner Oxygen Vacancy and Exterior $\mathrm{Co}^{3+} / \mathrm{Co}^{2+}$ Ratio. ACS Catal. 2017, 7, 6533-6541. [CrossRef]

79. Xu, J.B.; Gao, P.; Zhao, T.S. Non-Precious $\mathrm{Co}_{3} \mathrm{O}_{4}$ Nano-Rod Electrocatalyst for Oxygen Reduction Reaction in Anion-Exchange Membrane Fuel Cells. Energy Environ. Sci. 2012, 5, 5333-5339. [CrossRef]

80. Odedairo, T.; Yan, X.C.; Ma, J.; Jiao, Y.L.; Yao, X.D.; Du, A.J.; Zhu, Z.H. Nanosheets $\mathrm{Co}_{3} \mathrm{O}_{4}$ Interleaved with Graphene for Highly Efficient Oxygen Reduction. ACS Appl. Mater. Interfaces 2015, 7, 21373-21380. [CrossRef] [PubMed]

81. Chen, Z.Y.; Li, Y.N.; Wang, M.Q.; Xu, M.W.; Bao, S.J. Hollow $\mathrm{Co}_{3} \mathrm{O}_{4}$ Nanocages Decorated Graphene Aerogels Derived from Carbon Wrapped Nano-Co for Efficient Oxygen Reduction Reaction. ChemistrySelect 2017, 2, 6359-6363. [CrossRef]

82. Wu, Z.X.; Wang, J.; Han, L.L.; Lin, R.Q.; Liu, H.F.; Xin, H.L.L.; Wang, D.L. Supramolecular Gel-Assisted Synthesis of Double Shelled Co@CoO@N-C/C Nanoparticles with Synergistic Electrocatalytic Activity for the Oxygen Reduction Reaction. Nanoscale 2016, 8, 4681-4687. [CrossRef] [PubMed]

83. Wang, D.D.; Chen, X.; Evans, D.G.; Yang, W.S. Well-Dispersed $\mathrm{Co}_{3} \mathrm{O}_{4} / \mathrm{Co}_{2} \mathrm{MnO}_{4}$ Nanocomposites as a Synergistic Bifunctional Catalyst for Oxygen Reduction and Oxygen Evolution Reactions. Nanoscale 2013, 5 , 5312-5315. [CrossRef] [PubMed]

84. Huang, W.; Zhong, H.H.; Li, D.Q.; Tang, P.G.; Feng, Y.J. Reduced Graphene Oxide Supported CoO/ $\mathrm{MnO}_{2}$ Electrocatalysts from Layered Double Hydroxides for Oxygen Reduction Reaction. Electrochim. Acta 2015, 173, 575-580. [CrossRef] 
85. Wang, Y.L.; Wang, Z.C.; Wu, X.Q.; Liu, X.W.; Li, M.G. Synergistic Effect between Strongly Coupled CoAl Layered Double Hydroxides and Graphene for the Electrocatalytic Reduction of Oxygen. Electrochim. Acta 2016, 192, 196-204. [CrossRef]

86. Huo, R.J.; Jiang, W.J.; Xu, S.L.; Zhang, F.Z.; Hu, J.S. Co/CoO/CoFe $\mathrm{O}_{4} / \mathrm{G}$ Nanocomposites Derived from Layered Double Hydroxides towards Mass Production of Efficient Pt-Free Electrocatalysts for Oxygen Reduction Reaction. Nanoscale 2014, 6, 203-206. [CrossRef] [PubMed]

87. Jasinski, R. A New Fuel Cell Cathode Catalyst. Nature 1964, 21, 1212-1213. [CrossRef]

88. Wu, G.; More, K.L.; Johnston, C.M.; Zelenay, P. High-Performance Electrocatalysts for Oxygen Reduction Derived from Polyaniline, Iron, and Cobalt. Science 2011, 332, 443-447. [CrossRef] [PubMed]

89. Kothandaraman, R.; Nallathambi, V.; Artyushkova, K.; Barton, S.C. Non-Precious Oxygen Reduction Catalysts Prepared by High-Pressure Pyrolysis for Low-Temperature Fuel Cells. Appl. Catal. B 2009, 92, 209-216. [CrossRef]

90. Bashyam, R.; Zelenay, P. A Class of Non-Precious Metal Composite Catalysts for Fuel Cells. Nature 2006, 443, 63-66. [CrossRef] [PubMed]

91. Morozan, A.; Jegou, P.; Jousselme, B.; Palacin, S. Electrochemical Performance of Annealed Cobalt-Benzotriazole/CNTs Catalysts towards the Oxygen Reduction Reaction. Phys. Chem. Chem. Phys. 2011, 13, 21600-21607. [CrossRef] [PubMed]

92. Chen, X.; Li, F.; Zhang, N.L.; An, L.; Xia, D.G. Mechanism of Oxygen Reduction Reaction Catalyzed by $\mathrm{Fe}(\mathrm{Co})-\mathrm{N}_{\mathrm{x}} / \mathrm{C}$. Phys. Chem. Chem. Phys. 2013, 15, 19330-19336. [CrossRef] [PubMed]

93. Jia, Q.Y.; Ramaswamy, N.; Tylus, U.; Strickland, K.; Li, J.K.; Serov, A.; Artyushkova, K.; Atanassov, P.; Anibal, J.; Gumeci, C.; et al. Spectroscopic Insights into the Nature of Active Sites in Iron-Nitrogen-Carbon Electrocatalysts for Oxygen Reduction in Acid. Nano Energy 2016, 29, 65-82. [CrossRef]

94. Wong, W.Y.; Daud, W.R.W.; Mohamad, A.B.; Kadhum, A.A.H.; Loh, K.S.; Majlan, E.H. Recent Progress in Nitrogen-Doped Carbon and its Composites as Electrocatalysts for Fuel Cell Applications. Int. J. Hydrogen Energy 2013, 38, 9370-9386. [CrossRef]

95. Niwa, H.; Horiba, K.; Harada, Y.; Oshima, M.; Ikeda, T.; Terakura, K.; Ozaki, J.; Miyata, S. X-ray Absorption Analysis of Nitrogen Contribution to Oxygen Reduction Reaction in Carbon Alloy Cathode Catalysts for Polymer Electrolyte Fuel Cells. J. Power Sources 2009, 187, 93-97. [CrossRef]

96. Hu, C.G.; Xiao, Y.; Zhao, Y.; Chen, N.; Zhang, Z.P.; Cao, M.H.; Qu, L.T. Highly Nitrogen-Doped Carbon Capsules: Scalable Preparation and High-Performance Applications in Fuel Cells and Lithium Ion Batteries. Nanoscale 2013, 5, 2726-2733. [CrossRef] [PubMed]

97. Kattel, S.; Atanassov, P.; Kiefer, B. Catalytic Activity of Co-N $\mathrm{N}_{\mathrm{x}} / \mathrm{C}$ Electrocatalysts for Oxygen Reduction Reaction: A Density Functional Theory Study. Phys. Chem. Chem. Phys. 2013, 15, 148-153. [CrossRef] [PubMed]

98. Yin, P.Q.; Yao, T.; Wu, Y.; Zheng, L.R.; Lin, Y.; Liu, W.; Ju, H.X.; Zhu, J.F.; Hong, X.; Deng, Z.X.; et al. Single Cobalt Atoms with Precise N-Coordination as Superior Oxygen Reduction Reaction Catalysts. Angew. Chem. Int. Ed. Engl. 2016, 55, 10800-10805. [CrossRef] [PubMed]

99. Amiinu, I.S.; Liu, X.B.; Pu, Z.H.; Li, W.Q.; Li, Q.D.; Zhang, J.; Tang, H.L.; Zhang, H.N.; Mu, S.C. From 3D ZIF Nanocrystals to Co-N $\mathrm{N}_{\mathrm{x}} / \mathrm{C}$ Nanorod Array Electrocatalysts for ORR, OER, and Zn-Air Batteries. Adv. Funct. Mater. 2018, 28, 1704638-1704646. [CrossRef]

100. Peng, H.L.; Liu, F.F.; Liu, X.J.; Liao, S.J.; You, C.H.; Tian, X.L.; Nan, H.X.; Luo, F.; Song, H.Y.; Fu, Z.Y.; et al. Effect of Transition Metals on the Structure and Performance of the Doped Carbon Catalysts Derived From Polyaniline and Melamine for ORR Application. ACS Catal. 2014, 4, 3797-3805. [CrossRef]

101. Wiesener, K. $\mathrm{N}_{4}$-Chelates as Electrocatalyst for Cathodic Oxygen Reduction. Electrochim. Acta 1986, 31, 1073-1078. [CrossRef]

102. Masa, J.; Xia, W.; Muhler, M.; Schuhmann, W. On the Role of Metals in Nitrogen-Doped Carbon Electrocatalysts for Oxygen Reduction. Angew. Chem. Int. Ed. Engl. 2015, 54, 10102-10120. [CrossRef] [PubMed]

103. Bagotzky, V.S.; Tarasevich, M.R.; Radyushkina, K.A.; Levina, O.A.; Andrusyova, S.I. Electrocatalysis of the Oxygen Reduction Process on Metal Chelates in Acid Electrolyte. J. Power Sources 1978, 2, 233-240. [CrossRef]

104. Wiesener, K.; Ohms, D.; Neumann, V.; Franke, R. $\mathrm{N}_{4}$ Macrocycles as Electrocatalysts for the Cathodic Reduction of Oxygen. Mater. Chem. Phys. 1989, 22, 457-475. [CrossRef] 
105. Liu, Y.Y.; Yue, X.P.; Li, K.X.; Qiao, J.L.; Wilkinson, D.P.; Zhang, J.J. PEM Fuel Cell Electrocatalysts Based on Transition Metal Macrocyclic Compounds. Coord. Chem. Rev. 2016, 315, 153-177. [CrossRef]

106. Osmieri, L.; Videla, A.H.A.M.; Specchia, S. Activity of Co-N Multi Walled Carbon Nanotubes Electrocatalysts for Oxygen Reduction Reaction in Acid Conditions. J. Power Sources 2015, 278, 296-307. [CrossRef]

107. Nallathambi, V.; Lee, J.W.; Kumaraguru, S.P.; Wu, G.; Popov, B.N. Development of High Performance Carbon Composite Catalyst for Oxygen Reduction Reaction in PEM Proton Exchange Membrane Fuel Cells. J. Power Sources 2008, 183, 34-42. [CrossRef]

108. Lalande, G.; Côté, R.; Tamizhmani, G.; Guay, D.; Dodelet, J.P.; Dignard-Bailey, L.; Weng, L.T.; Bertrand, P. Physical, Chemical and Electrochemical Characterization of Heat-Treated Tetracarboxylic Cobalt Phthalocyanine Adsorbed on Carbon Black as Electrocatalyst for Oxygen Reduction in Polymer Electrolyte Fuel Cells. Electrochim. Acta 1995, 40, 2635-2646. [CrossRef]

109. Weng, L.T.; Bertrand, P.; Lalande, G.; Guay, D.; Dodelet, J.P. Surface Characterization by Time-of-Flight SIMS of a Catalyst for Oxygen Electroreduction: Pyrolyzed Cobalt Phthalocyanine-on-Carbon Black. Appl. Surf. Sci. 1985, 84, 9-21. [CrossRef]

110. Jahnke, H.; Schōnborn, M.; Zirnmermann, G. Organic Dyestuffs as Catalysts for Fuel Cells. Top. Curr. Chem. 1976, 61, 133-181. [PubMed]

111. Kong, A.G.; Kong, Y.Y.; Zhu, X.F.; Han, Z.; Shan, Y.K. Ordered Mesoporous Fe (or Co)-N-Graphitic Carbons as Excellent Non-Precious-Metal Electrocatalysts for Oxygen Reduction. Carbon 2014, 78, 49-59. [CrossRef]

112. Tang, C.; Wang, B.; Wang, H.F.; Zhang, Q. Defect Engineering toward Atomic Co- $\mathrm{N}_{\mathrm{x}}-\mathrm{C}$ in Hierarchical Graphene for Rechargeable Flexible Solid Zn-Air Batteries. Adv. Mater. 2017, 29, 1703185-1703191. [CrossRef] [PubMed]

113. Zhang, L.L.; Wang, A.Q.; Wang, W.T.; Huang, Y.Q.; Liu, X.Y.; Miao, S.; Liu, J.Y.; Zhang, T. Co-N-C Catalyst for C-C Coupling Reactions: On the Catalytic Performance and Active Sites. ACS Catal. 2015, 5, 6563-6572. [CrossRef]

114. Hu, F.; Yang, H.C.; Wang, C.H.; Zhang, Y.J.; Lu, H.; Wang, Q.B. Co-N-Doped Mesoporous Carbon Hollow Spheres as Highly Efficient Electrocatalysts for Oxygen Reduction Reaction. Small 2017, 13, 1602507-1602514. [CrossRef] [PubMed]

115. Cai, S.C.; Meng, Z.H.; Tang, H.L.; Wang, Y.; Tsiakaras, P. 3D Co-N-doped Hollow Carbon Spheres as Excellent Bifunctional Electrocatalysts for Oxygen Reduction Reaction and Oxygen Evolution Reaction. Appl. Catal. B 2017, 217, 477-484. [CrossRef]

116. Aijaz, A.; Masa, J.; Rosler, C.; Xia, W.; Weide, P.; Botz, A.J.R.; Fischer, R.A.; Schuhmann, W.; Muhler, M. $\mathrm{Co} @ \mathrm{Co}_{3} \mathrm{O}_{4}$ Encapsulated in Carbon Nanotube-Grafted Nitrogen-Doped Carbon Polyhedra as an Advanced Bifunctional Oxygen Electrode. Angew. Chem. Int. Ed. Engl. 2016, 55, 4087-4091. [CrossRef] [PubMed]

117. Kuang, M.; Wang, Q.; Han, P.; Zheng, G.F. Cu, Co-Embedded N-Enriched Mesoporous Carbon for Efficient Oxygen Reduction and Hydrogen Evolution Reactions. Adv. Energy Mater. 2017, 7, 1700193-1700200. [CrossRef]

118. Lin, Q.P.; Bu, X.H.; Kong, A.G.; Mao, C.Y.; Bu, F.; Feng, P.Y. Heterometal-Embedded Organic Conjugate Frameworks from Alternating Monomeric Iron and Cobalt Metalloporphyrins and Their Application in Design of Porous Carbon Catalysts. Adv. Mater. 2015, 27, 3431-3436. [CrossRef] [PubMed]

119. Fan, X.J.; Peng, Z.W.; Ye, R.Q.; Zhou, H.Q.; Guo, X. M 3 C (M: Fe, Co, Ni) Nanocrystals Encased in Graphene Nanoribbons: An Active and Stable Bifunctional Electrocatalyst for Oxygen Reduction and Hydrogen Evolution Reactions. ACS Nano 2015, 9, 7407-7418. [CrossRef] [PubMed]

120. Zhu, L.; Teo, M.; Wong, P.C.; Wong, K.C.; Narita, I.; Ernst, F.; Mitchell, K.A.R.; Campbell, S.A. Synthesis, Characterization of $\mathrm{C} \mathrm{CoSe}_{2}$ Catalyst for the Oxygen Reduction Reaction. Appl. Catal. A 2010, 386, $157-165$. [CrossRef]

121. Qiao, X.C.; Jin, J.T.; Fan, H.B.; Li, Y.W.; Liao, S.J. In Situ Growth of Cobalt Sulfide Hollow Nanospheres Embedded in Nitrogen and Sulfur Co-doped Graphene Nanoholes as a Highly Active Electrocatalyst for Oxygen Reduction and Evolution. J. Mater. Chem. A 2017, 5, 12354-12360. [CrossRef]

122. Liang, H.; Li, C.W.; Chen, T.; Cui, L.; Han, J.R.; Peng, Z.; Liu, J.Q. Facile Preparation of Three-Dimensional $\mathrm{Co}_{1-x} \mathrm{~S} /$ Sulfur and Nitrogen-Codoped Graphene/Carbon Foam for Highly Efficient Oxygen Reduction Reaction. J. Power Sources 2018, 378, 699-706. [CrossRef] 
123. Zhang, Y.; Li, P.W.; Yin, X.Y.; Yan, Y.; Zhan, K.; Yang, J.H.; Zhao, B. Cobalt Sulfide Supported on Nitrogen and Sulfur Dual-Doped Reduced Graphene Oxide for Highly Active Oxygen Reduction Reaction. RSC Adv. 2017, 7, 50246-50253. [CrossRef]

124. Ganesan, P.; Prabu, M.; Sanetuntikul, J.; Shanmugam, S. Cobalt Sulfide Nanoparticles Grown on Nitrogen and Sulfur Codoped Graphene Oxide: An Efficient Electrocatalyst for Oxygen Reduction and Evolution Eeactions. ACS Catal. 2015, 5, 3625-3637. [CrossRef]

125. Mahmood, N.; Zhang, C.Z.; Jiang, J.; Liu, F.; Hou, Y.L. Multifunctional $\mathrm{Co}_{3} \mathrm{~S}_{4} /$ Graphene Composites for Lithium Ion Batteries and Oxygen Reduction Reaction. Chem. Eur. J. 2013, 19, 5183-5190. [CrossRef] [PubMed]

126. Sennu, P.; Christy, M.; Aravindan, V.; Lee, Y.G.; Nahm, K.S.; Lee, Y.S. Two-Dimensional Mesoporous Cobalt Sulfide Nanosheets as a Superior Anode for a Li-Ion Battery and a Bifunctional Electrocatalyst for the $\mathrm{LiO}_{2}$ System. Chem. Mater. 2015, 27, 5726-5735. [CrossRef]

127. Arunchander, A.; Peera, S.G.; Giridhar, V.V.; Sahu, A.K. Synthesis of Cobalt Sulfide-Graphene as an Efficient Oxygen Reduction Catalyst in Alkaline Medium and its Application in Anion Exchange Membrane Fuel Cells. J. Electrochem. Soc. 2016, 164, F71-F80. [CrossRef]

128. Fu, S.F.; Zhu, C.Z.; Song, J.H.; Feng, S.; Du, D.; Engelhard, M.H.; Xiao, D.D.; Li, D.S.; Lin, Y.H. Two-Dimensional N, S-Codoped Carbon/Cog $\mathrm{S}_{8}$ Catalysts Derived from $\mathrm{Co}(\mathrm{OH})_{2}$ Nanosheets for Oxygen Reduction Reaction. ACS Appl. Mater. Interfaces 2017, 9, 36755-36761. [CrossRef] [PubMed]

129. Zhou, Y.X.; Yao, H.B.; Wang, Y.; Liu, H.L.; Gao, M.R.; Shen, P.K.; Yu, S.H. Hierarchical Hollow Cog $S_{8}$ Microspheres: Solvothermal Synthesis, Magnetic, Electrochemical, and Electrocatalytic Properties. Chemistry 2010, 16, 12000-12007. [CrossRef] [PubMed]

130. Tang, Y.P.; Jing, F.; Xu, Z.X.; Zhang, F.; Mai, Y.Y.; Wu, D.Q. Highly Crumpled Hybrids of Nitrogen/Sulfur Dual-Doped Graphene and $\mathrm{Co}_{9} \mathrm{~S}_{8}$ Nanoplates as Efficient Bifunctional Oxygen Electrocatalysts. ACS Appl. Mater. Interfaces 2017, 9, 12340-12347. [CrossRef] [PubMed]

131. Mattioli, G.; Giannozzi, P.; Bonapasta, A.A.; Guidoni, L. Reaction Pathways for Oxygen Evolution Promoted by Cobalt Catalyst. J. Am. Chem. Soc. 2013, 135, 15353-15363. [CrossRef] [PubMed]

132. García-Mota, M.; Bajdich, M.; Viswanathan, V.; Vojvodic, A.; Bell, A.T.; Nørskov, J.K. Importance of Correlation in Determining Electrocatalytic Oxygen Evolution Activity on Cobalt Oxides. J. Phys. Chem. C 2012, 116, 21077-21082. [CrossRef]

133. Bajdich, M.; Garcia-Mota, M.; Vojvodic, A.; Norskov, J.K.; Bell, A.T. Theoretical Investigation of the Activity of Cobalt Oxides for the Electrochemical Oxidation of Water. J. Am. Chem. Soc. 2013, 135, 13521-13530. [CrossRef] [PubMed]

134. Liu, Y.W.; Cheng, H.; Lyu, M.J.; Fan, S.J.; Liu, Q.H.; Zhang, W.S.; Zhi, Y.D.; Wang, C.M.; Xiao, C.; Wei, S.Q.; et al. Low Overpotential in Vacancy-Rich Ultrathin $\mathrm{CoSe}_{2}$ Nanosheets for Water Oxidation. J. Am. Chem. Soc. 2014, 136, 15670-15675. [CrossRef] [PubMed]

135. Gao, M.R.; Cao, X.; Gao, Q.; Xu, Y.F.; Zheng, Y.R.; Jiang, J.; Yu, S. Nitrogen-Doped Graphene Supported $\mathrm{CoSe}_{2}$ Nanobelt Composite Catalyst for Efficient Water Oxidation. ACS Nano 2014, 8, 3970-3978. [CrossRef] [PubMed]

136. Guo, Y.X.; Yao, Z.Y.; Shang, C.S.; Wang, E.K. Amorphous $\mathrm{Co}_{2} \mathrm{~B}$ Grown on $\mathrm{CoSe}_{2}$ Nanosheets as a Hybrid Catalyst for Efficient Overall Water Splitting in Alkaline Medium. ACS Appl. Mater. Interfaces 2017, 9, 39312-39317. [CrossRef] [PubMed]

137. Lyons, M.E.G.; Brandon, M.P. The Oxygen Evolution Reaction on Passive Oxide Covered Transition Metal Electrodes in Alkaline Solution. Part III - Iron. Int. J. Electrochem. Sci. 2008, 3, 1425-1462.

138. Yeo, B.S.; Bell, A.T. Enhanced Activity of Gold-Supported Cobalt Oxide for the Electrochemical Evolution of Oxygen. J. Am. Chem. Soc. 2011, 133, 5587-5593. [CrossRef] [PubMed]

139. Simmons, G.W.; Kellerman, E.; Leidheiser, H.J. In Situ Studies of the Passivation and Anodic Oxidation of Cobalt by Emission Moessbauer Spectroscopy. J. Electrochem. Soc. 1976, 123, 1276-1284. [CrossRef]

140. Liu, J.; Liu, Y.; Liu, N.Y.; Han, Y.Z.; Zhang, X.; Huang, H.; Lifshitz, Y.; Lee, S.T.; Zhong, J.; Kang, Z.H. Metal-Free Efficient Photocatalyst for Stable Visible Water Splitting via A Two-Electron Pathway. Science 2015, 347, 970-974. [CrossRef] [PubMed]

141. Barkaoui, S.; Haddaoui, M.; Dhaouadi, H.; Raouafi, N.; Touati, F. Hydrothermal Synthesis of Urchin-Like $\mathrm{Co}_{3} \mathrm{O}_{4}$ Nanostructures and their Electrochemical Sensing Performance of $\mathrm{H}_{2} \mathrm{O}_{2}$. J. Solid State Chem. 2015, 228, 226-231. [CrossRef] 
142. Du, S.C.; Ren, Z.Y.; Qu, Y.; Wu, J.; Xi, W.; Zhu, J.Q.; Fu, H.G. $\mathrm{Co}_{3} \mathrm{O}_{4}$ Nanosheets as a High-Performance Catalyst for Oxygen Evolution Proceeding via a Double Two-Electron Process. Chem. Commun. 2016, 52, 6705-6708. [CrossRef] [PubMed]

143. Wang, Y.C.; Zhou, T.; Jiang, K.; Da, P.M.; Peng, Z.; Tang, J.; Kong, B.A.; Cai, W.B.; Yang, Z.Q.; Zheng, G.F. Reduced Mesoporous $\mathrm{Co}_{3} \mathrm{O}_{4}$ Nanowires as Efficient Water Oxidation Electrocatalysts and Supercapacitor Electrodes. Adv. Energy Mater. 2014, 4, 1400696-1400702. [CrossRef]

144. Xia, Y.S.; Dai, H.X.; Jiang, H.Y.; Zhang, L. Three-Dimensional Ordered Mesoporous Cobalt Oxides: Highly Active Catalysts for the Oxidation of Toluene and Methanol. Catal. Commun. 2010, 11, 1171-1175. [CrossRef]

145. Zhao, Y.F.; Chen, S.Q.; Sun, B.; Su, D.W.; Huang, X.D.; Liu, H.; Yan, Y.M.; Sun, K.N.; Wang, G.X. Graphene- $\mathrm{Co}_{3} \mathrm{O}_{4}$ Nanocomposite as Electrocatalyst with High Performance for Oxygen Evolution Reaction. Sci. Rep. 2015, 5, 7629-7635. [CrossRef] [PubMed]

146. Jadhav, A.R.; Bandal, H.A.; Tamboli, A.H.; Kim, H. Environment Friendly Hydrothermal Synthesis of Carbon- $\mathrm{Co}_{3} \mathrm{O}_{4}$ Nanorods Composite as an Efficient Catalyst for Oxygen Evolution Reaction. J. Energy Chem. 2017, 26, 695-702. [CrossRef]

147. Du, S.C.; Ren, Z.Y.; Zhang, J.; Wu, J.; Xi, W.; Zhu, J.Q.; Fu, H.G. $\mathrm{Co}_{3} \mathrm{O}_{4}$ Nanocrystal Ink Printed on Carbon Fiber Paper as a Large-Area Electrode for Electrochemical Water Splitting. Chem. Commun. 2015, 51, 8066-8069. [CrossRef] [PubMed]

148. Wei, Y.C.; Ren, X.; Ma, H.M.; Sun, X.; Zhang, Y.; Kuang, X.; Yan, T.; Ju, H.X.; Wu, D.; Wei, Q. CoC $\mathrm{O}_{4} \cdot 2 \mathrm{H}_{2} \mathrm{O}$ Derived $\mathrm{Co}_{3} \mathrm{O}_{4}$ Nanorods Array: A High-Efficiency 1D Electrocatalyst for Alkaline Oxygen Evolution Reaction. Chem. Commun. 2018, 54, 1533-1536. [CrossRef] [PubMed]

149. Nai, J.W.; Yin, H.J.; You, T.T.; Zheng, L.R.; Zhang, J.; Wang, P.X.; Jin, Z.; Tian, Y.; Liu, J.Z.; Tang, Z.Y.; et al. Efficient Electrocatalytic Water Oxidation by Using Amorphous Ni-Co Double Hydroxides Nanocages. Adv. Energy Mater. 2015, 5, 1401880-1401887. [CrossRef]

150. Surendranath, Y.; Lutterman, D.A.; Liu, Y.; Nocera, D.G. Nucleation, Growth, and Repair of Acobalt-Based Oxygen Evolving Catalyst. J. Am. Chem. Soc. 2012, 134, 6326-6336. [CrossRef] [PubMed]

151. Ni, B.; Wang, X. Edge Overgrowth of Spiral Bimetallic Hydroxides Ultrathin-Nanosheets for Water Oxidation. Chem. Sci. 2015, 6, 3572-3576. [CrossRef] [PubMed]

152. Wu, J.; Ren, Z.Y.; Du, S.C.; Kong, L.J.; Liu, B.W.; Xi, W.; Zhu, J.Q.; Fu, H.G. A Highly Active Oxygen Evolution Electrocatalyst: Ultrathin CoNi Double Hydroxide/CoO Nanosheets Synthesized via Interface-Directed Assembly. Nano Res. 2016, 9, 713-725. [CrossRef]

153. Maiyalagan, T.; Jarvis, K.A.; Therese, S.; Ferreira, P.J.; Manthiram, A. Spinel-Type Lithium Cobalt Oxide as a Bifunctional Electrocatalyst for the Oxygen Evolution and Oxygen Reduction Reactions. Nat. Commun. 2014, 5, 3949-3956. [CrossRef] [PubMed]

154. Qian, L.; Lu, Z.Y.; Xu, T.H.; Wu, X.C.; Tian, Y.; Li, Y.P.; Huo, Z.Y.; Sun, X.M.; Duan, X. Trinary Layered Double Hydroxides as High-Performance Bifunctional Materials for Oxygen Electrocatalysis. Adv. Energy Mater. 2015, 5, 1500245-1500250. [CrossRef]

155. Grimaud, A.; May, K.J.; Carlton, C.E.; Lee, Y.L.; Risch, M.; Hong, W.T.; Zhou, J.G.; Shao-Horn, Y. Double Perovskites as a Family of Highly Active Catalysts for Oxygen Evolution in Alkaline Solution. Nat. Commun. 2013, 4, 2439-2745. [CrossRef] [PubMed]

156. Lukowski, M.A.; Daniel, A.S.; Meng, F.; Forticaux, A.; Li, L.S.; Jin, S. Enhanced Hydrogen Evolution Catalysis from Chemically Exfoliated Metallic $\mathrm{MoS}_{2}$ Nanosheets. J. Am. Chem. Soc. 2013, 135, 10274-10277. [CrossRef] [PubMed]

157. Voiry, D.; Yamaguchi, H.; Li, J.W.; Silva, R.; Alves, D.C.B.; Fujita, T.; Chen, M.W.; Asefa, T.; Shenoy, V.B.; Eda, G.; et al. Enhanced Catalytic Activity in Strained Chemically Exfoliated $\mathrm{WS}_{2}$ Nanosheets for Hydrogen Evolution. Nat. Mater. 2013, 12, 850-855. [CrossRef] [PubMed]

158. Yu, L.; Yan, Y.X.; Liu, Q.; Wang, J.; Yang, B.; Wang, B.; Jing, X.Y.; Liu, L.H. Exfoliation at Room Temperature for Improving Electrochemical Performance for Supercapacitors of Layered $\mathrm{MnO}_{2}$. J. Electrochem. Soc. 2013, 161, E1-E5. [CrossRef]

159. Song, F.; Hu, X.L. Exfoliation of Layered Double Hydroxides for Enhanced Oxygen Evolution Catalysis. Nat. Commun. 2014, 5, 4477-4485. [CrossRef] [PubMed]

160. Liang, H.F.; Meng, F.; Caban-Acevedo, M.; Li, L.S.; Forticaux, A.; Xiu, L.C.; Wang, Z.C.; Jin, S. Hydrothermal Continuous Flow Synthesis and Exfoliation of NiCo Layered Double Hydroxide Nanosheets for Enhanced Oxygen Evolution Catalysis. Nano Lett. 2015, 15, 1421-1427. [CrossRef] [PubMed] 
161. Zhao, S.; Yan, L.T.; Luo, H.; Mustain, W.; Xu, H. Recent Progress and Perspectives of Bifunctional Oxygen Reduction/Evolution Catalyst Development for Regenerative Anion Exchange Membrane Fuel Cells. Nano Energy 2018, 47, 172-198. [CrossRef]

162. Mamlouk, M.; Kumar, S.M.S.; Gouerec, P.; Scott, K. Electrochemical and Fuel Cell Evaluation of Co Based Catalyst for Oxygen Reduction in Anion Exchange Polymer Membrane Fuel Cells. J. Power Sources 2011, 196, 7594-7600. [CrossRef]

163. Wu, X.; Scott, K. A Non-Precious Metal Bifunctional Oxygen Electrode for Alkaline Anion Exchange Membrane Cells. J. Power Sources 2012, 206, 14-19. [CrossRef]

164. Kong, D.S.; Cha, J.J.; Wang, H.T.; Lee, H.R.; Cui, Y. First-Row Transition Metal Dichalcogenide Catalysts for Hydrogen Evolution Reaction. Energy Environ. Sci. 2013, 6, 3553-3558. [CrossRef]

165. Anantharaj, S.; Ede, S.R.; Sakthikumar, K.; Karthick, K.; Mishra, S.; Kundu, S. Recent Trends and Perspectives in Electrochemical Water Splitting with an Emphasis on Sulfide, Selenide, and Phosphide Catalysts of Fe, Co, and Ni: A Review. ACS Catal. 2016, 6, 8069-8097. [CrossRef]

166. Liu, Q.; Shi, J.L.; Hu, J.M.; Asiri, A.M.; Luo, Y.L.; Sun, X.P. CoSe 2 Nanowires Array as a 3D Electrode for Highly Efficient Electrochemical Hydrogen Evolution. ACS Appl. Mater. Interfaces 2015, 7, 3877-3881. [CrossRef] [PubMed]

167. Zhang, H.X.; Yang, B.; Wu, X.L.; Li, Z.J.; Lei, L.C.; Zhang, X.W. Polymorphic CoSe 2 with Mixed Orthorhombic and Cubic Phases for Highly Efficient Hydrogen Evolution Reaction. ACS Appl. Mater. Interfaces 2015, 7, 1772-1779. [CrossRef] [PubMed]

168. Li, H.M.; Qian, X.; Zhu, C.L.; Jiang, X.X.; Shao, L.; Hou, L.X. Template Synthesis of $\mathrm{CoSe}_{2} / \mathrm{Co}_{3} \mathrm{Se}_{4}$ Nanotubes: Tuning of their Crystal Structures for Photovoltaics and Hydrogen Evolution in Alkaline Medium. J. Mater. Chem. A 2017, 5, 4513-4526. [CrossRef]

169. Wang, K.; Xi, D.; Zhou, C.J.; Shi, Z.Q.; Xia, H.Y.; Liu, G.W.; Qiao, G.J. CoSe 2 Necklace-Like Nanowires Supported by Carbon Fiber Paper: A 3D Integrated Electrode for the Hydrogen Evolution Reaction. J. Mater. Chem. A 2015, 3, 9415-9420. [CrossRef]

170. Yue, H.H.; Yu, B.; Qi, F.; Zhou, J.H.; Wang, X.Q.; Zheng, B.J.; Zhang, W.L.; Li, Y.R.; Chen, Y.F. Interwoven $\mathrm{CoSe}_{2} / \mathrm{CNTs}$ Hybrid as a Highly Efficient and Stable Electrocatalyst for Hydrogen Evolution Reaction. Electrochim. Acta 2017, 253, 200-207. [CrossRef]

171. Kim, J.K.; Park, G.D.; Kim, J.H.; Park, S.K.; Kang, Y.C. Rational Design and Synthesis of Extremely Efficient Macroporous $\mathrm{CoSe}_{2}-\mathrm{CNT}$ Composite Microspheres for Hydrogen Evolution Reaction. Small 2017, 13, 1700068. [CrossRef] [PubMed]

172. Dai, C.; Tian, X.K.; Nie, Y.L.; Tian, C.; Yang, C.; Zhou, Z.X.; Li, Y.; Gao, X.Y. Successful Synthesis of 3D CoSe 2 Hollow Microspheres with High Surface Roughness and its Excellent Performance in Catalytic Hydrogen Evolution Reaction. Chem. Eng. J. 2017, 321, 105-112. [CrossRef]

173. Xiao, H.Q.; Wang, S.T.; Wang, C.; Li, Y.Y.; Zhang, H.R.; Wang, Z.J.; Zhou, Y.; An, C.H.; Zhang, J. Lamellar Structured $\mathrm{CoSe}_{2}$ Nanosheets Directly Arrayed on Ti Plate as an Efficient Electrochemical Catalyst for Hydrogen Evolution. Electrochim. Acta 2016, 217, 156-162. [CrossRef]

174. Di, J.; Yan, C.; Handoko, A.D.; Seh, Z.W.; Li, H.M.; Liu, Z. Ultrathin Two-Dimensional Materials for Photoand Electrocatalytic Hydrogen Evolution. Mater. Today 2018, 21, 749-770. [CrossRef]

175. Liu, Y.W.; Hua, X.M.; Xiao, C.; Zhou, T.F.; Huang, P.C.; Guo, Z.P.; Pan, B.C.; Xie, Y. Heterogeneous Spin States in Ultrathin Nanosheet Inducing Subtle Lattice Distortion for Efficiently Triggering Hydrogen Evolution. J. Am. Chem. Soc. 2016, 138, 5087-5092. [CrossRef] [PubMed]

176. Yang, Y.Y.; Li, F.; Li, W.Z.; Gao, W.B.; Wen, H.; Li, J.; Hu, Y.P.; Luo, Y.T.; Li, R. Porous $\mathrm{CoS}_{2}$ Nanostructures Based on ZIF-9 Supported on Reduced Graphene Oxide: Favourable Electrocatalysis for Hydrogen Evolution Reaction. Int. J. Hydrogen Energy 2017, 42, 6665-6673. [CrossRef]

177. Zhang, X.; Liu, S.W.; Zang, Y.P.; Liu, R.R.; Liu, G.Q.; Wang, G.Z.; Zhang, Y.X.; Zhang, H.M.; Zhao, H.J. Co/Cog $S_{8} @ S$, N-Doped Porous Graphene Sheets Derived from S, N Dual Organic Ligands Assembled Co-MOFs as Superior Electrocatalysts for Full Water Splitting in Alkaline Media. Nano Energy 2016, 30, 93-102. [CrossRef]

178. Lin, J.; He, J.R.; Qi, F.; Zheng, B.J.; Wang, X.Q.; Yu, B.; Zhou, K.R.; Zhang, W.L.; Li, Y.R.; Chen, Y.F. In-Situ Selenization of Co-based Metal-Organic Frameworks as a Highly Efficient Electrocatalyst for Hydrogen Evolution Reaction. Electrochim. Acta 2017, 247, 258-264. [CrossRef] 
179. Zhang, H.X.; Lei, L.C.; Zhang, X.W. One-Step Synthesis of Cubic Pyrite-Type CoSe 2 at Low Temperature for Efficient Hydrogen Evolution Reaction. RSC Adv. 2014, 4, 54344-54348. [CrossRef]

180. Li, Y.Z.; Niu, S.Q.; Rakov, D.; Wang, Y.; Caban-Acevedo, M.; Zheng, S.J.; Song, B.; Xu, P. Metal Organic Framework-Derived CoPS/N-doped Carbon for Efficient Electrocatalytic Hydrogen Evolution. Nanoscale 2018, 10, 7291-7297. [CrossRef] [PubMed]

181. Li, N.; Liu, X.; Li, G.D.; Wu, Y.Y.; Gao, R.Q.; Zou, X.X. Vertically Grown CoS Nanosheets on Carbon Cloth as Efficient Hydrogen Evolution Electrocatalysts. Int. J. Hydrogen Energy 2017, 42, 9914-9921. [CrossRef]

182. Ouyang, C.B.; Wang, X.; Wang, S.Y. Phosphorus-Doped $\mathrm{CoS}_{2}$ Nanosheet Arrays as Ultra-Efficient Electrocatalysts for the Hydrogen Evolution Reaction. Chem. Commun. 2015, 51, 14160-14163. [CrossRef] [PubMed]

183. Li, H.M.; Qian, X.; Xu, C.; Huang, S.W.; Zhu, C.L.; Jiang, X.C.; Shao, L.; Hou, L.X. Hierarchical Porous $\mathrm{Co}_{9} \mathrm{~S}_{8} /$ Nitrogen-Doped Carbon@ $\mathrm{MoS}_{2}$ Polyhedrons as $\mathrm{pH}$ Universal Electrocatalysts for Highly Efficient Hydrogen Evolution Reaction. ACS Appl. Mater. Interfaces 2017, 9, 28394-28405. [CrossRef] [PubMed]

(C) 2018 by the authors. Licensee MDPI, Basel, Switzerland. This article is an open access article distributed under the terms and conditions of the Creative Commons Attribution (CC BY) license (http:/ / creativecommons.org/licenses/by/4.0/). 